\title{
Triplet State (Anti)aromaticity of Some Monoheterocyclic Analogues of Benzene, Naphthalene and Anthracene
}

\author{
Marija Baranac-Stojanović, ${ }^{\text {** }}$ Milovan Stojanović, ${ }^{b}$ Jovana Aleksić $^{b}$ \\ ${ }^{a}$ University of Belgrade - Faculty of Chemistry, Studentski trg 12-16, P.O.Box 158, 11000 Belgrade, Serbia \\ ${ }^{b}$ University of Belgrade - Institute of Chemistry, Technology and Metallurgy - Center for Chemistry, Njegoševa 12, P.O.Box \\ 473, 11000 Belgrade, Serbia
}

\section{Supplementary Information}

\section{Table of Contents}

Figure S1. Correlation of B3LYP and PBE0, CAM-B3LYP, M062X and MP2

bond lengths for all monocycles studied. S2

Figure S2. Correlations between aromaticity indices calculated for monocycles. S2

Tables S1-S4. Comparison of aromaticity indices calculated

with different methods . $\mathrm{S} 3$

Figures S3-S28. ACID plots of studied compounds. S4

Absolute energies and $\mathrm{x}, \mathrm{y}, \mathrm{z}$ coordinates of optimized structures. $\mathrm{S} 18$ 

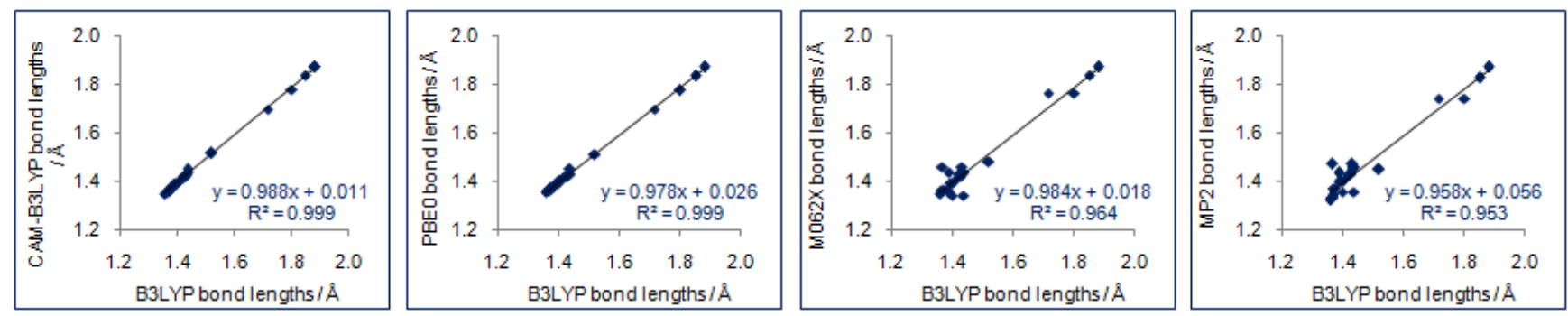

Figure S1. Correlations between B3LYP and CAM-B3LYP, PBE0, M062X and MP2(fc) bond lengths of optimized triplet state structures of monocycles studied.
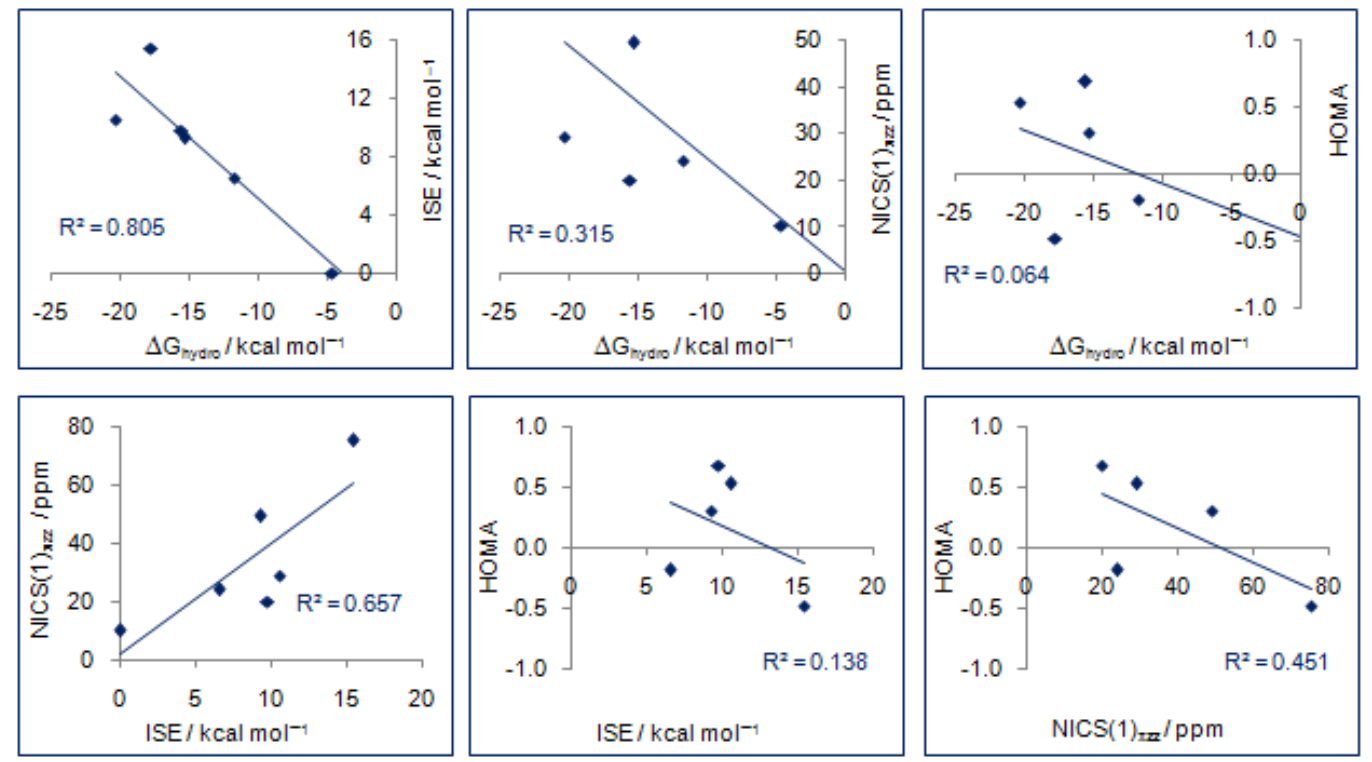

Figure S2. Correlations between different aromaticity indices calculated for monocycles studied. 
Table S1. Adiabatic $\mathrm{S}_{0}-\mathrm{T}_{1}$ energy gaps in $\mathrm{eV}$.

\begin{tabular}{|l|c|c|c|c|c|c|c|c|c|c|}
\hline Molecule & \multicolumn{2}{|c|}{ B3LYP } & \multicolumn{2}{c|}{ CAM-B3LYP } & \multicolumn{2}{c|}{ PBE0 } & \multicolumn{2}{c|}{ M062X } & \multicolumn{2}{c|}{ MP2(fc) } \\
\hline Benzene & $D_{2 h}$ & 3.8 & $D_{2 h}$ & 3.8 & $D_{2 h}$ & 3.8 & $C_{s}$ & 4.0 & $C_{s}$ & 5.2 \\
\hline Silabenzene & $C_{s}$ & 2.0 & $C_{s}$ & 2.0 & $C_{s}$ & 2.0 & $C_{s}$ & 2.1 & $C_{s}$ & 2.9 \\
\hline Pyridine & $C_{s}$ & 3.6 & $C_{s}$ & 3.7 & $C_{s}$ & 3.6 & $C_{s}$ & 3.8 & $C_{s}$ & 4.8 \\
\hline Phosphinine & $C_{s}$ & 2.7 & $C_{1}$ & 2.7 & $C_{s}$ & 2.7 & $C_{1}$ & 2.9 & $C_{s}$ & 3.7 \\
\hline Pyrylium ion & $C_{s}$ & 3.3 & $C_{s}$ & 3.4 & $C_{s}$ & 3.3 & $C_{s}$ & 3.5 & $C_{s}$ & 3.9 \\
\hline Thiopyrylium ion & $C_{1}$ & 3.2 & $C_{1}$ & 3.2 & $C_{1}$ & 3.2 & $C_{s}$ & 3.5 & $C_{s}$ & 3.8 \\
\hline
\end{tabular}

Table S2. Calculated HOMA values for T1 states.

\begin{tabular}{|l|c|c|c|c|c|}
\hline Molecule & B3LYP & CAM-B3LYP & PBE0 & M062X & MP2(fc) \\
\hline Benzene & -0.484 & -0.412 & -0.342 & -0.094 & 0.491 \\
\hline Silabenzene & $/$ & $/$ & $/$ & $/$ & $/$ \\
\hline Pyridine & 0.689 & 0.705 & 0.741 & 0.729 & 0.385 \\
\hline Phosphinine & -0.185 & -0.106 & 0.002 & -0.123 & -0.459 \\
\hline Pyrylium ion & 0.313 & 0.435 & 0.438 & 0.418 & 0.334 \\
\hline Thiopyrylium ion & 0.532 & 0.560 & 0.598 & 0.140 & 0.200 \\
\hline
\end{tabular}

Table S3. Calculated NICS $(1)_{\pi z z}$ values for T1 states in ppm.

\begin{tabular}{|l|c|c|c|c|c|}
\hline Molecule & B3LYP & CAM-B3LYP & PBE0 & M062X & MP2(fc) $^{a}$ \\
\hline Benzene & 75.4 & 66.2 & 70.1 & 17.7 & 36.8 \\
\hline Silabenzene & 10.2 & 9.8 & 9.2 & 9.7 & 6.0 \\
\hline Pyridine & 20.1 & 18.5 & 19.1 & 19.2 & 2.8 \\
\hline Phosphinine & 24.2 & 20.3 & 19.1 & 18.2 & 6.9 \\
\hline Pyrylium ion & 49.4 & 47.6 & 43.4 & 39.1 & 6.5 \\
\hline Thiopyrylium ion & 29.2 & 18.3 & 15.9 & 38.8 & 16.7 \\
\hline${ }^{a}$ NICS(1) zz in this case. &
\end{tabular}

Table S4. Calculated Gibbs energy of hydrogenation for T1 states in kcal/mol.

\begin{tabular}{|l|c|c|c|c|c|}
\hline Molecule & B3LYP & CAM-B3LYP & PBE0 & M062X & MP2(fc) \\
\hline Benzene & -17.8 & -21.1 & -24.1 & -21.8 & -32.1 \\
\hline Silabenzene & -4.6 & -8.3 & -10.9 & -9.5 & -15.4 \\
\hline Pyridine & -15.6 & -19.3 & -21.4 & -19.3 & -24.5 \\
\hline Phosphinine & -11.8 & -15.4 & -18.1 & -15.8 & -18.4 \\
\hline Pyrylium ion & -15.3 & -18.8 & -21.7 & -20.1 & -24.5 \\
\hline Thiopyrylium ion & -20.4 & -24.3 & -27.0 & -26.4 & -44.0 \\
\hline
\end{tabular}




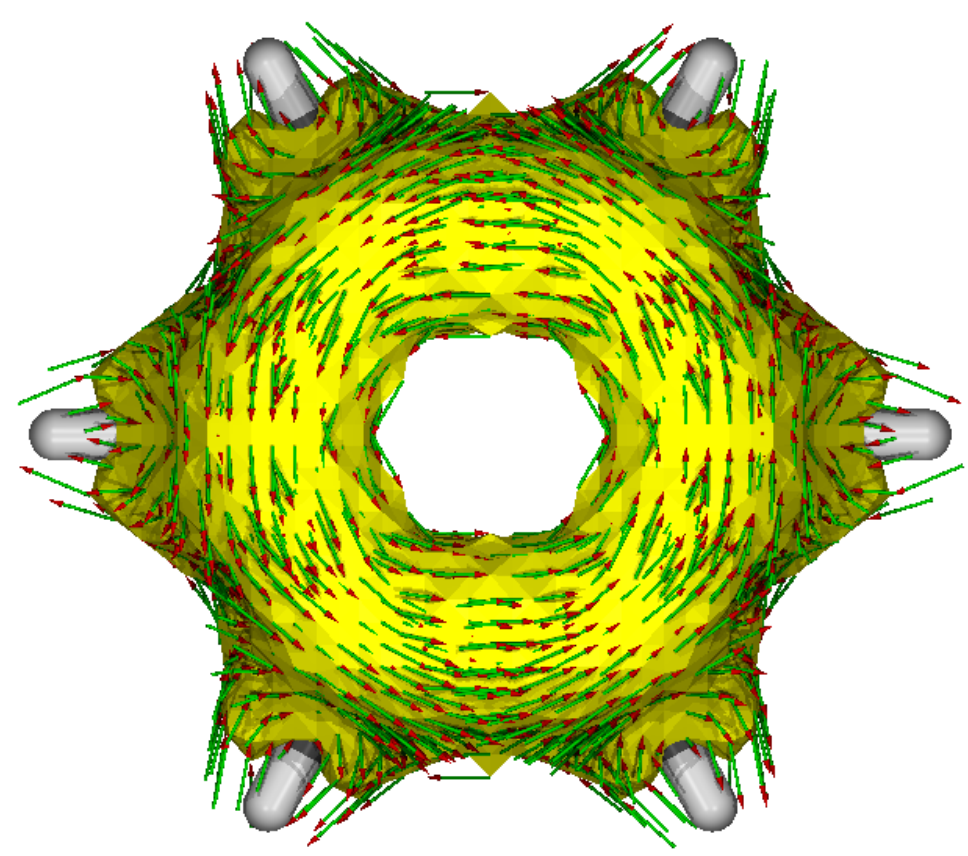

Figure S3. ACID plot of $\mathrm{T}_{1}$ benzene at an isosurface value of 0.05 a.u. Clockwise circulation is diatropic and counterclockwise circulation is paratropic.

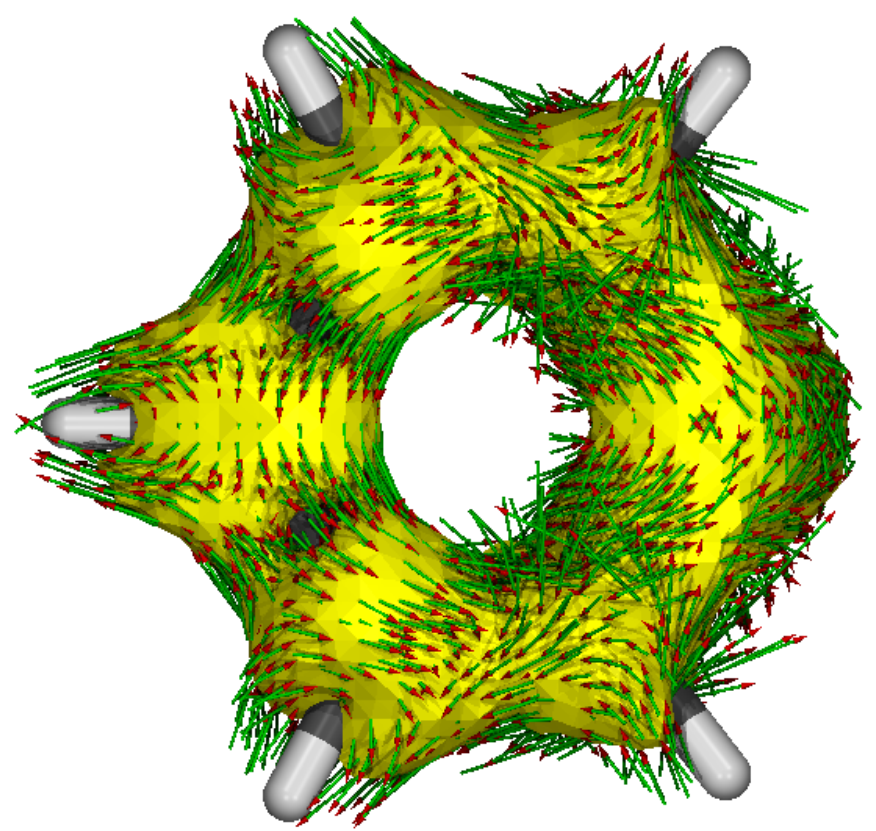

Figure S4. ACID plot of $\mathrm{T}_{1}$ pyridine at an isosurface value of 0.05 a.u. Clockwise circulation is diatropic and counterclockwise circulation is paratropic. 


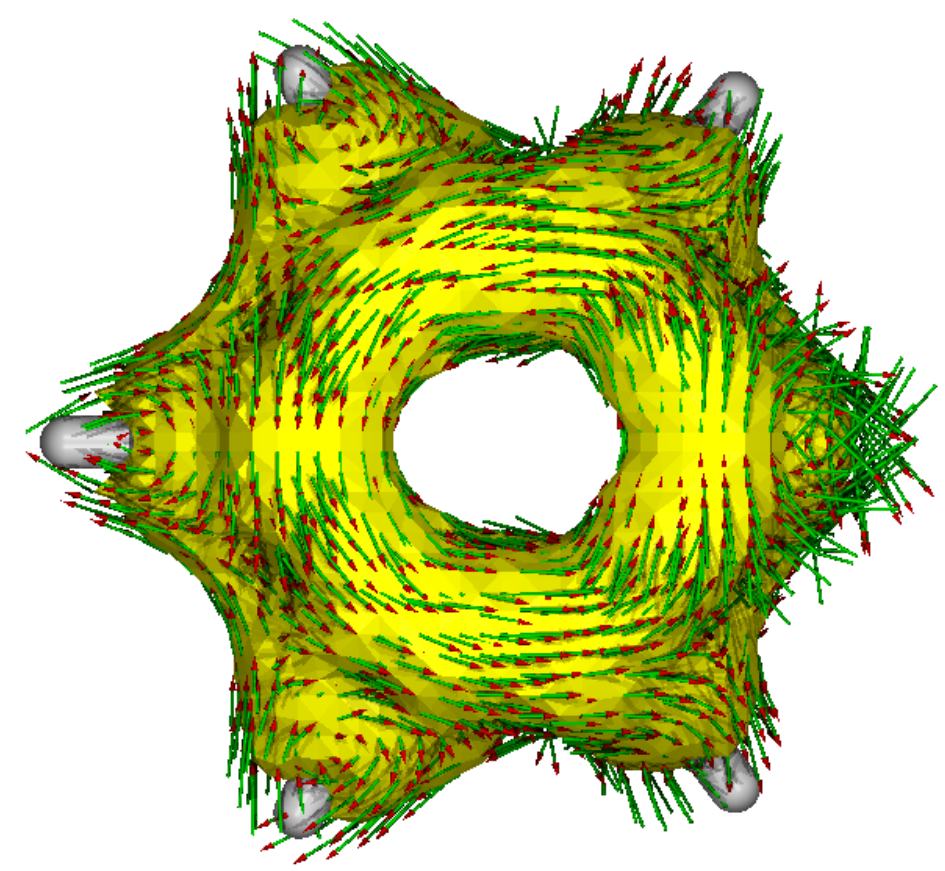

Figure S5. ACID plot of $T_{1}$ pyrylium ion at an isosurface value of 0.05 a.u. Clockwise circulation is diatropic and counterclockwise circulation is paratropic.

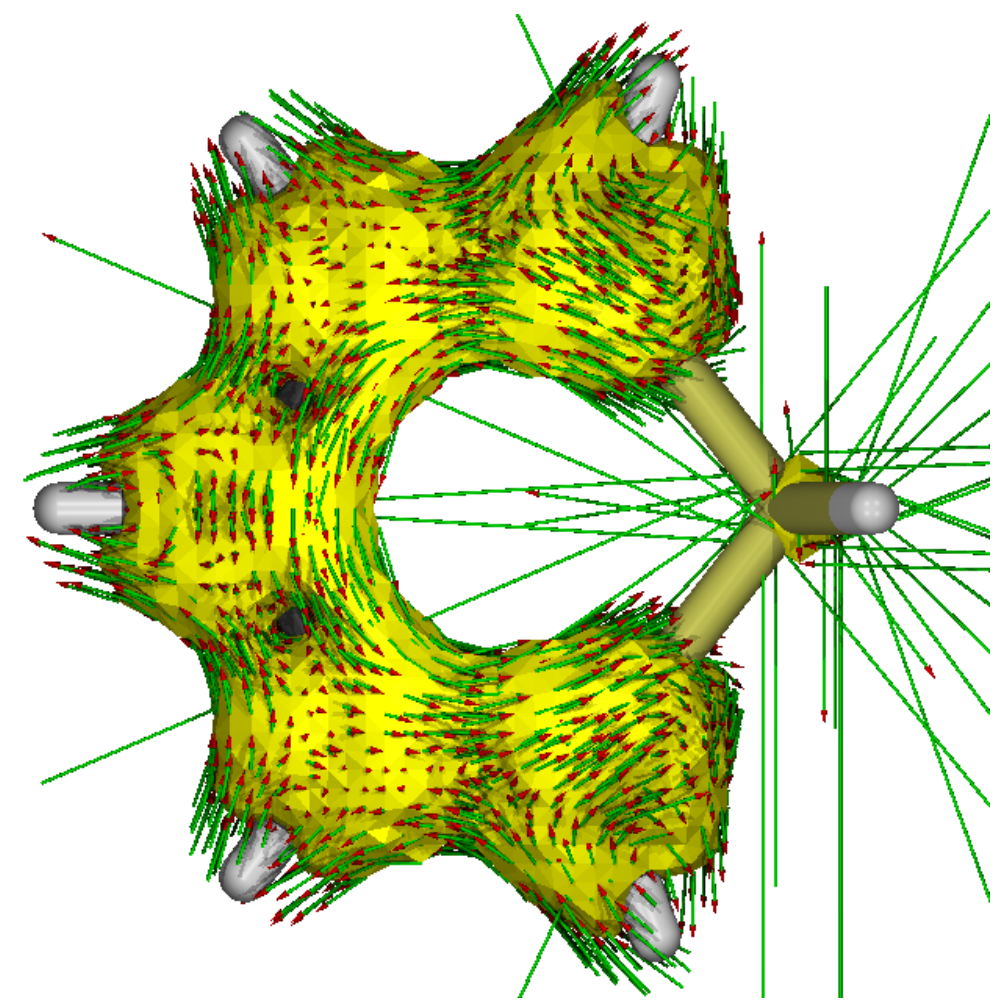

Figure S6. ACID plot of $T_{1}$ silabenzene at an isosurface value of 0.05 a.u. Clockwise circulation is diatropic and counterclockwise circulation is paratropic. 


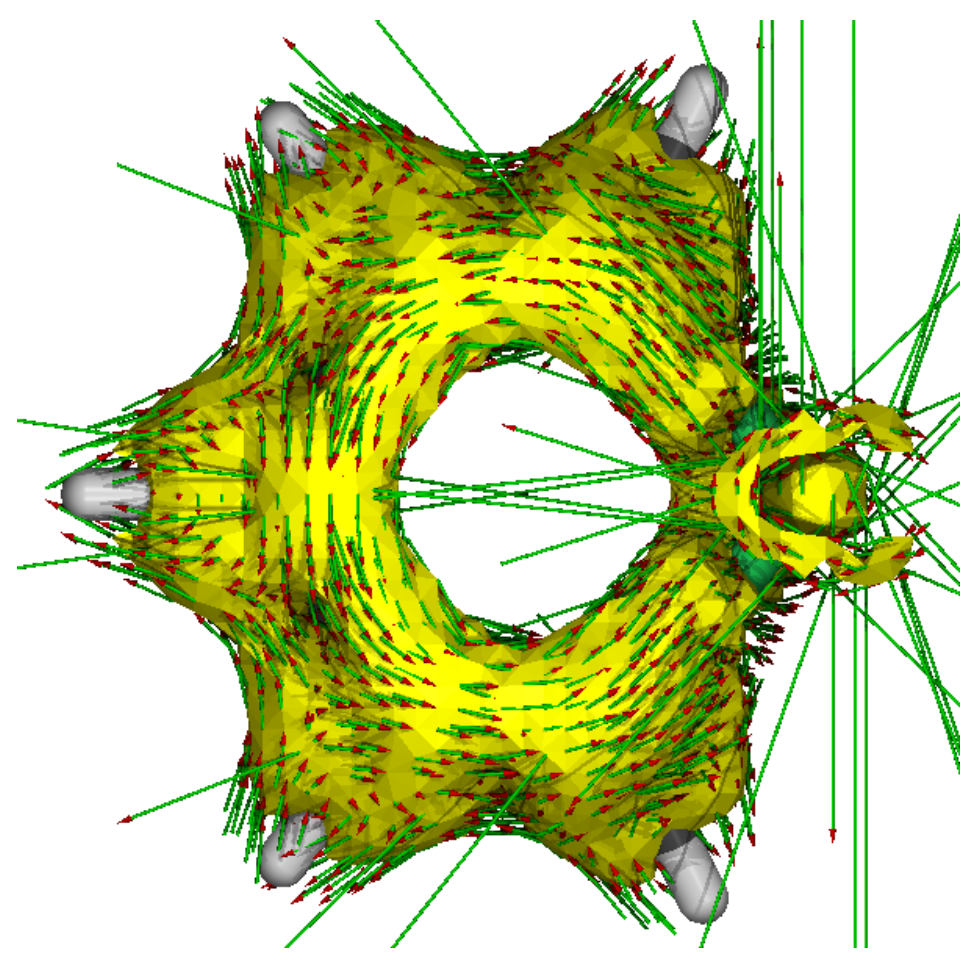

Figure S7. ACID plot of $\mathrm{T}_{1}$ phosphinine at an isosurface value of 0.05 a.u. Clockwise circulation is diatropic and counterclockwise circulation is paratropic

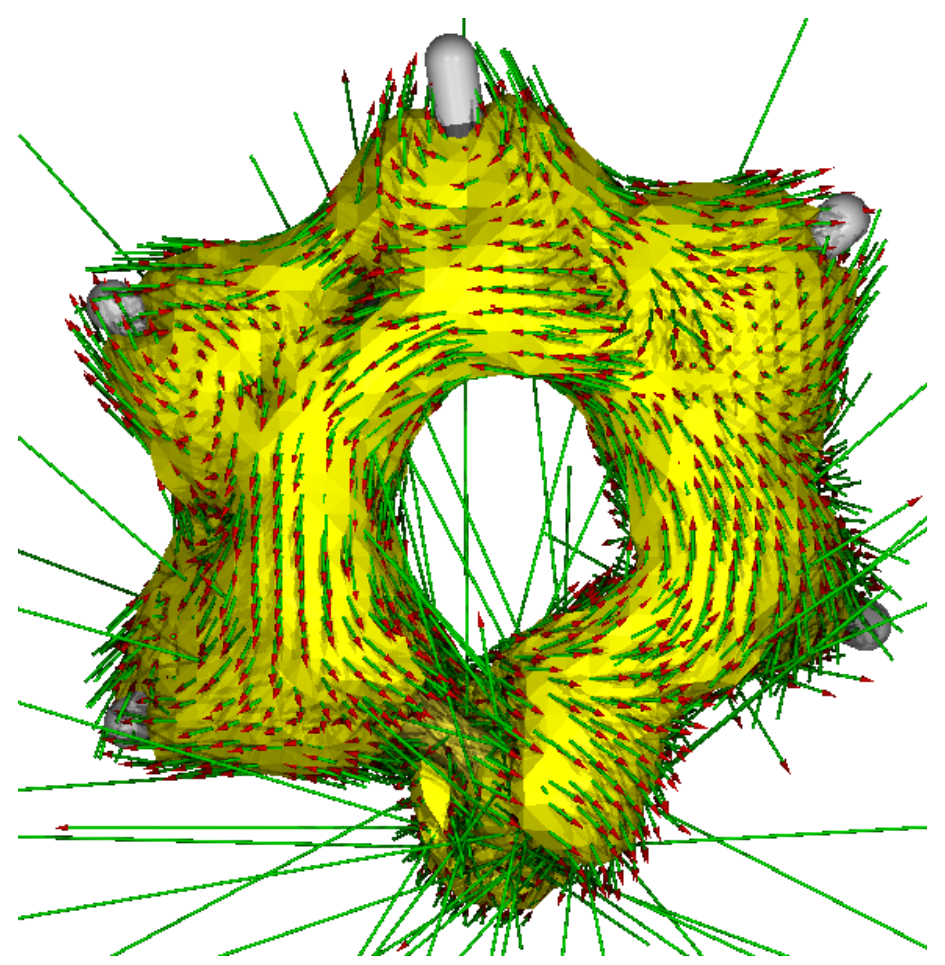

Figure S8. ACID plot of $\mathrm{T}_{1}$ thiopyrylium ion at an isosurface value of 0.05 a.u. Clockwise circulation is diatropic and counterclockwise circulation is paratropic. 


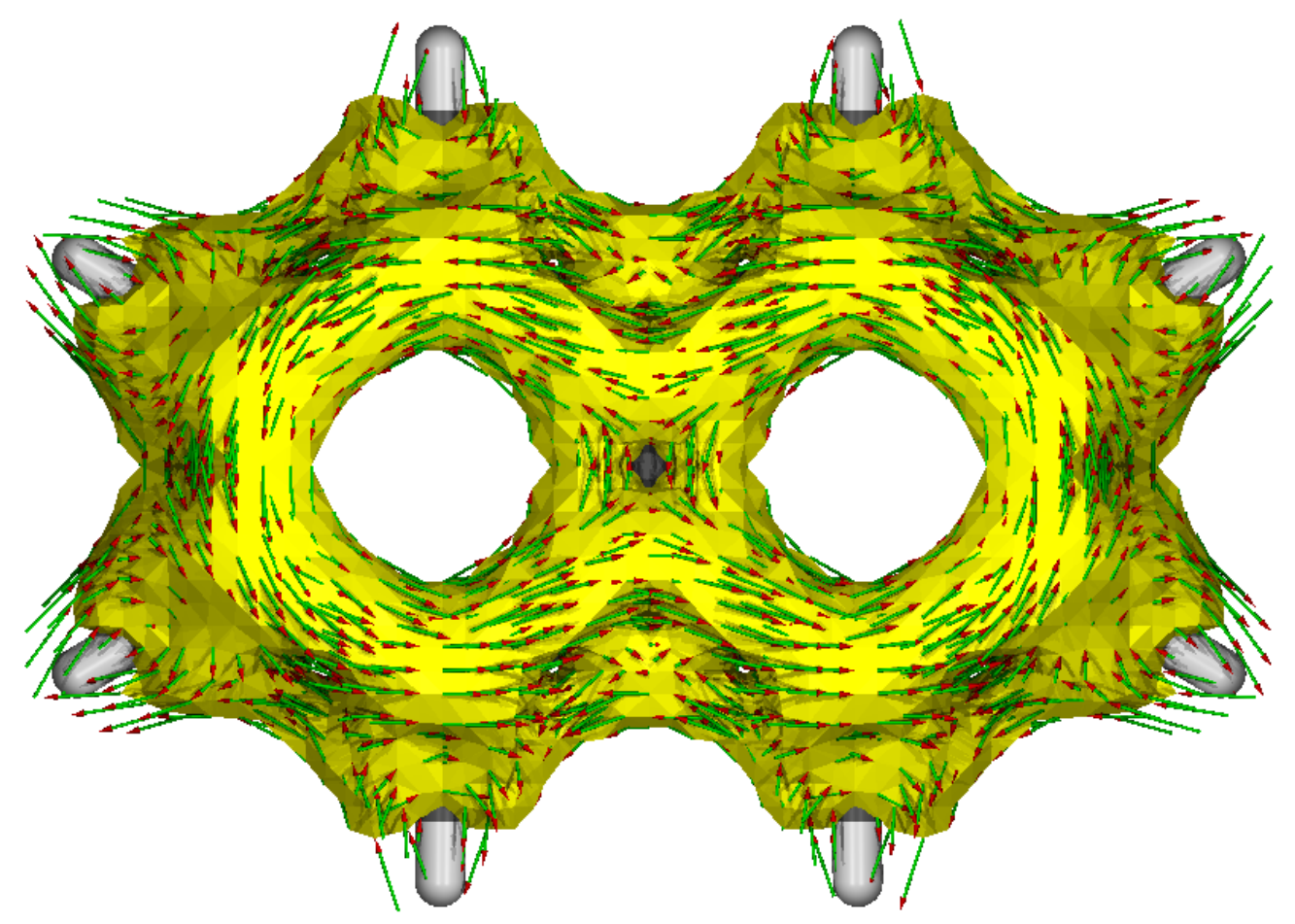

Figure S9. ACID plot of $T_{1}$ naphthalene at an isosurface value of 0.05 a.u. Clockwise circulation is diatropic and counterclockwise circulation is paratropic. 


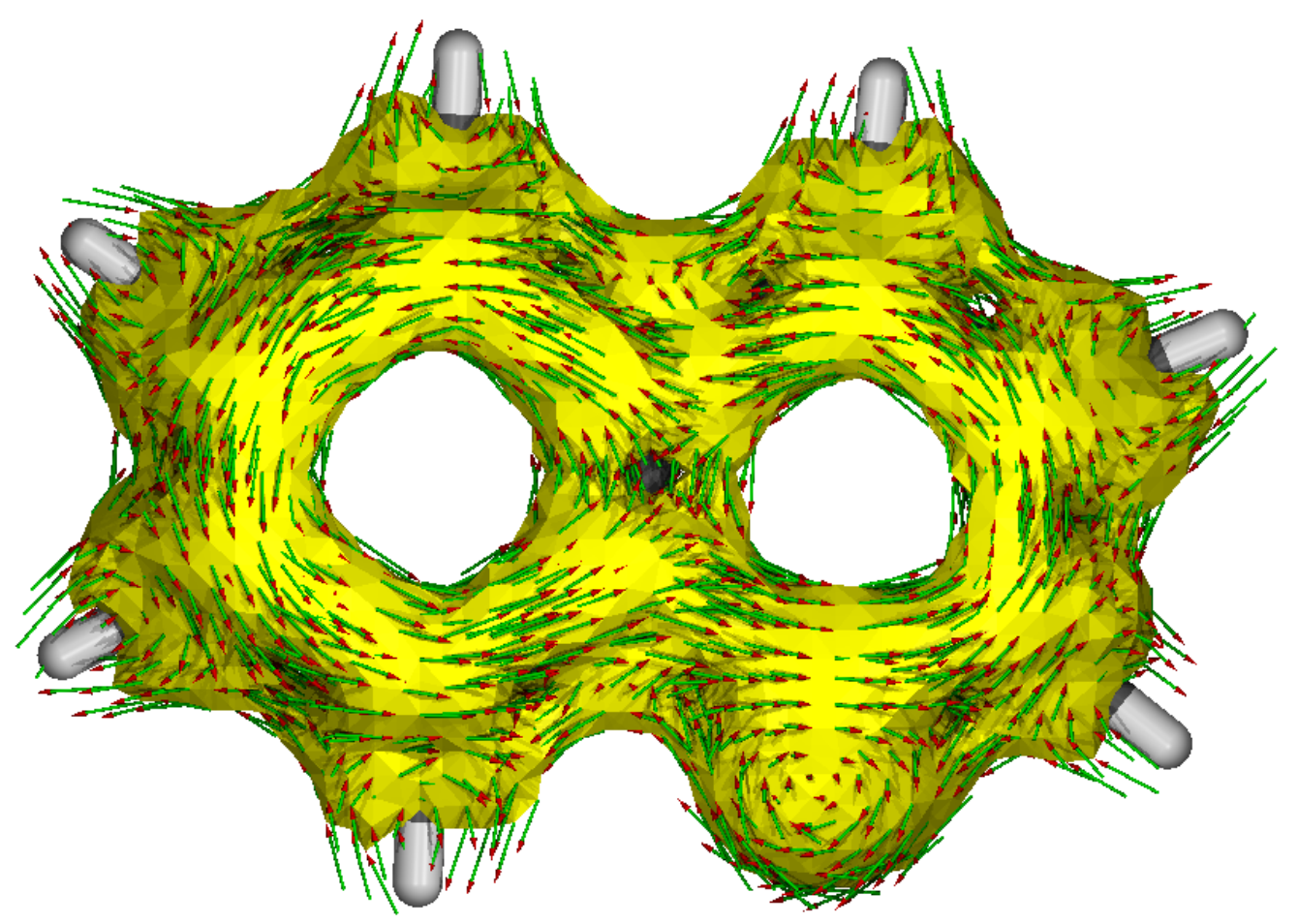

Figure S10. ACID plot of $\mathrm{T}_{1}$ quinoline at an isosurface value of 0.05 a.u. Clockwise circulation is diatropic and counterclockwise circulation is paratropic.

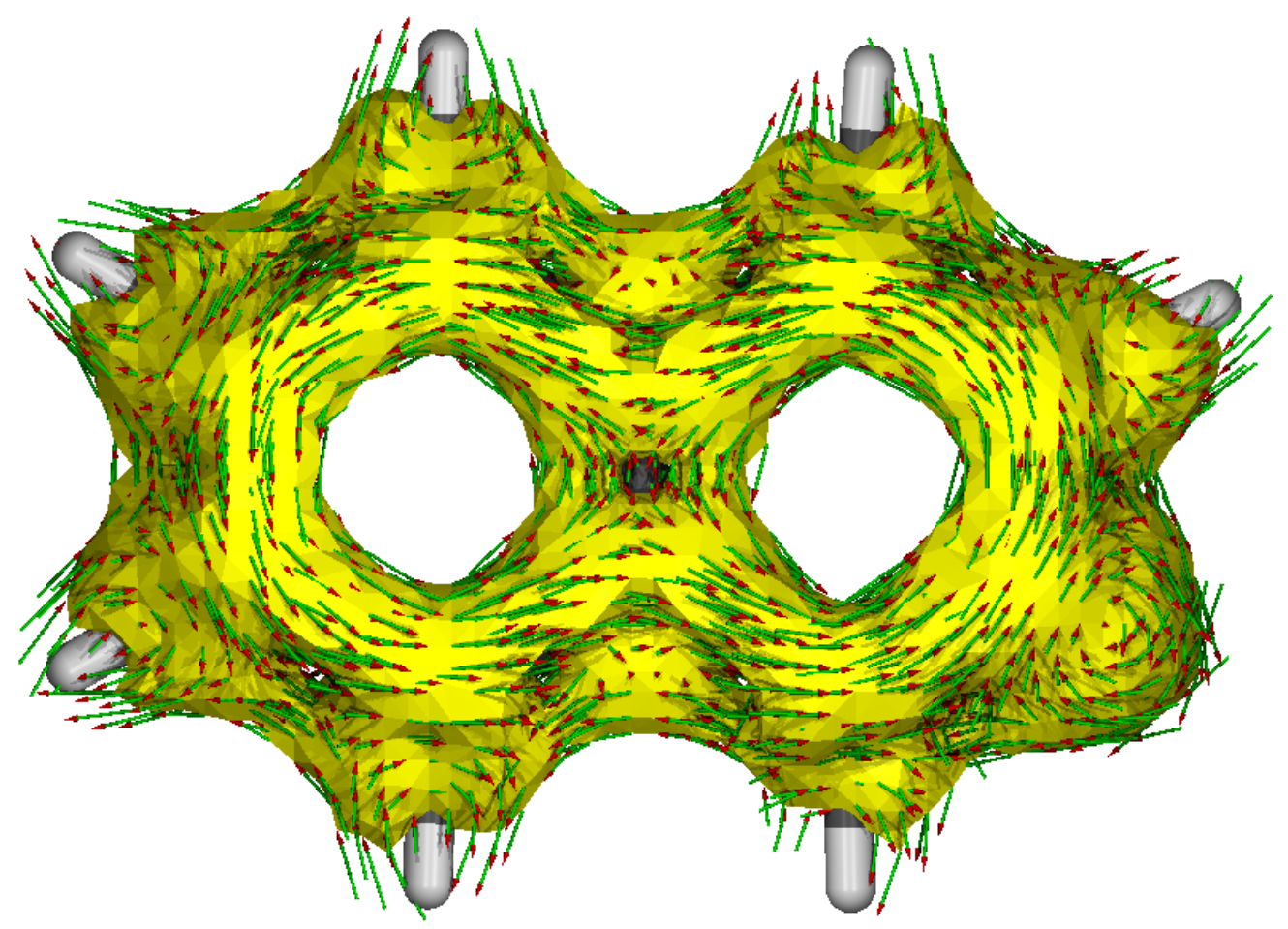

Figure S11. ACID plot of $T_{1}$ isoquinoline at an isosurface value of 0.05 a.u. Clockwise circulation is diatropic and counterclockwise circulation is paratropic. 


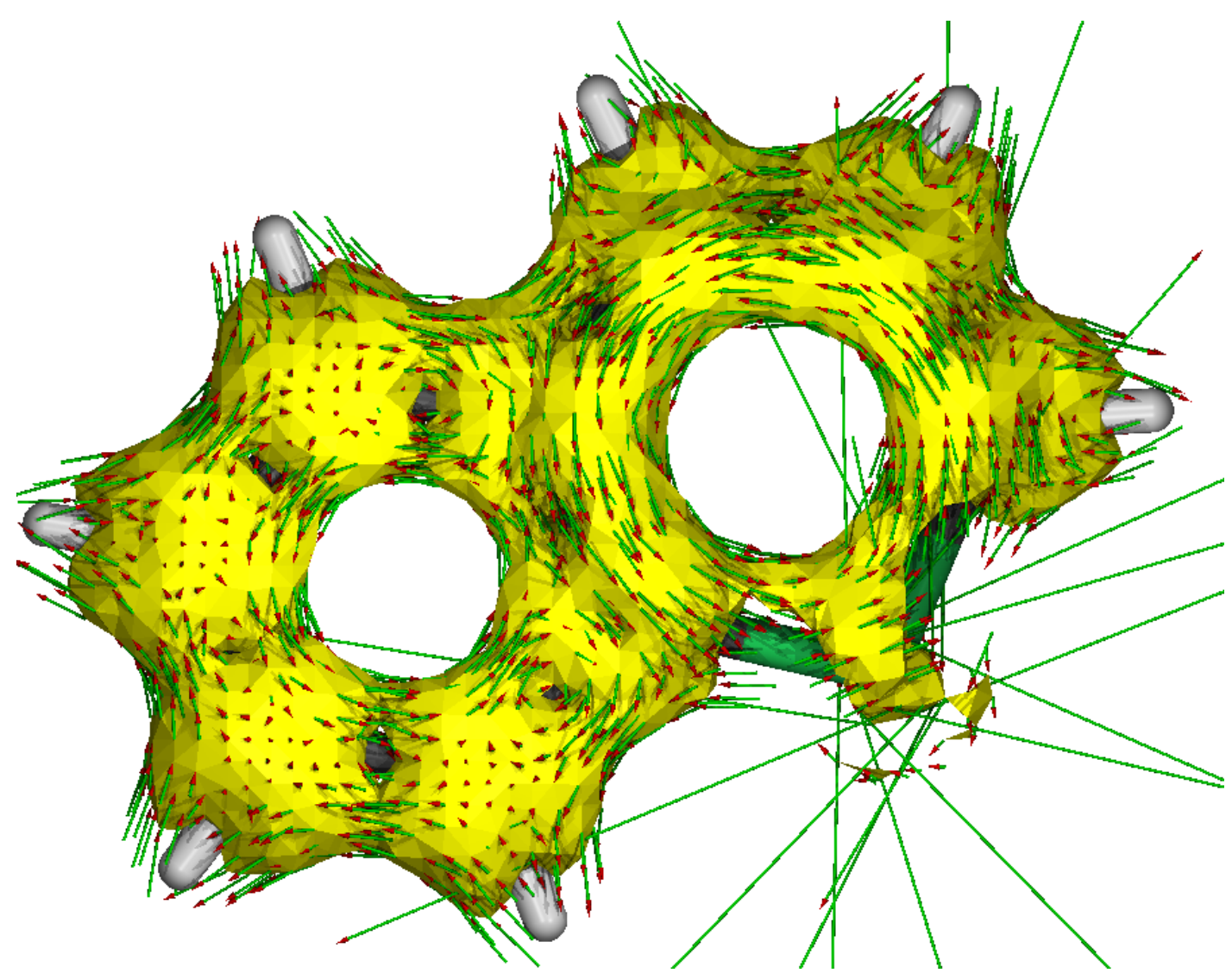

Figure S12. ACID plot of $\mathrm{T}_{1}$ 1-phosphanaphthalene at an isosurface value of 0.05 a.u. Clockwise circulation is diatropic and counterclockwise circulation is paratropic.

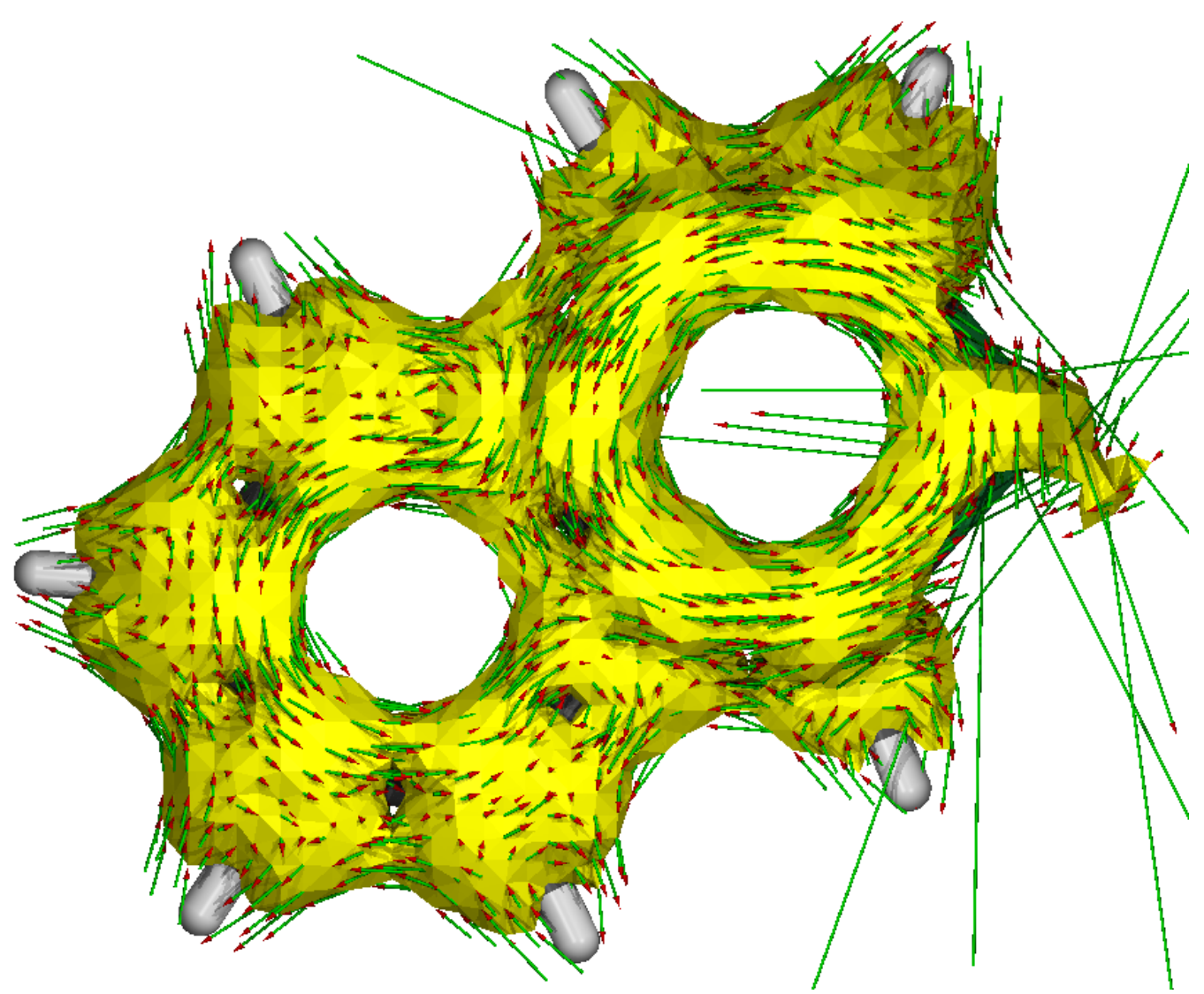

Figure S13. ACID plot of $\mathrm{T}_{1}$ 2-phosphanaphthalene at an isosurface value of 0.05 a.u. Clockwise circulation is diatropic and counterclockwise circulation is paratropic. 


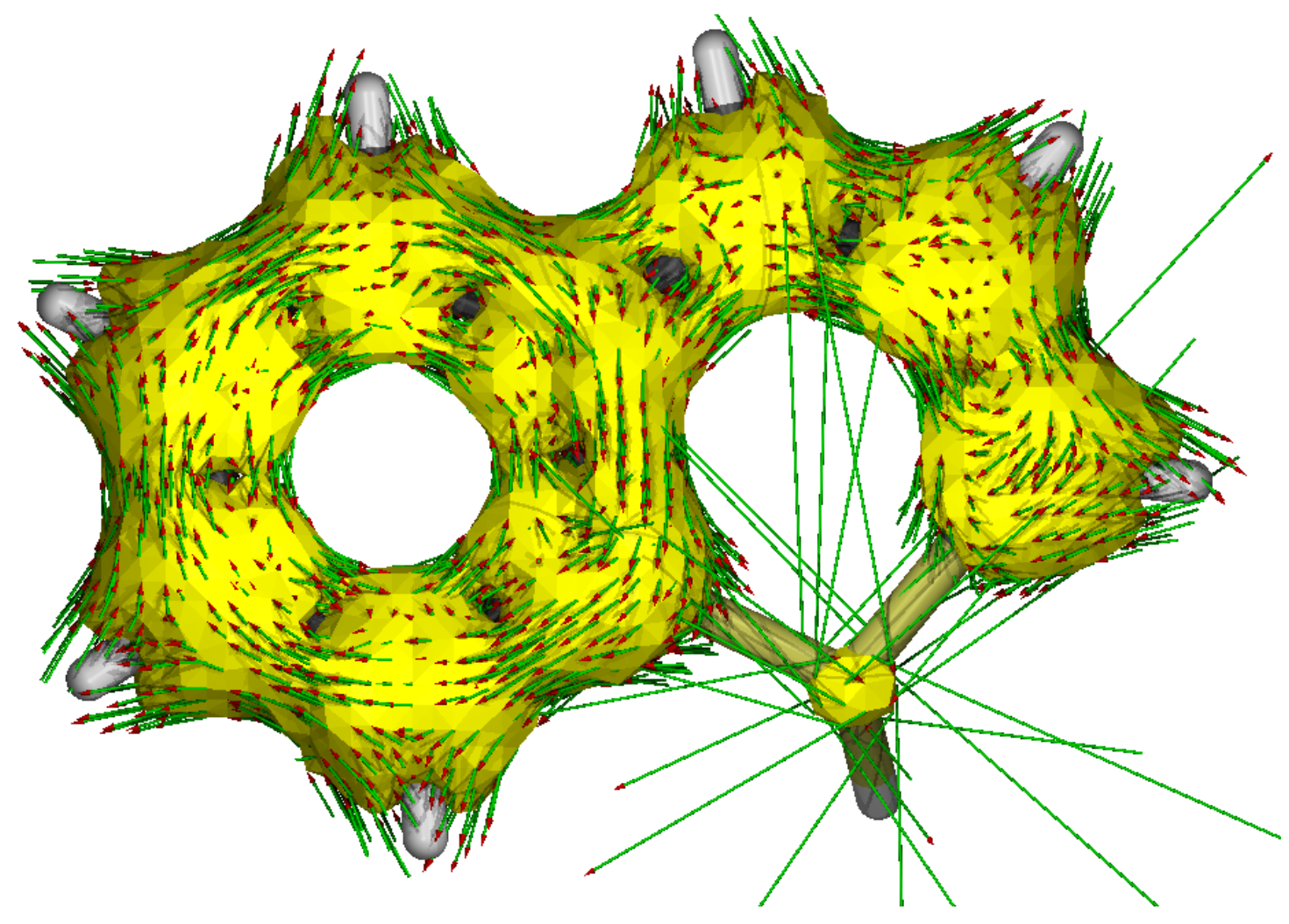

Figure S14. ACID plot of $T_{1} 1$-silanaphthalene at an isosurface value of 0.05 a.u. Clockwise circulation is diatropic and counterclockwise circulation is paratropic.

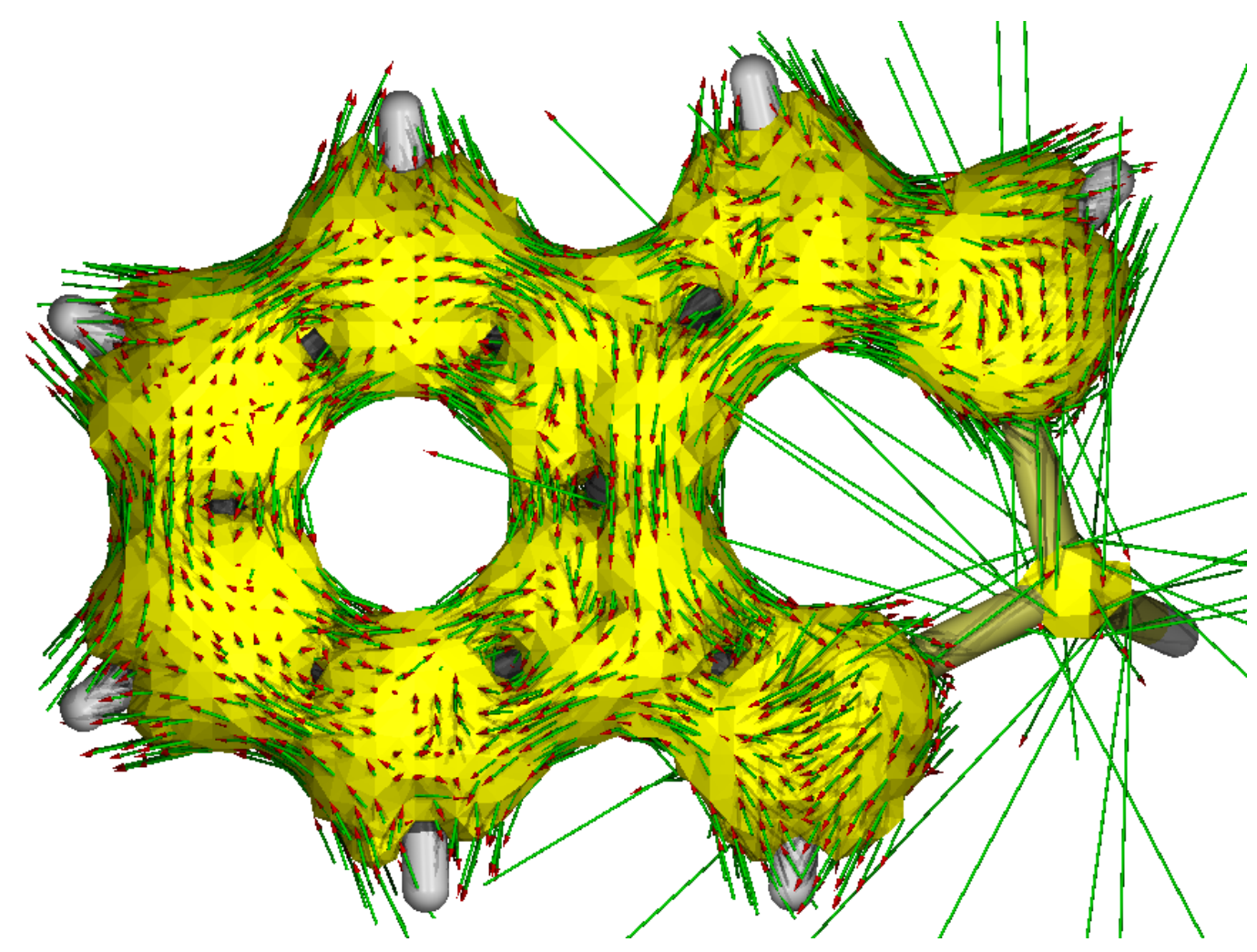

Figure S15. ACID plot of $T_{1}$ 2-silanaphthalene at an isosurface value of 0.05 a.u. Clockwise circulation is diatropic and counterclockwise circulation is paratropic. 


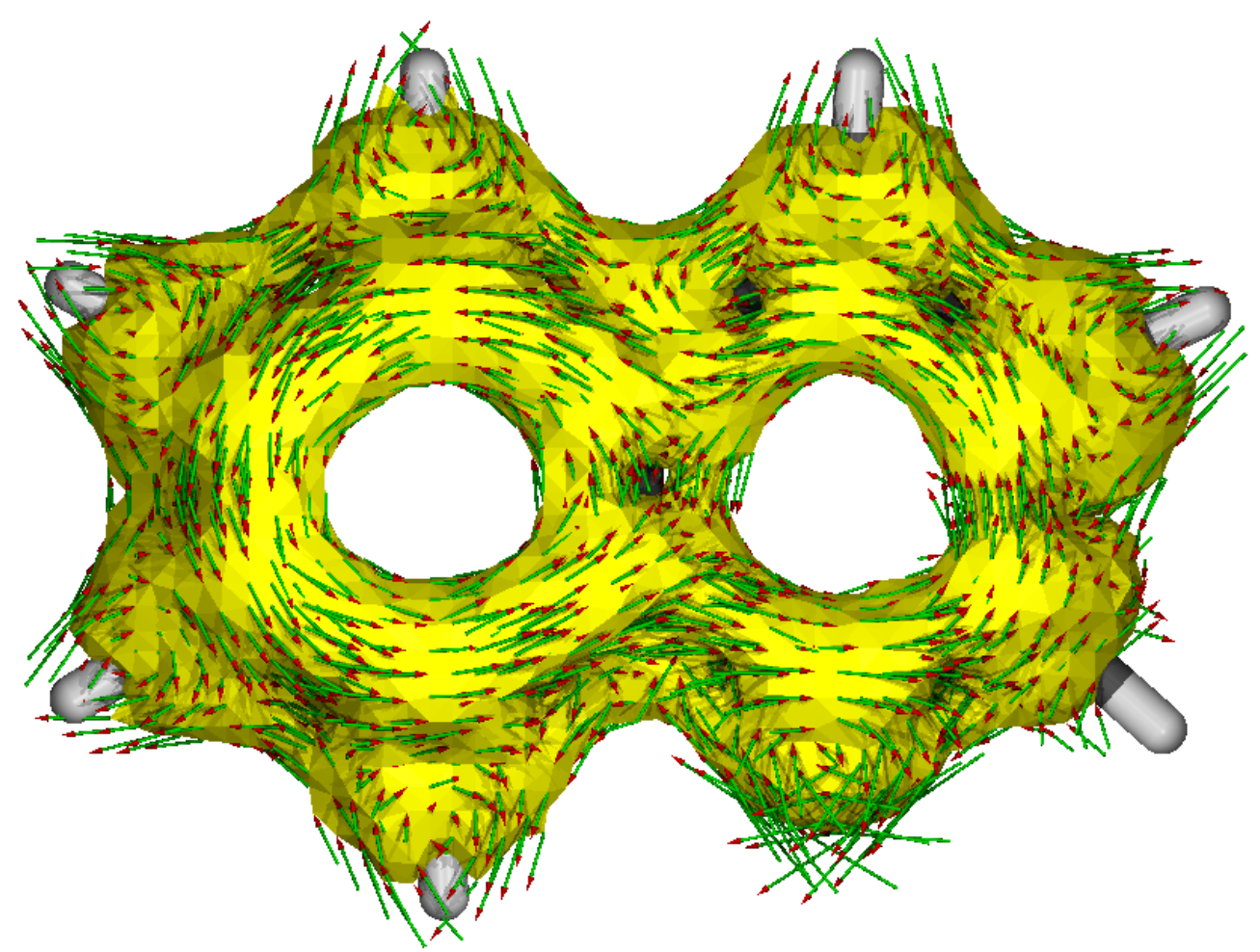

Figure S16. ACID plot of $\mathrm{T}_{1}$ chromenylium ion at an isosurface value of 0.05 a.u. Clockwise circulation is diatropic and counterclockwise circulation is paratropic.

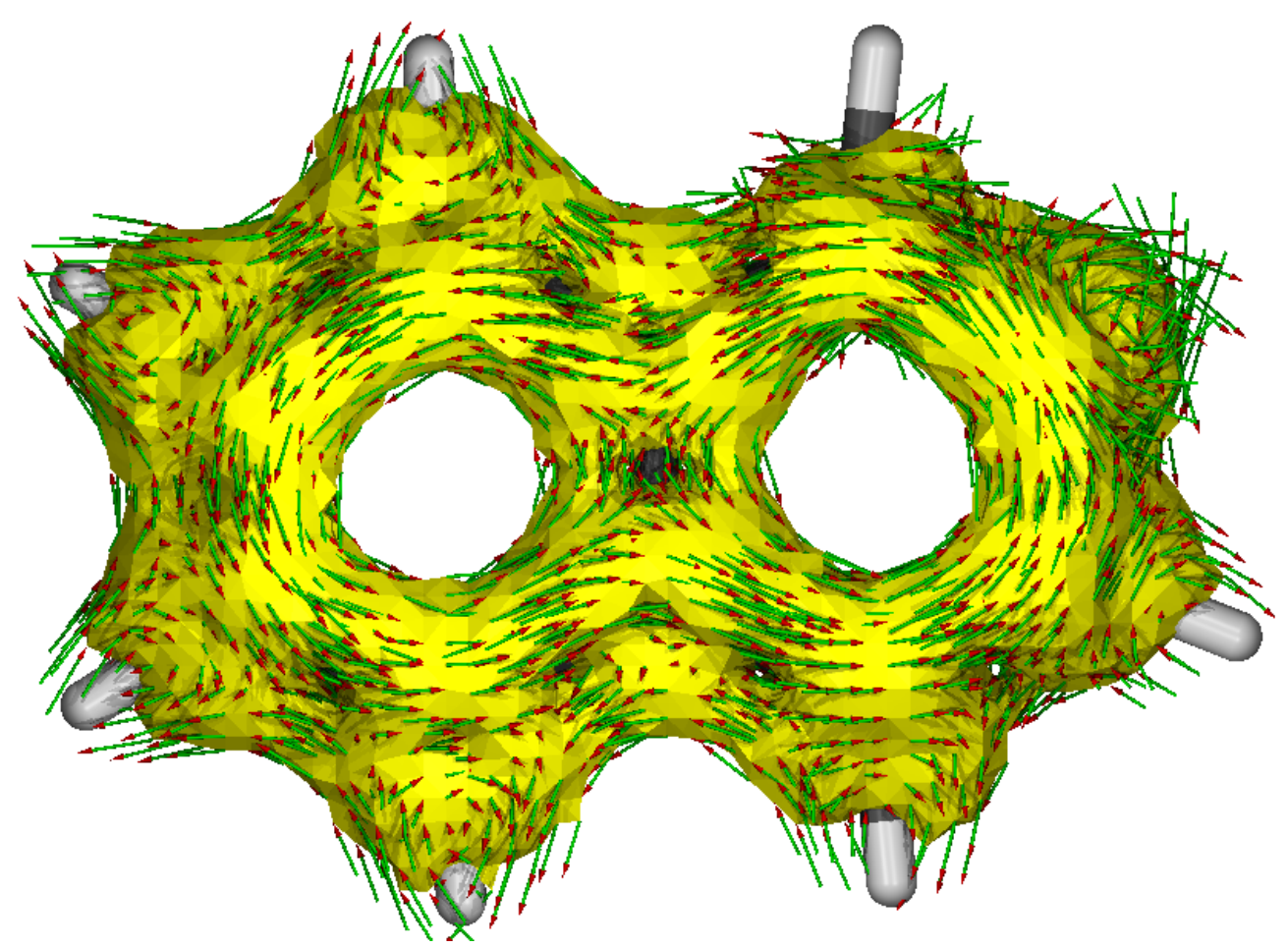

Figure S17. ACID plot of $\mathrm{T}_{1}$ isochromenylium ion at an isosurface value of 0.05 a.u. Clockwise circulation is diatropic and counterclockwise circulation is paratropic. 


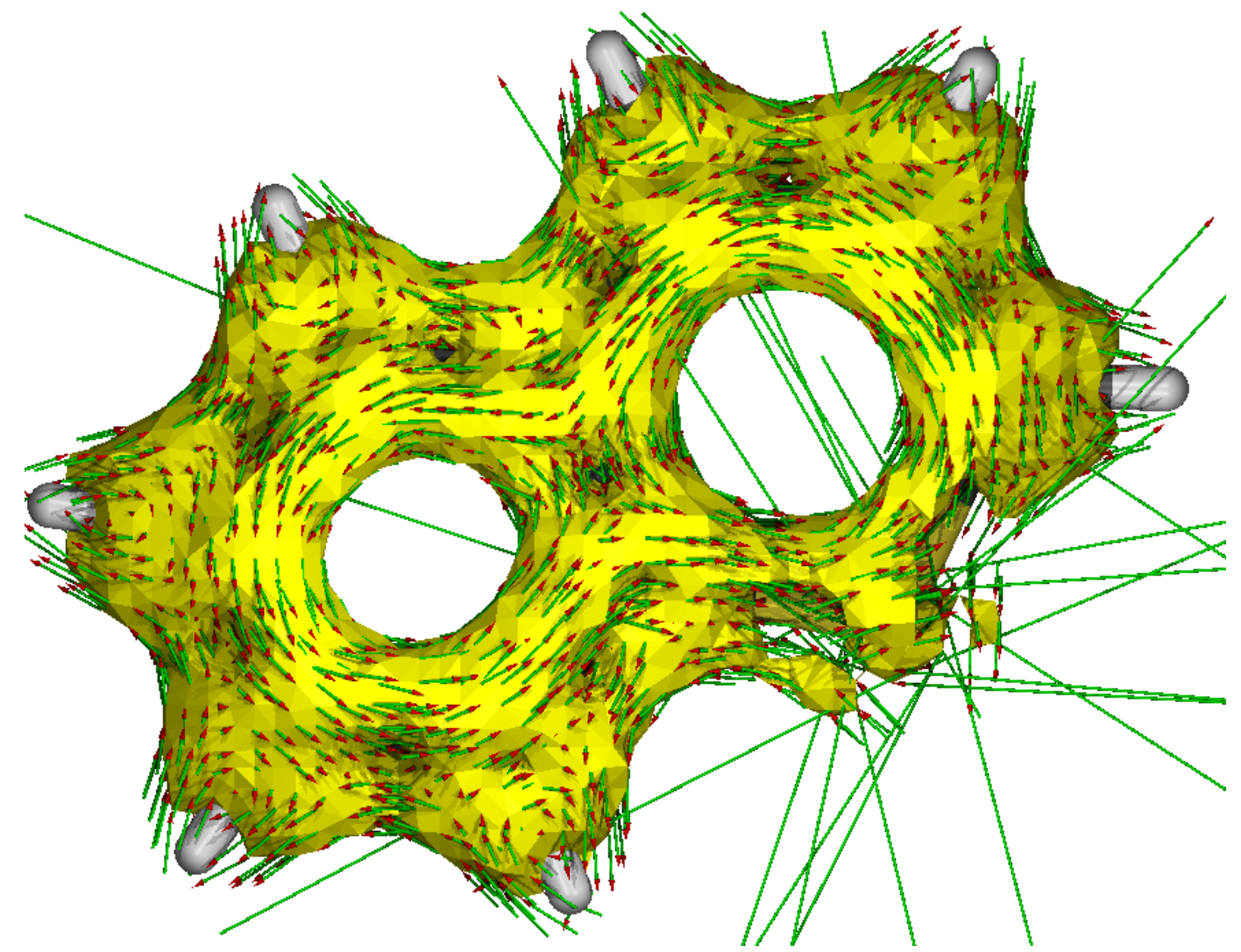

Figure S18. ACID plot of $\mathrm{T}_{1}$ thiochromenylium ion at an isosurface value of 0.05 a.u. Clockwise circulation is diatropic and counterclockwise circulation is paratropic.

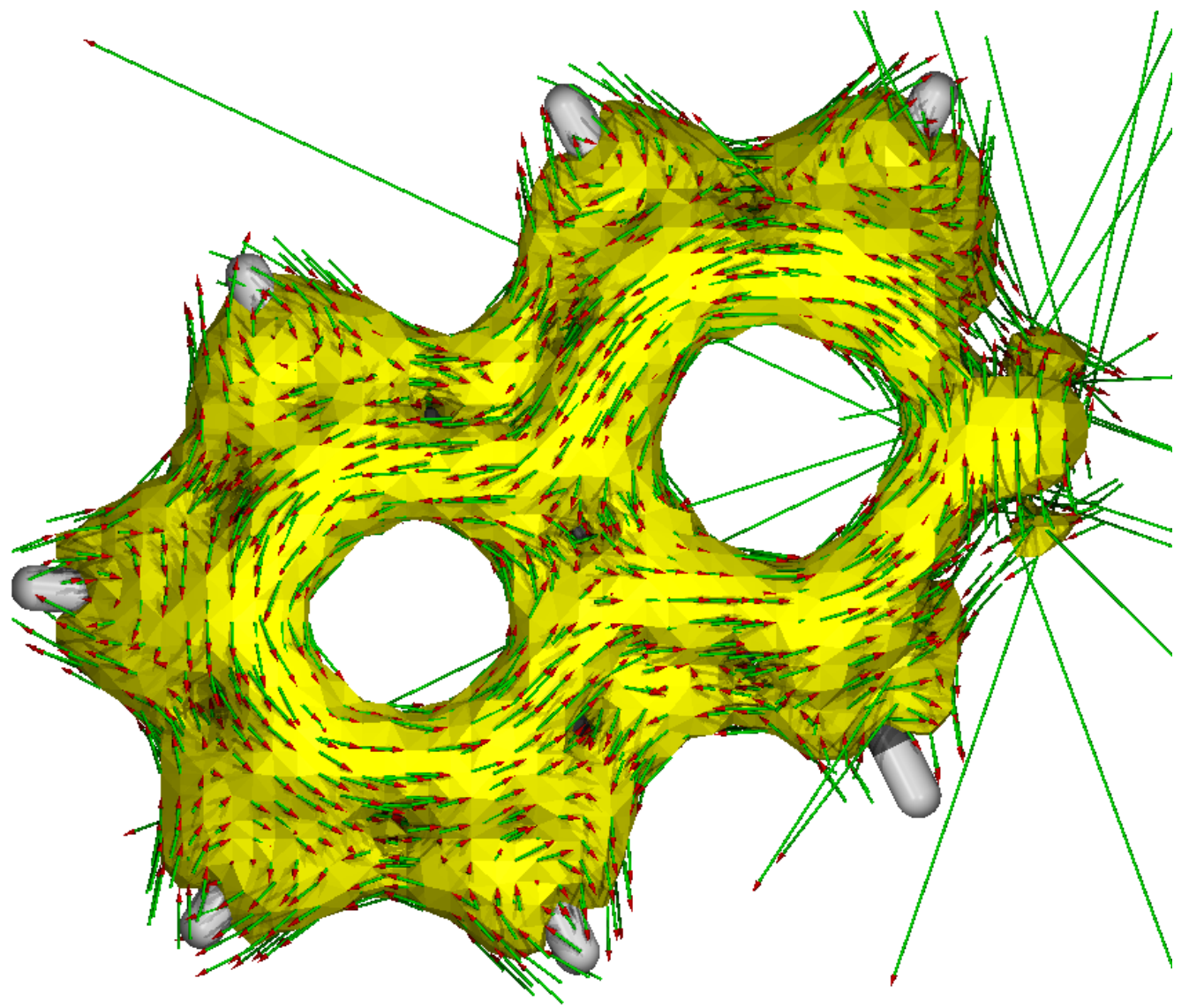

Figure S19. ACID plot of $\mathrm{T}_{1}$ isothiochromenylium ion at an isosurface value of 0.05 a.u. Clockwise circulation is diatropic and counterclockwise circulation is paratropic. 


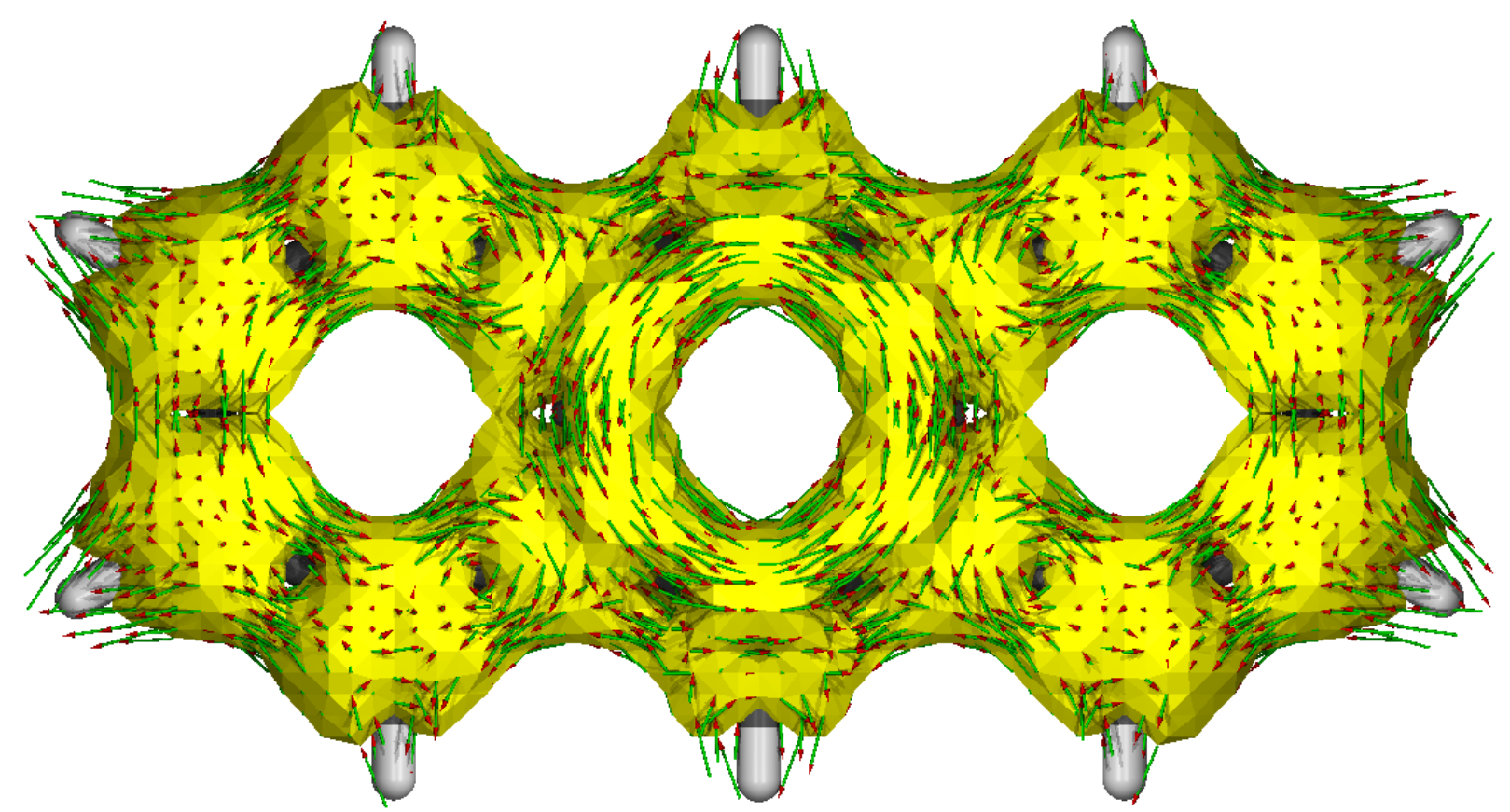

Figure S20. ACID plot of $T_{1}$ anthracene at an isosurface value of 0.05 a.u. Clockwise circulation is diatropic and counterclockwise circulation is paratropic.

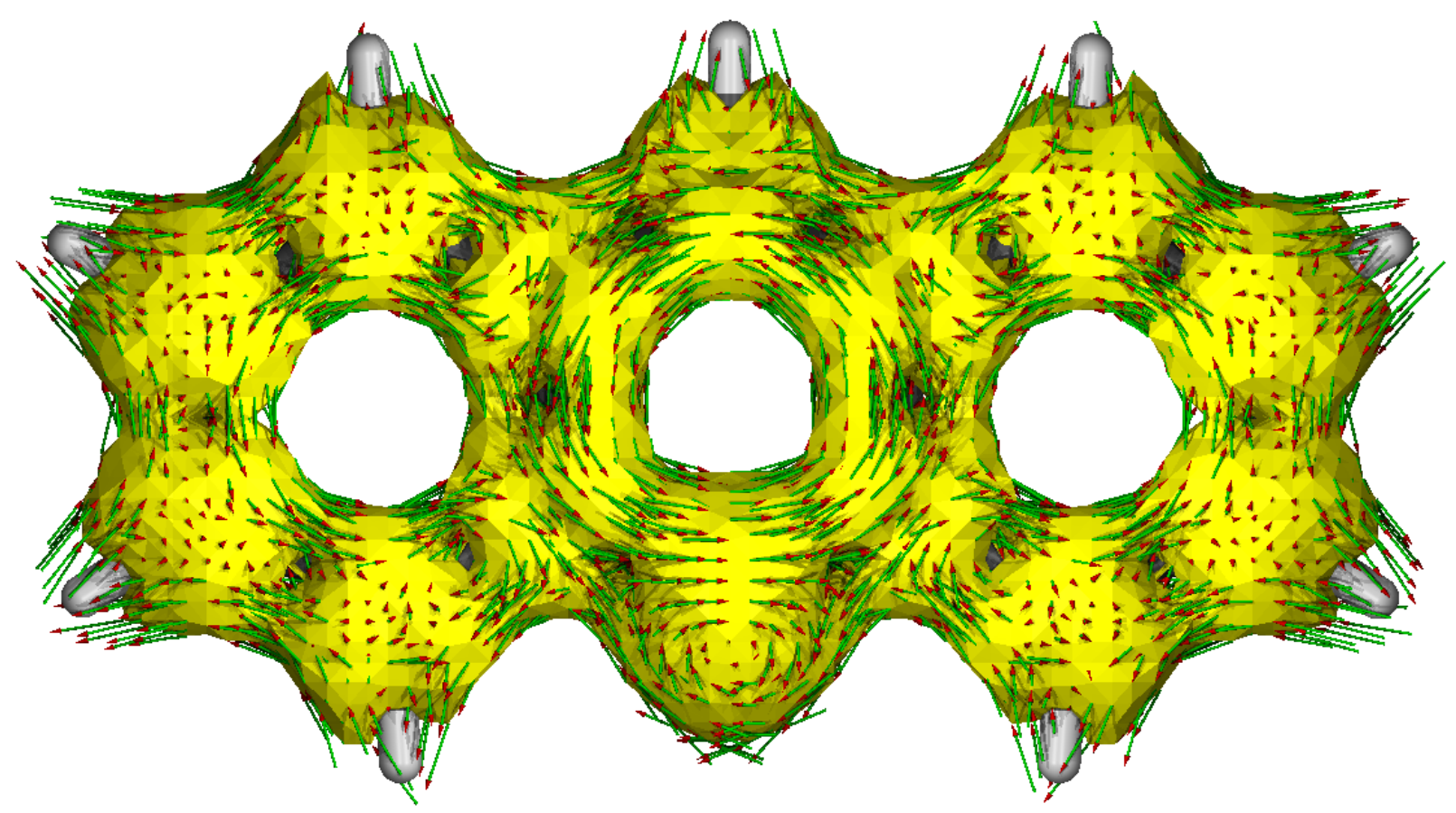

Figure S21. ACID plot of $\mathrm{T}_{1}$ acridine at an isosurface value of 0.05 a.u. Clockwise circulation is diatropic and counterclockwise circulation is paratropic. 


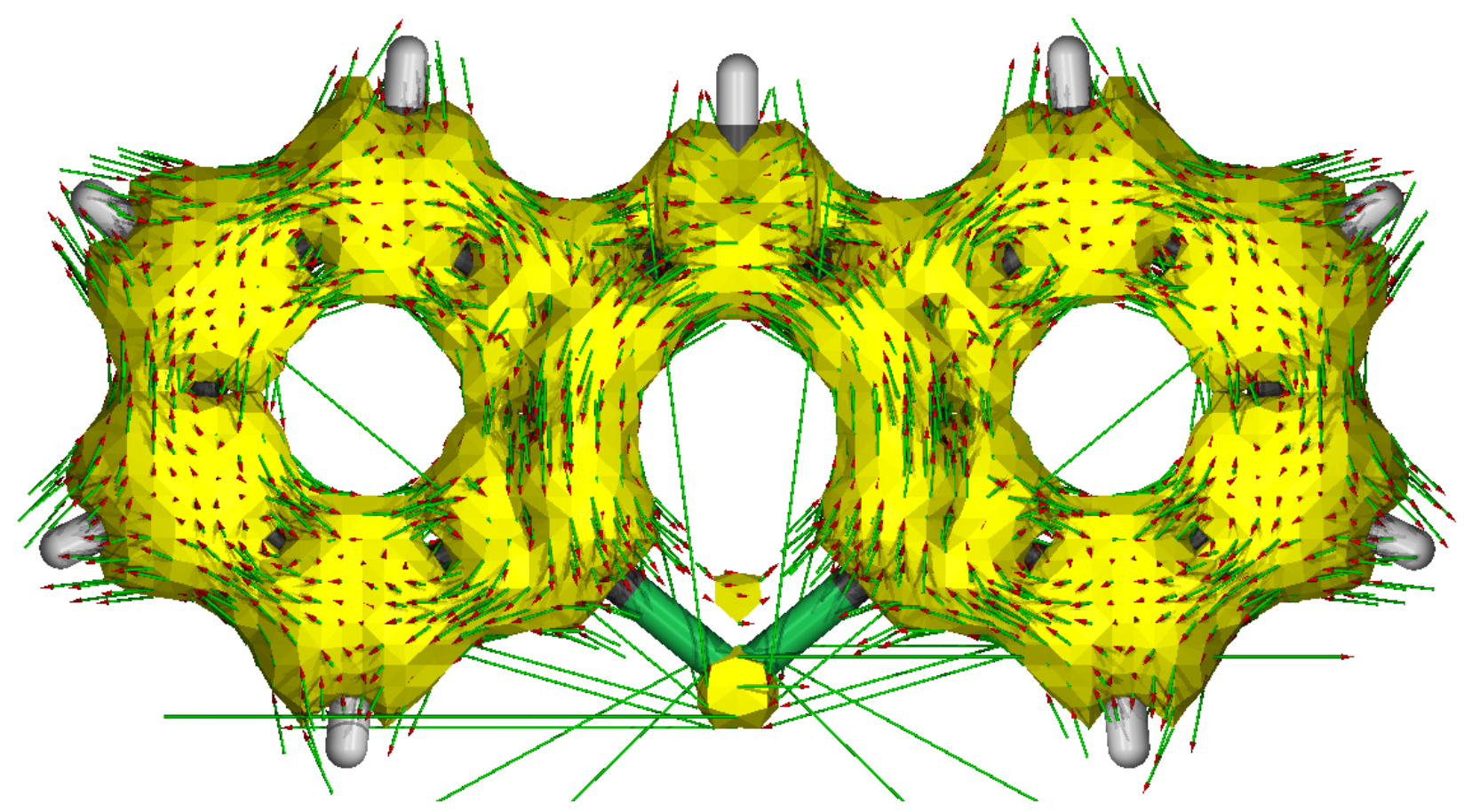

Figure S22. ACID plot of $\mathrm{T}_{1}$ 9-phosphaanthracene at an isosurface value of 0.05 a.u. Clockwise circulation is diatropic and counterclockwise circulation is paratropic.

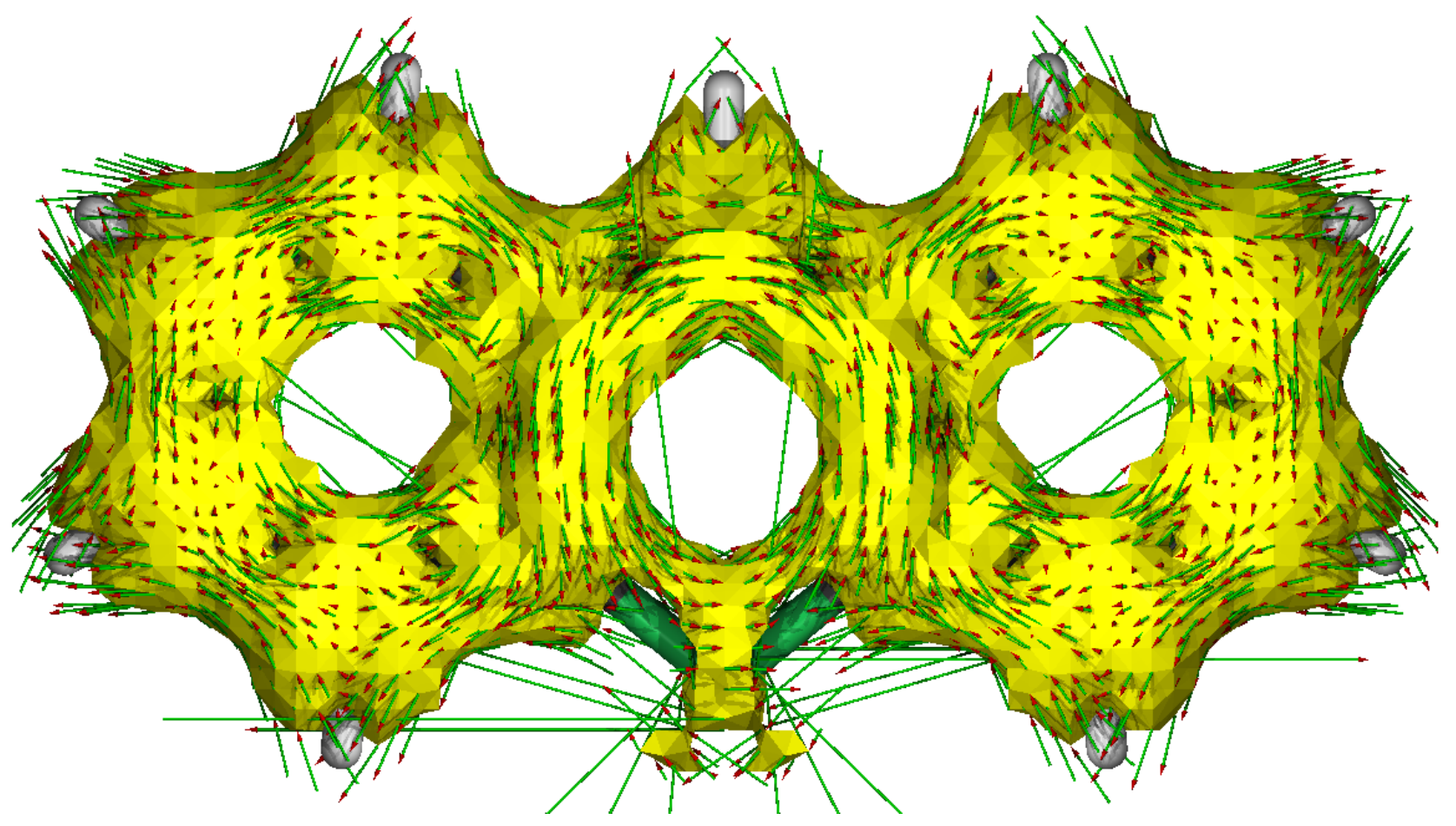

Figure S23. ACID plot of $\mathrm{T}_{1}$ 9-phosphaanthracene at an isosurface value of 0.04 a.u. Clockwise circulation is diatropic and counterclockwise circulation is paratropic. 


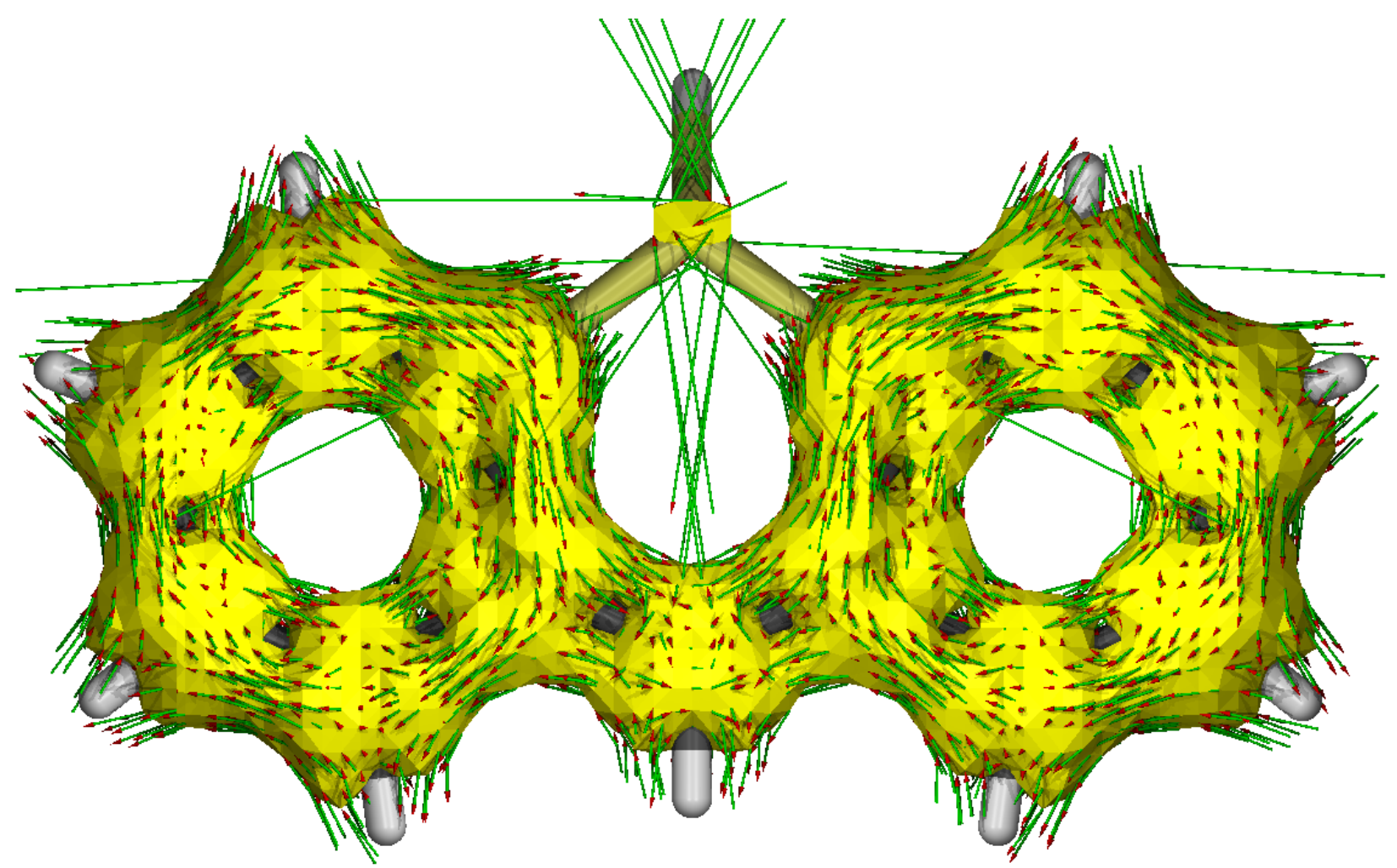

Figure S24. ACID plot of $T_{1}$ 9-silaanthracene at an isosurface value of 0.05 a.u. Clockwise circulation is diatropic and counterclockwise circulation is paratropic.

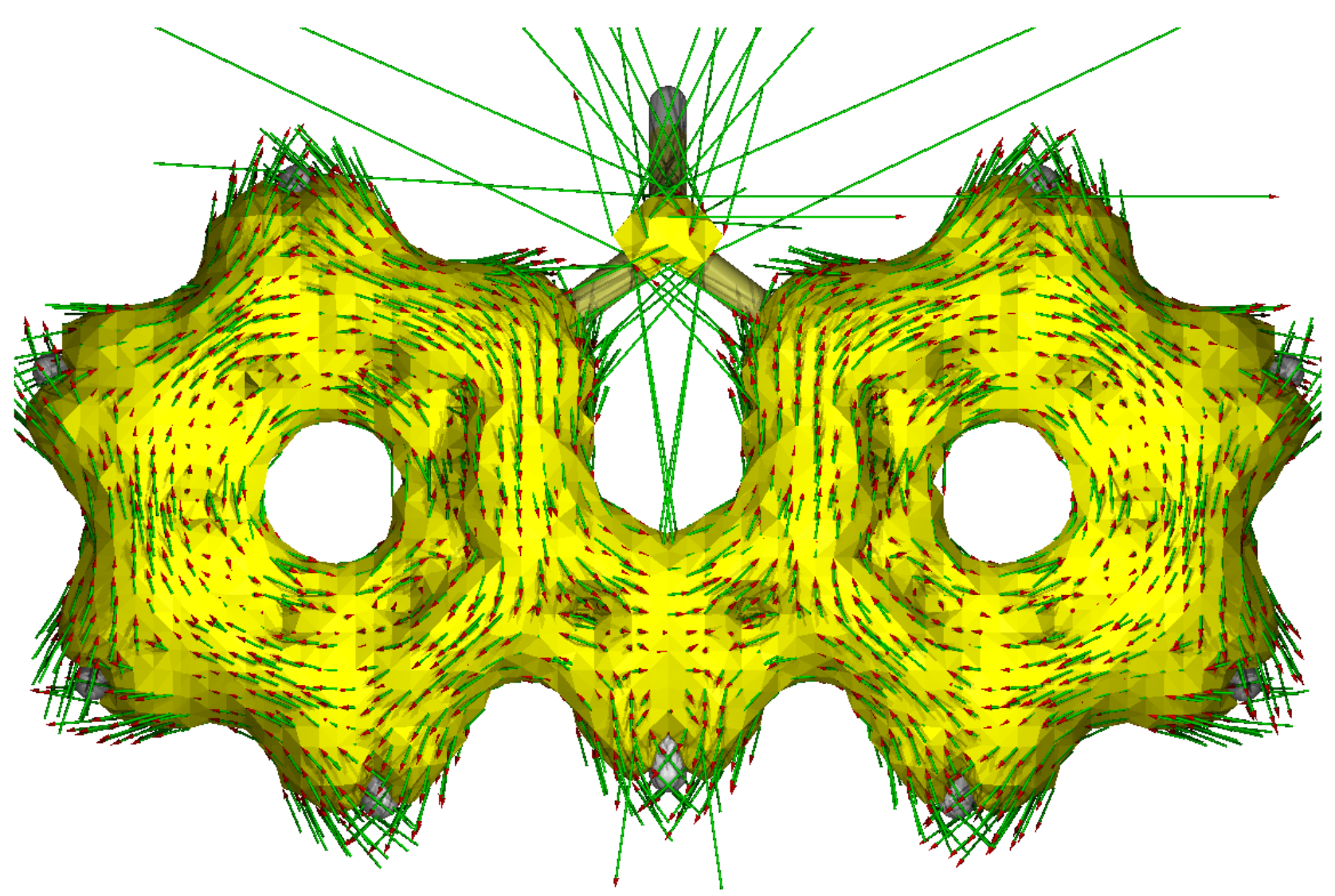

Figure S25. ACID plot of $\mathrm{T}_{1}$ 9-silaanthracene at an isosurface value of 0.03 a.u.. Clockwise circulation is diatropic and counterclockwise circulation is paratropic. 


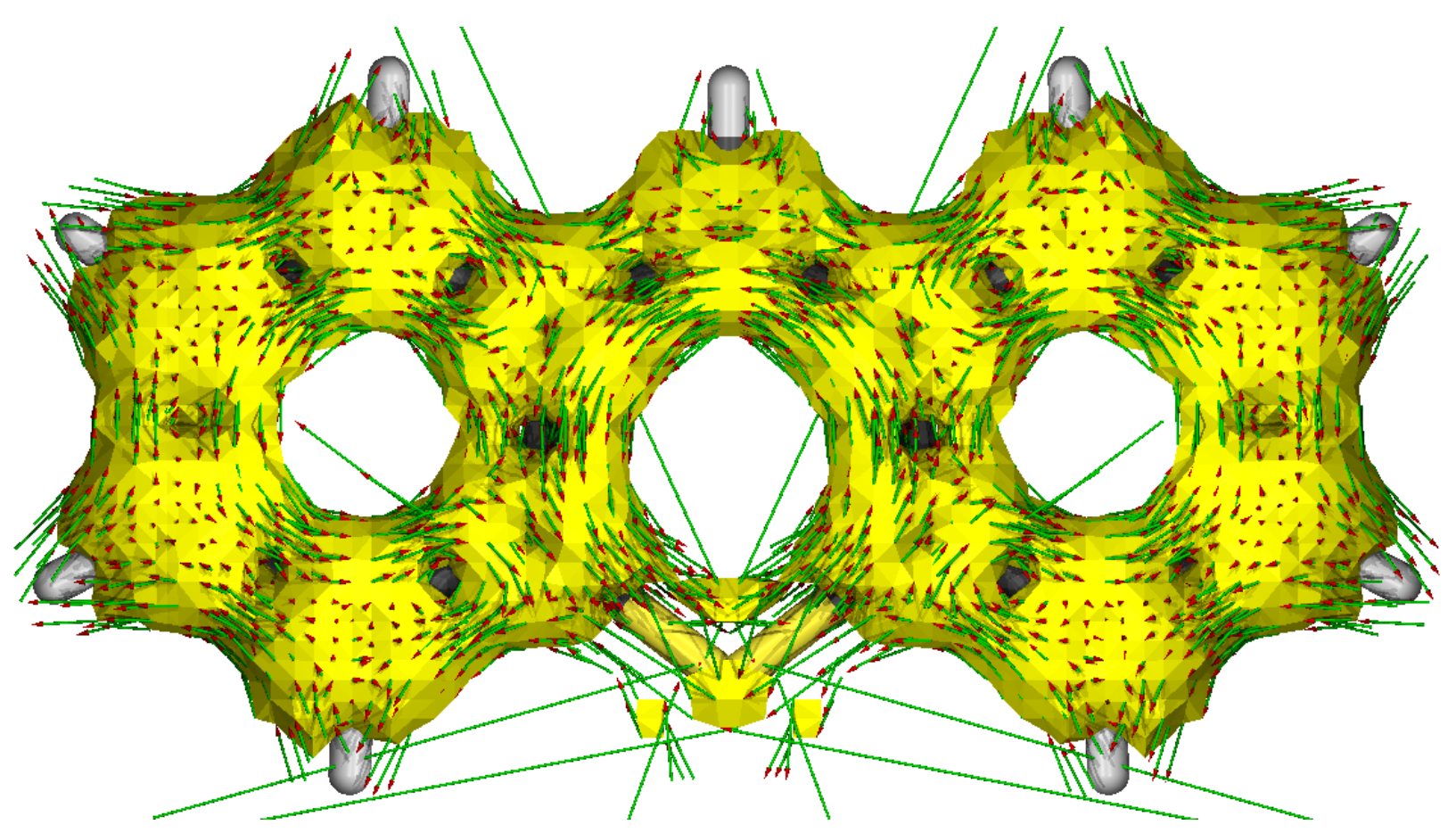

Figure S26. ACID plot of $T_{1}$ thioxanthylium ion at an isosurface value of 0.05 a.u. Clockwise circulation is diatropic and counterclockwise circulation is paratropic.

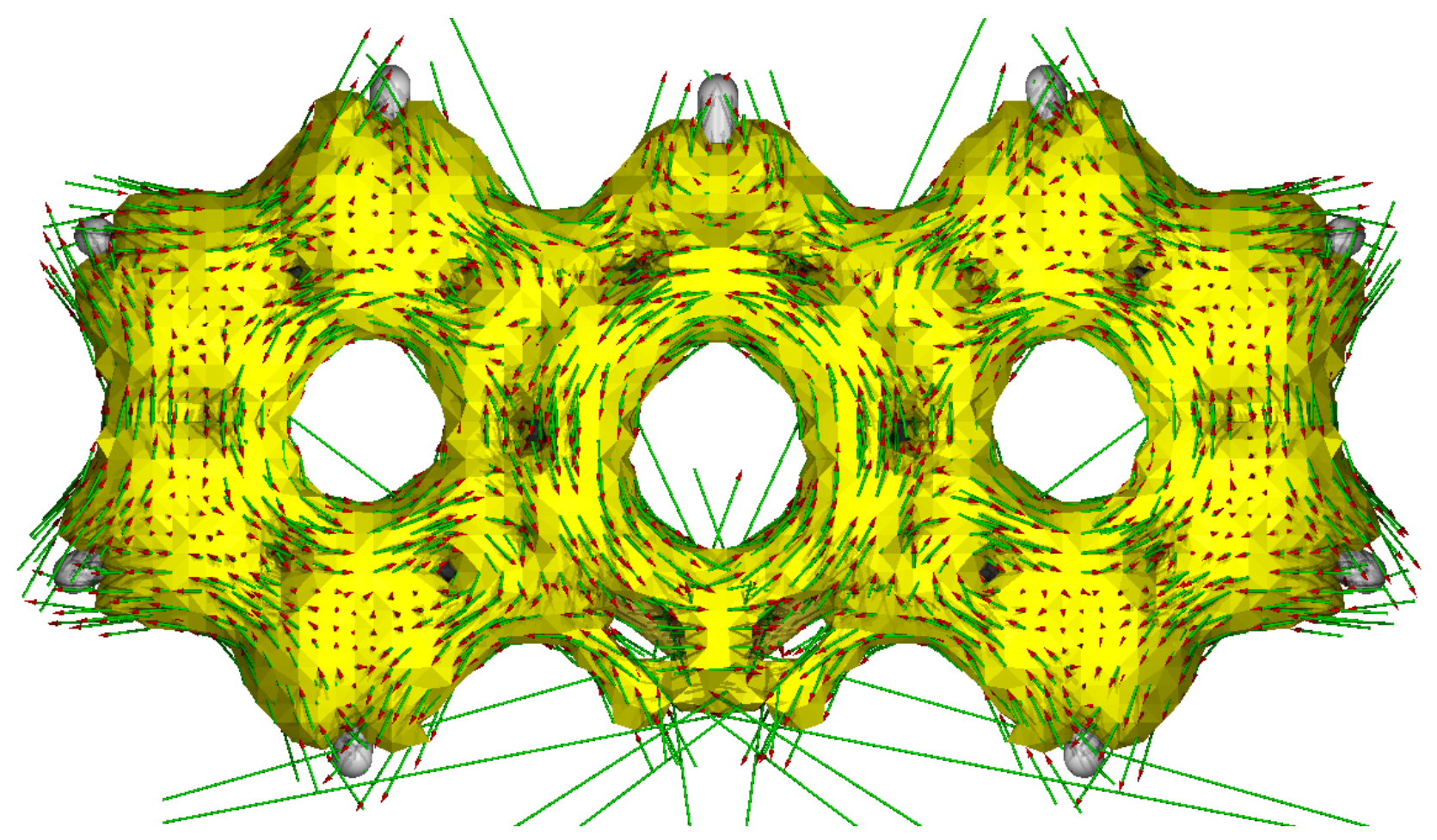

Figure S27. ACID plot of $T_{1}$ thioxanthylium ion at an isosurface value of 0.04 a.u. Clockwise circulation is diatropic and counterclockwise circulation is paratropic. 


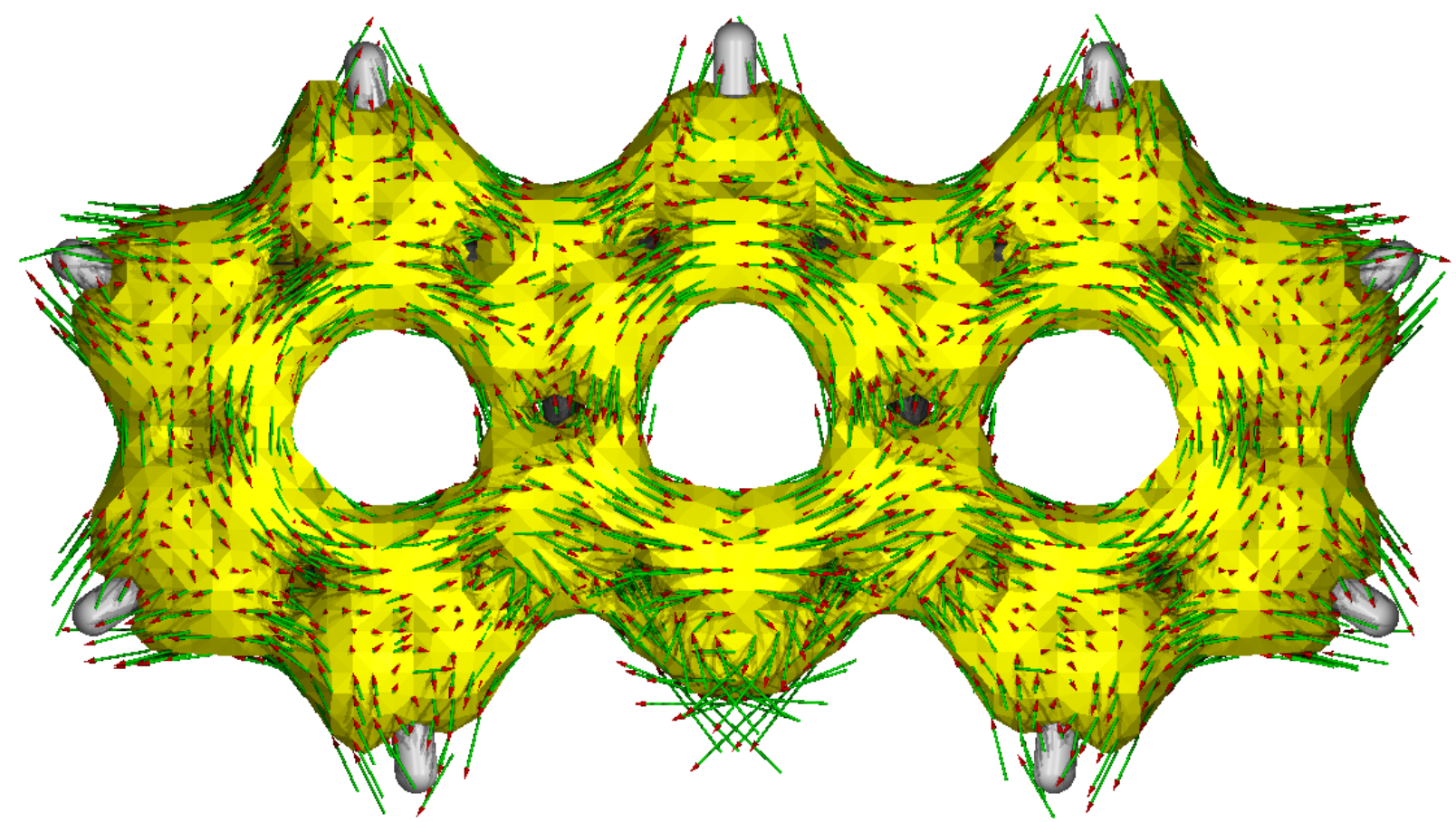

Figure S28. ACID plot of $T_{1}$ xanthylium ion at an isosurface value of 0.05 a.u. Clockwise circulation is diatropic and counterclockwise circulation is paratropic. 


\section{Absolute Energies and x, y, z Coordinates of Optimized Structures}

Benzene $\mathrm{S}_{\mathbf{0}}$

$\mathrm{E}=-232.3112416$ a.u.

\begin{tabular}{|c|c|c|c|c|c|}
\hline \multirow{2}{*}{$\begin{array}{l}\text { Center } \\
\text { Number }\end{array}$} & Atomic & \multirow{2}{*}{$\begin{array}{c}\text { Atomic } \\
\text { Type }\end{array}$} & \multicolumn{3}{|c|}{ Coordinates (Angstroms) } \\
\hline & Number & & $x$ & $Y$ & Z \\
\hline 1 & 6 & $\Theta$ & $\odot, 000000$ & 1.394301 & 0.000000 \\
\hline 2 & 6 & $\odot$ & 1.207500 & $\odot .697151$ & $\odot . \odot \odot \odot \odot \odot \odot$ \\
\hline 3 & 6 & $\odot$ & 1.207500 & -0.697151 & $\odot . \odot \odot \odot \odot \odot \odot$ \\
\hline 4 & 6 & $\odot$ & 0.000000 & -1.394301 & $\odot .00000 \odot$ \\
\hline 5 & 6 & $\odot$ & -1.207500 & -0.697151 & $\odot .00000 \odot$ \\
\hline 6 & 6 & 0 & -1.207500 & 0.697151 & $\odot .000000$ \\
\hline 7 & 1 & 0 & 0.000000 & 2.478574 & $\odot .000000$ \\
\hline 8 & 1 & $\odot$ & 2.146508 & 1.239287 & $\odot . \odot \odot \odot \odot \odot \odot$ \\
\hline 9 & 1 & $\odot$ & 2.146508 & -1.239287 & $\odot . \odot \odot \odot \odot \odot \odot$ \\
\hline 10 & 1 & $\odot$ & $\odot .0 \odot \odot \odot \odot \odot$ & -2.478574 & $\odot .0 \odot \odot \odot \odot \odot$ \\
\hline 11 & 1 & $\odot$ & -2.146508 & -1.239287 & $\odot . \odot \odot \odot \odot \odot \odot$ \\
\hline 12 & 1 & $\odot$ & -2.146508 & 1.239287 & $\odot . \odot \odot \odot \odot \odot \odot$ \\
\hline
\end{tabular}

\section{Benzene $\mathbf{T}_{1}$}

$\mathrm{E}=-232.1699199$ a.u.

\begin{tabular}{|c|c|c|c|c|c|}
\hline \multirow{2}{*}{$\begin{array}{l}\text { Center } \\
\text { Number }\end{array}$} & Atomic & \multirow{2}{*}{$\begin{array}{c}\text { Atomic } \\
\text { Type }\end{array}$} & \multicolumn{3}{|c|}{ Coordinates (Angstroms) } \\
\hline & Number & & $X$ & Y & Z \\
\hline 1 & 6 & 0 & $\odot .00000 \odot$ & 1.207797 & 0.759712 \\
\hline 2 & 6 & $\odot$ & $\odot . \odot \odot \odot \odot \odot \odot$ & $\odot . \odot \odot \odot \odot \odot \odot$ & 1.441395 \\
\hline 3 & 6 & $\odot$ & $\odot . \odot \odot \odot \odot \odot \odot$ & -1.207797 & $\odot .759712$ \\
\hline 4 & 6 & $\odot$ & $\odot .00000 \odot$ & -1.207797 & $-\odot .759712$ \\
\hline 5 & 6 & $\odot$ & $\odot .00000 \odot$ & 0.000000 & -1.441395 \\
\hline 6 & 6 & $\odot$ & $\odot .00000 \odot$ & 1.207797 & $-\odot .759712$ \\
\hline 7 & 1 & $\Theta$ & $\odot .00000 \odot$ & 2.152534 & 1.287125 \\
\hline 8 & 1 & $\Theta$ & $\odot .00000 \odot$ & 0.000000 & 2.526694 \\
\hline 9 & 1 & $\Theta$ & $\odot .00000 \odot$ & -2.152534 & 1.287125 \\
\hline 10 & 1 & $\Theta$ & $\odot .00000 \odot$ & -2.152534 & -1.287125 \\
\hline 11 & 1 & $\Theta$ & $\odot .00 \odot \odot \odot \odot$ & $\odot . ๑ \odot \odot \odot \odot \odot$ & -2.526694 \\
\hline 12 & 1 & $\Theta$ & $\odot .0000 \odot \odot$ & 2.152534 & -1.287125 \\
\hline
\end{tabular}


Pyridine $\mathrm{S}_{\mathbf{0}}$

$\mathrm{E}=-248.3512166$ a.u.

\begin{tabular}{|c|c|c|c|c|c|}
\hline \multirow{2}{*}{$\begin{array}{l}\text { Center } \\
\text { Number }\end{array}$} & \multirow{2}{*}{$\begin{array}{l}\text { Atomic } \\
\text { Number }\end{array}$} & \multirow{2}{*}{$\begin{array}{l}\text { Atomic } \\
\text { Type }\end{array}$} & \multicolumn{3}{|c|}{ Coordinates (Angstroms) } \\
\hline & & & $\mathrm{X}$ & $\mathrm{Y}$ & Z \\
\hline 1 & 6 & $\odot$ & $\odot .0 \odot \odot \odot \odot \odot$ & 1.141638 & $\odot .721422$ \\
\hline 2 & 6 & 0 & 0.000000 & 1.196726 & -0.671684 \\
\hline 3 & 6 & $\odot$ & $\odot .00000 \odot$ & $\odot .00 \odot \odot \odot \odot$ & -1.382952 \\
\hline 4 & 6 & $\odot$ & $\odot .00000 \odot$ & -1.196726 & -0.671684 \\
\hline 5 & 6 & $\odot$ & $\odot .00000 \odot$ & -1.141638 & 0.721422 \\
\hline 6 & 7 & 0 & 0.000000 & $\odot .000 \odot \odot \odot$ & 1.416462 \\
\hline 7 & 1 & 0 & 0.000000 & $\odot .000 \odot \odot \odot$ & -2.467373 \\
\hline 8 & 1 & 0 & 0.000000 & 2.057168 & 1.306729 \\
\hline 9 & 1 & $\odot$ & $\odot .0 \odot \odot \odot \odot \odot$ & 2.153679 & -1.180237 \\
\hline 10 & 1 & $\odot$ & $\odot . \odot \odot \odot \odot \odot \odot$ & -2.153679 & -1.180237 \\
\hline 11 & 1 & $\odot$ & $\odot . \odot \odot \odot \odot \odot \odot$ & -2.057168 & 1.306729 \\
\hline
\end{tabular}

Pyridine $\mathbf{T}_{\mathbf{1}}$

$\mathrm{E}=-248.2175069$ a.u.

\begin{tabular}{|c|c|c|c|c|c|}
\hline \multirow{2}{*}{$\begin{array}{l}\text { Center } \\
\text { Number }\end{array}$} & Atomic & \multirow{2}{*}{$\begin{array}{c}\text { Atomic } \\
\text { Type }\end{array}$} & \multicolumn{3}{|c|}{ Coordinates (Angstroms) } \\
\hline & Number & & $x$ & $\mathrm{Y}$ & Z \\
\hline 1 & 6 & & 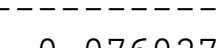 & 0728864 & 1 \\
\hline 1 & 0 & ๑ & -0.076027 & -0.728864 & 1.196978 \\
\hline 2 & 6 & 0 & -0.076027 & 0.637213 & 1. 227391 \\
\hline 3 & 6 & $\odot$ & 0.046814 & 1.360119 & $\odot .000000$ \\
\hline 4 & 6 & $\odot$ & $-\odot .076 \odot 27$ & 0.637213 & -1.227391 \\
\hline 5 & 6 & $\odot$ & $-\odot .076 \odot 27$ & -0.728864 & -1.196978 \\
\hline 6 & 7 & $\odot$ & 0.369474 & -1.293265 & $\odot .000000$ \\
\hline 7 & 1 & $\odot$ & 0.003602 & 2.440956 & $\odot .000000$ \\
\hline 8 & 1 & $\odot$ & -0.275993 & -1.379946 & 2.038164 \\
\hline 9 & 1 & $\Theta$ & -0.247084 & 1.155443 & 2.164088 \\
\hline 10 & 1 & 0 & -0.247084 & 1.155443 & -2.164088 \\
\hline 11 & 1 & 0 & -0.275993 & -1.379946 & -2.038164 \\
\hline
\end{tabular}




\section{Pyrylium ion $\mathrm{S}_{\mathbf{0}}$}

$\mathrm{E}=-268.5421271$ a.u.

\begin{tabular}{|c|c|c|c|c|c|}
\hline \multirow{2}{*}{$\begin{array}{l}\text { Center } \\
\text { Number }\end{array}$} & Atomic & \multirow{2}{*}{$\begin{array}{c}\text { Atomic } \\
\text { Type }\end{array}$} & \multicolumn{3}{|c|}{ Coordinates (Angstroms) } \\
\hline & Number & & $\mathrm{X}$ & $\mathrm{Y}$ & Z \\
\hline 1 & 6 & 0 & 0.000000 & 1.161805 & 0.681284 \\
\hline 2 & 6 & $\odot$ & $\odot .00 \odot \odot \odot \odot$ & 1.208605 & -0.690128 \\
\hline 3 & 6 & $\odot$ & $\odot .00 \odot \odot \odot \odot$ & $\odot .0 \odot \odot \odot \odot \odot$ & -1.393802 \\
\hline 4 & 6 & $\odot$ & $\odot .0 \odot \odot \odot \odot \odot$ & -1.208605 & $-\odot .690128$ \\
\hline 5 & 6 & $\odot$ & $\odot . \odot \odot \odot \odot \odot \odot$ & -1.161805 & $\odot .681284$ \\
\hline 6 & 1 & $\odot$ & $\odot . \odot \odot \odot \odot \odot \odot$ & $\odot .000000$ & -2.478036 \\
\hline 7 & 1 & $\odot$ & $\odot . \odot \odot \odot \odot \odot \odot$ & 2.008928 & 1.354521 \\
\hline 8 & 1 & $\odot$ & $\odot .00000 \odot$ & 2.168116 & -1.190710 \\
\hline 9 & 1 & 0 & $\odot .00000 \odot$ & -2.168116 & -1.190710 \\
\hline 10 & 1 & 0 & $\odot .0000 \odot \odot$ & $-2.0 \odot 8928$ & 1.354521 \\
\hline 11 & 8 & $\Theta$ & 0.000000 & $\odot .00000 \odot$ & 1.327420 \\
\hline
\end{tabular}

\section{Pyrylium ion $\mathbf{T}_{\mathbf{1}}$}

$\mathrm{E}=-268.4192919$ a.u.

\begin{tabular}{|c|c|c|c|c|c|}
\hline \multirow{2}{*}{$\begin{array}{l}\text { Center } \\
\text { Number }\end{array}$} & \multirow{2}{*}{$\begin{array}{l}\text { Atomic } \\
\text { Number }\end{array}$} & \multirow{2}{*}{$\begin{array}{c}\text { Atomic } \\
\text { Type }\end{array}$} & \multicolumn{3}{|c|}{ Coordinates (Angstroms) } \\
\hline & & & $\mathrm{X}$ & Y & Z \\
\hline 1 & 6 & $\odot$ & 0.050191 & -0.701122 & 1.151469 \\
\hline 2 & 6 & $\odot$ & 0.050191 & 0.714733 & 1.180547 \\
\hline 3 & 6 & $\odot$ & -0.029747 & 1.464033 & 0.000000 \\
\hline 4 & 6 & $\odot$ & 0.050191 & 0.714733 & -1.180547 \\
\hline 5 & 6 & $\odot$ & 0.050191 & -0.701122 & -1.151469 \\
\hline 6 & 1 & $\Theta$ & -0.059823 & 2.543165 & $\odot .000000$ \\
\hline 7 & 1 & $\odot$ & 0.241246 & -1.340372 & 2.003149 \\
\hline 8 & 1 & $\odot$ & 0.144664 & 1.188436 & 2.152674 \\
\hline 9 & 1 & $\odot$ & 0.144664 & 1.188436 & -2.152674 \\
\hline 10 & 1 & $\odot$ & 0.241246 & -1.340372 & -2.003149 \\
\hline 11 & 8 & $\Theta$ & -0.217263 & -1.398353 & $\odot .000000$ \\
\hline
\end{tabular}


Silabenzene $\mathbf{S}_{\mathbf{0}}$

$\mathrm{E}=-483.6733009$ a.u.

\begin{tabular}{|c|c|c|c|c|c|}
\hline Center & Atomic & Atomic & Coor & nates (An & croms ) \\
\hline Number & Number & Type & $x$ & $Y$ & z \\
\hline 1 & 6 & $\odot$ & $\odot . \diamond \odot \odot \odot \odot \odot$ & -1.244450 & -1.015482 \\
\hline 2 & 6 & $\odot$ & $\odot . ๑ \odot \odot \odot \odot \odot$ & -1.447606 & $\odot .367934$ \\
\hline 3 & 6 & $\odot$ & $\odot .000000$ & 1.447606 & 0.367934 \\
\hline 4 & 6 & $\odot$ & $\odot .00000 \odot$ & 1.244450 & -1.015482 \\
\hline 5 & 6 & 0 & $\odot .0 \odot \odot \odot \odot \odot$ & $\odot .0 \odot ० \odot \odot \odot$ & -1.659999 \\
\hline 6 & 1 & $\odot$ & $\odot . \diamond \odot \odot \odot \odot \odot$ & -2.123393 & -1.657035 \\
\hline 7 & 1 & $\Theta$ & $\odot .000000$ & -2.465445 & $\odot .741762$ \\
\hline 8 & 1 & $\odot$ & $\odot .00000 \odot$ & $\odot .0 \odot \odot \odot \odot \odot$ & 2.862981 \\
\hline 9 & 1 & $\odot$ & $\odot . \odot \odot \odot \odot \odot \odot$ & 2.465445 & 0.741762 \\
\hline 10 & 1 & $\odot$ & $\odot .00000 \odot$ & 2.123393 & -1.657035 \\
\hline 11 & 1 & $\odot$ & ๑. $.0 \odot \odot \odot \odot$ & $\odot .00 \odot \odot \odot \odot$ & -2.744635 \\
\hline 12 & 14 & $\odot$ & $\odot .00000 \odot$ & $\odot .000 \odot \odot \odot$ & 1.388769 \\
\hline
\end{tabular}

\section{Silabenzene $\mathbf{T}_{\mathbf{1}}$}

$\mathrm{E}=-483.5991289$ a.u.

\begin{tabular}{|c|c|c|c|c|c|}
\hline \multirow{2}{*}{$\begin{array}{l}\text { Center } \\
\text { Number }\end{array}$} & \multirow{2}{*}{$\begin{array}{l}\text { Atomic } \\
\text { Number }\end{array}$} & \multirow{2}{*}{$\begin{array}{l}\text { Atomic } \\
\text { Type }\end{array}$} & \multicolumn{3}{|c|}{ Coordinates (Angstroms) } \\
\hline & & & $x$ & $\mathrm{Y}$ & Z \\
\hline 1 & 6 & $\theta$ & -0.111228 & 1.014421 & -1.269039 \\
\hline 2 & 6 & 0 & -0.111228 & -0.339798 & -1.466899 \\
\hline 3 & 6 & $\odot$ & $-\odot .111228$ & -0.339798 & 1.466899 \\
\hline 4 & 6 & $\odot$ & $-\odot .111228$ & 1.014421 & 1.269039 \\
\hline 5 & 6 & $\odot$ & $-\odot .077111$ & 1.663631 & $\odot .0 \odot \odot \odot \odot \odot$ \\
\hline 6 & 1 & $\odot$ & -0.177084 & 1.670750 & -2.135619 \\
\hline 7 & 1 & $\odot$ & $-\odot .180405$ & -0.710029 & -2.485392 \\
\hline 8 & 1 & $\odot$ & $-\odot .18 \odot 4 \odot 5$ & -0.710029 & 2.485392 \\
\hline 9 & 1 & $\odot$ & -0.177084 & 1.670750 & 2.135619 \\
\hline 10 & 1 & $\odot$ & -0.087859 & 2.748313 & 0.000000 \\
\hline 11 & 14 & 0 & 0.167395 & -1.483450 & ๑.००००००० \\
\hline 12 & 1 & 0 & 1.591458 & -1.978721 & $\odot .0 \odot ० \odot \odot \odot$ \\
\hline
\end{tabular}


Phosphinine $\mathbf{S}_{\mathbf{0}}$

$\mathrm{E}=-534.9552778$ a.u.

\begin{tabular}{|c|c|c|c|c|c|}
\hline \multirow{2}{*}{$\begin{array}{l}\text { Center } \\
\text { Number }\end{array}$} & \multirow{2}{*}{$\begin{array}{l}\text { Atomic } \\
\text { Number }\end{array}$} & \multirow{2}{*}{$\begin{array}{l}\text { Atomic } \\
\text { Type }\end{array}$} & \multicolumn{3}{|c|}{ Coordinates (Angstroms) } \\
\hline & & & $x$ & $\mathrm{Y}$ & Z \\
\hline 1 & 6 & $\odot$ & $\odot .000000$ & 1.335965 & $\odot .368049$ \\
\hline 2 & 6 & $\odot$ & 0.000000 & 1.224803 & -1.018210 \\
\hline 3 & 6 & $\odot$ & $\odot . \odot \odot \odot \odot \odot \odot$ & 0.000000 & -1.687164 \\
\hline 4 & 6 & $\odot$ & $\odot .0 \odot \odot \odot \odot \odot$ & -1.224803 & -1.018210 \\
\hline 5 & 6 & $\Theta$ & $\odot .000 \odot \odot \odot$ & -1.335965 & $\odot .368049$ \\
\hline 6 & 1 & $\Theta$ & $\odot .0 \odot \odot \odot \odot \odot$ & $\odot .000 \odot \odot \odot$ & -2.771736 \\
\hline 7 & 1 & $\odot$ & $\odot . \odot \odot \odot \odot \odot \odot$ & 2.332144 & $\odot .801292$ \\
\hline 8 & 1 & $\odot$ & $\odot .0 \odot \odot \odot \odot \odot$ & 2.133808 & -1.613501 \\
\hline 9 & 1 & $\Theta$ & $\odot .000 \odot \odot \odot$ & -2.133808 & -1.613501 \\
\hline 10 & 1 & $\odot$ & $\odot .0 \odot \odot \odot \odot \odot$ & -2.332144 & ๑.801292 \\
\hline 11 & 15 & $\odot$ & $\odot . \odot \odot \odot \odot \odot \odot$ & $\odot . \odot \odot \odot \odot \odot \odot$ & 1. 488071 \\
\hline
\end{tabular}

\section{Phosphinine $\mathbf{T}_{\mathbf{1}}$}

$\mathrm{E}=-534.8535473$ a.u.

\begin{tabular}{|c|c|c|c|c|c|}
\hline \multirow{2}{*}{$\begin{array}{l}\text { Center } \\
\text { Number }\end{array}$} & Atomic & \multirow{2}{*}{$\begin{array}{c}\text { Atomic } \\
\text { Type }\end{array}$} & \multicolumn{3}{|c|}{ Coordinates (Angstroms) } \\
\hline & Number & & $\mathrm{X}$ & Y & Z \\
\hline 1 & 6 & 0 & 0.191464 & -0.373195 & 1.387954 \\
\hline 2 & 6 & 0 & 0.191464 & 0.977063 & 1.259780 \\
\hline 3 & 6 & $\odot$ & 0.035994 & 1.650436 & $\odot .000000$ \\
\hline 4 & 6 & $\odot$ & $\odot .191464$ & 0.977063 & -1.259780 \\
\hline 5 & 6 & $\odot$ & $\odot .191464$ & -0.373195 & -1.387954 \\
\hline 6 & 1 & $\odot$ & $-\odot .0 \odot 6 \odot 99$ & 2.733261 & $\odot . \odot \odot \odot \odot \odot \odot$ \\
\hline 7 & 1 & $\odot$ & $\odot .401897$ & -0.842450 & 2.343073 \\
\hline 8 & 1 & $\odot$ & $\odot .384796$ & 1.598242 & 2.131647 \\
\hline 9 & 1 & $\odot$ & 0.384796 & 1.598242 & -2.131647 \\
\hline 10 & 1 & $\odot$ & $\odot .401897$ & -0.842450 & -2.343073 \\
\hline 11 & 15 & $\Theta$ & $-\odot .425226$ & -1.426259 & $\odot . \odot \odot \odot \odot \odot \odot$ \\
\hline
\end{tabular}


Thiopyrylium ion $\mathbf{S}_{\mathbf{0}}$

$\mathrm{E}=-591.5272925$ a.u.

\begin{tabular}{|c|c|c|c|c|c|}
\hline \multirow{2}{*}{$\begin{array}{l}\text { Center } \\
\text { Number }\end{array}$} & \multirow{2}{*}{$\begin{array}{l}\text { Atomic } \\
\text { Number }\end{array}$} & \multirow{2}{*}{$\begin{array}{c}\text { Atomic } \\
\text { Type }\end{array}$} & \multicolumn{3}{|c|}{ Coordinates (Angstroms) } \\
\hline & & & $X$ & $Y$ & Z \\
\hline 1 & 6 & $\odot$ & $\odot .0 \odot \odot \odot \odot \odot$ & -1.331183 & $\odot .351397$ \\
\hline 2 & 6 & $\odot$ & $\odot . \odot \odot \odot \odot \odot \odot$ & -1.229833 & -1.024139 \\
\hline 3 & 6 & $\odot$ & $\odot . \odot \odot \odot \odot \odot \odot$ & $\odot . \odot \odot \odot \odot \odot \odot$ & -1.689611 \\
\hline 4 & 6 & 0 & $\odot .00000 \odot$ & 1.229833 & -1.024139 \\
\hline 5 & 6 & $\Theta$ & $\odot .000000$ & 1.331183 & ๑. 351397 \\
\hline 6 & 1 & $\odot$ & $\odot .000 \odot \odot \odot$ & 0.000000 & -2.773759 \\
\hline 7 & 1 & $\odot$ & $\odot .000 \odot \odot \odot$ & -2.289857 & 0.858378 \\
\hline 8 & 1 & $\odot$ & $\odot .00000 \odot$ & -2.147532 & -1.601310 \\
\hline 9 & 1 & $\Theta$ & $\odot .000000$ & 2.147532 & -1.601310 \\
\hline 10 & 1 & $\Theta$ & $\odot .00000 \odot$ & 2.289857 & 0.858378 \\
\hline 11 & 16 & $\Theta$ & $\odot .000000$ & $\odot .00000 \odot$ & 1.404387 \\
\hline
\end{tabular}

\section{Thiopyrylium ion $\mathbf{T}_{\mathbf{1}}$}

$\mathrm{E}=-591.4105558$ a.u.

\begin{tabular}{|c|c|c|c|c|c|}
\hline Center & Atomic & Atomic & \multicolumn{3}{|c|}{ Coordinates (Angstroms) } \\
\hline Number & Number & Type & $X$ & Y & Z \\
\hline 1 & 6 & $\Theta$ & 0.506383 & 1.259931 & -0.170624 \\
\hline 2 & 6 & $\odot$ & -0.889124 & 1.287173 & -0.080120 \\
\hline 3 & 6 & 0 & -1.728779 & 0.149383 & 0.142160 \\
\hline 4 & 6 & 0 & -1.208202 & -1.112018 & 0.051430 \\
\hline 5 & 6 & 0 & 0.182062 & -1.343189 & -0.224240 \\
\hline 6 & 1 & 0 & -2.783712 & 0.301904 & ๑. 325651 \\
\hline 7 & 1 & 0 & 1.066993 & 2.165353 & -0.378515 \\
\hline 8 & 1 & 0 & -1.356176 & 2.265507 & -0.154639 \\
\hline 9 & 1 & 0 & -1.858036 & -1.981912 & 0.109718 \\
\hline 10 & 1 & $\Theta$ & 0.496235 & -2.107389 & -0.930697 \\
\hline 11 & 16 & 0 & 1.453791 & -0.130696 & 0.169803 \\
\hline
\end{tabular}




\section{Naphthalene $\mathbf{S}_{\mathbf{0}}$}

$\mathrm{E}=-385.9888708$ a.u.

\begin{tabular}{|c|c|c|c|c|c|}
\hline Center & Atomic & Atomic & Coor & inates (An & roms ) \\
\hline Number & Number & Type & $x$ & Y & Z \\
\hline 1 & 6 & $\odot$ & $\odot . \odot \odot \odot \odot \odot \odot$ & 2.430634 & $\odot .707529$ \\
\hline 2 & 6 & $\odot$ & $\odot . \odot \odot \odot \odot \odot \odot$ & 1.243886 & 1.400697 \\
\hline 3 & 6 & 0 & $\odot .00000 \odot$ & 0.000000 & $\odot .715970$ \\
\hline 4 & 6 & 0 & $\odot .00 \odot \odot \odot \odot$ & $\odot .00000 \odot$ & -0.715970 \\
\hline 5 & 6 & $\odot$ & $\odot . \diamond \odot \odot \odot \odot \odot$ & 1.243886 & -1.400697 \\
\hline 6 & 6 & $\odot$ & $\odot . \odot \odot \odot \odot \odot \odot$ & 2.430634 & $-\odot .707529$ \\
\hline 7 & 1 & $\odot$ & $\odot . \odot \odot \odot \odot \odot \odot$ & -1.243119 & 2.485975 \\
\hline 8 & 1 & $\odot$ & $\odot . \odot \odot \odot \odot \odot \odot$ & 3.373020 & 1.243931 \\
\hline 9 & 1 & $\odot$ & $\odot . \diamond \odot \odot \odot \odot \odot$ & 1.243119 & 2.485975 \\
\hline 10 & 6 & $\odot$ & $\odot . \odot \odot \odot \odot \odot \odot$ & -1.243886 & 1. 400697 \\
\hline 11 & 6 & $\odot$ & $\odot . ๑ \odot \odot \odot \odot \odot$ & -1.243886 & -1.400697 \\
\hline 12 & 1 & $\odot$ & $\odot .000 \odot \odot \odot$ & 1.243119 & -2.485975 \\
\hline 13 & 1 & $\odot$ & $\odot . \odot \odot \odot \odot \odot \odot$ & 3.373020 & -1.243931 \\
\hline 14 & 6 & $\odot$ & $\odot .0 \odot \odot \odot \odot \odot$ & -2.430634 & -0.707529 \\
\hline 15 & 6 & $\odot$ & $\odot .0 \odot \odot \odot \odot \odot$ & -2.430634 & $\odot .707529$ \\
\hline 16 & 1 & $\odot$ & $\odot . \odot \odot \odot \odot \odot \odot$ & -1.243119 & -2.485975 \\
\hline 17 & 1 & $\odot$ & $\odot .00000 \odot$ & -3.373020 & -1.243931 \\
\hline 18 & 1 & $\odot$ & $\odot . \diamond \odot \odot \odot \odot \odot$ & -3.373020 & 1.243931 \\
\hline
\end{tabular}

\section{Naphthalene $\mathbf{T}_{\mathbf{1}}$}

$\mathrm{E}=-385.8896466$ a.u.

\begin{tabular}{|c|c|c|c|c|c|}
\hline \multirow{2}{*}{$\begin{array}{l}\text { Center } \\
\text { Number }\end{array}$} & \multirow{2}{*}{$\begin{array}{l}\text { Atomic } \\
\text { Number }\end{array}$} & \multirow{2}{*}{$\begin{array}{c}\text { Atomic } \\
\text { Type }\end{array}$} & \multicolumn{3}{|c|}{ Coordinates (Angstroms) } \\
\hline & & & $\mathrm{x}$ & $Y$ & $z$ \\
\hline 1 & 6 & 0 & $\odot .00000 \odot$ & -2.484690 & $-\odot .68069 \odot$ \\
\hline 2 & 6 & $\odot$ & $\odot . \odot \odot \odot \odot \odot \odot$ & -1.236673 & -1.399394 \\
\hline 3 & 6 & $\odot$ & $\odot . \odot \odot \odot \odot \odot \odot$ & $\odot . \odot \odot \odot \odot \odot \odot$ & $-\odot .724072$ \\
\hline 4 & 6 & $\odot$ & 0.000000 & $\odot .000000$ & 0.724072 \\
\hline 5 & 6 & $\odot$ & 0.000000 & -1.236673 & 1.399394 \\
\hline 6 & 6 & $\odot$ & 0.000000 & -2.484690 & 0.680690 \\
\hline 7 & 1 & $\odot$ & 0.000000 & 1.245668 & -2.483664 \\
\hline 8 & 1 & $\odot$ & $\odot .00000 \odot$ & -3.415172 & -1.236225 \\
\hline 9 & 1 & $\Theta$ & $\odot .00000 \odot$ & -1.245668 & -2.483664 \\
\hline 10 & 6 & $\odot$ & 0.000000 & 1.236673 & -1.399394 \\
\hline 11 & 6 & 0 & $\odot .00000 \odot$ & 1.236673 & 1.399394 \\
\hline 12 & 1 & $\odot$ & 0.000000 & -1.245668 & 2.483664 \\
\hline 13 & 1 & $\odot$ & $\odot . \odot \odot \odot \odot \odot \odot$ & -3.415172 & 1.236225 \\
\hline 14 & 6 & $\odot$ & $\odot . \odot \odot \odot \odot \odot \odot$ & 2.484690 & $\odot .680690$ \\
\hline 15 & 6 & $\odot$ & $\odot .000 \odot \odot \odot$ & 2.484690 & -0.680690 \\
\hline 16 & 1 & 0 & $\odot .00000 \odot$ & 1.245668 & 2.483664 \\
\hline 17 & 1 & 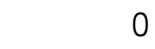 & $\odot .0000 \odot \odot$ & 3.415172 & 1.236225 \\
\hline 18 & 1 & $\Theta$ & $\odot .00000 \odot$ & 3.415172 & -1.236225 \\
\hline
\end{tabular}


Quinoline $\mathrm{S}_{\mathbf{0}}$

$\mathrm{E}=-402.0310543$ a.u.

\begin{tabular}{|c|c|c|c|c|c|}
\hline \multirow{2}{*}{$\begin{array}{l}\text { Center } \\
\text { Number }\end{array}$} & \multirow{2}{*}{$\begin{array}{l}\text { Atomic } \\
\text { Number }\end{array}$} & \multirow{2}{*}{$\begin{array}{c}\text { Atomic } \\
\text { Type }\end{array}$} & \multicolumn{3}{|c|}{ Coordinates (Angstroms) } \\
\hline & & & $x$ & $\mathrm{Y}$ & Z \\
\hline 1 & 6 & 0 & -2.445032 & $\odot .551568$ & $\odot . \odot \odot \odot \odot \odot \odot$ \\
\hline 2 & 6 & $\odot$ & -1.321000 & 1.338394 & $\odot .000000$ \\
\hline 3 & 6 & $\odot$ & -0.044134 & 0.725023 & 0.000000 \\
\hline 4 & 6 & $\odot$ & $\odot .0 \odot \odot \odot \odot \odot$ & -0.704675 & $\odot .000 \odot \odot \odot$ \\
\hline 5 & 6 & $\odot$ & -2.290556 & -0.856485 & $\odot .000000$ \\
\hline 6 & 1 & 0 & 1.133037 & 2.540232 & 0.000000 \\
\hline 7 & 1 & 0 & -3.438512 & $\odot .984068$ & 0.000000 \\
\hline 8 & 1 & $\odot$ & -1.394227 & 2.421377 & 0.000000 \\
\hline 9 & 6 & 0 & 1.171993 & 1.455632 & $\odot .0000 \odot \odot$ \\
\hline 10 & 6 & 0 & 1.262163 & -1.352348 & $\odot .000 \odot \odot \odot$ \\
\hline 11 & 1 & 0 & -3.172836 & -1.492476 & $\odot .000 \odot \odot \odot$ \\
\hline 12 & 6 & 0 & 2.422682 & -0.616406 & $\odot .00 \odot \odot \odot \odot$ \\
\hline 13 & 6 & $\odot$ & 2.379032 & $\odot .799027$ & $\odot .0000 \odot \odot$ \\
\hline 14 & 1 & $\odot$ & 1.272696 & -2.435728 & $\odot . \odot \odot \odot \odot \odot \odot$ \\
\hline 15 & 1 & $\odot$ & 3.383121 & -1.119526 & $\odot . \odot \odot \odot \odot \odot \odot$ \\
\hline 16 & 1 & $\odot$ & 3.304838 & 1.363034 & $\odot . \odot \odot \odot \odot \odot \odot$ \\
\hline 17 & 7 & $\odot$ & -1.128429 & -1.471337 & $\odot .0 \odot \odot \odot \odot \odot$ \\
\hline
\end{tabular}

\section{Quinoline $\mathbf{T}_{1}$}

$\mathrm{E}=-401.9294179$ a.u.

\begin{tabular}{|c|c|c|c|c|c|}
\hline \multirow{2}{*}{$\begin{array}{l}\text { Center } \\
\text { Number }\end{array}$} & \multirow{2}{*}{$\begin{array}{l}\text { Atomic } \\
\text { Number }\end{array}$} & \multirow{2}{*}{$\begin{array}{c}\text { Atomic } \\
\text { Type }\end{array}$} & \multicolumn{3}{|c|}{ Coordinates (Angstroms) } \\
\hline & & & $x$ & $\mathrm{Y}$ & Z \\
\hline 1 & 6 & 0 & -2.499841 & 0.462174 & $\odot . \odot \odot \odot \odot \odot \odot$ \\
\hline 2 & 6 & 0 & -1.354313 & 1.315961 & $\odot . \odot \odot \odot \odot \odot \odot$ \\
\hline 3 & 6 & $\odot$ & -0.076579 & 0.738934 & 0.000000 \\
\hline 4 & 6 & $\odot$ & $\odot . \odot \odot \odot \odot \odot \odot$ & $-\odot .706741$ & $\odot .0 \odot \odot \odot \odot \odot$ \\
\hline 5 & 6 & $\odot$ & -2.320358 & $-\odot .890945$ & $\odot . \diamond \odot \odot \odot \odot \odot$ \\
\hline 6 & 1 & $\odot$ & 1.082543 & 2.561518 & $\odot . \odot \odot \odot \odot \odot \odot$ \\
\hline 7 & 1 & $\odot$ & -3.498062 & 0.883417 & $\odot . \odot \odot \odot \odot \odot \odot$ \\
\hline 8 & 1 & $\odot$ & -1.467948 & 2.393890 & $\odot . \odot \odot \odot \odot \odot \odot$ \\
\hline 9 & 6 & $\odot$ & 1.127650 & 1.477943 & $\odot . \odot \odot \odot \odot \odot \odot$ \\
\hline 10 & 6 & 0 & 1.287935 & -1.318245 & $\odot .0 \odot \odot \odot \odot \odot$ \\
\hline 11 & 1 & $\odot$ & -3.163814 & -1.572325 & 0.000000 \\
\hline 12 & 6 & $\odot$ & 2.497378 & -0.532987 & $\odot .0 \odot \odot \odot \odot \odot$ \\
\hline 13 & 6 & $\odot$ & 2.421857 & 0.822558 & 0.000000 \\
\hline 14 & 1 & $\odot$ & 1.326889 & -2.400416 & 0.000000 \\
\hline 15 & 1 & $\odot$ & 3.455674 & -1.038322 & 0.000000 \\
\hline 16 & 1 & $\odot$ & 3.317886 & 1.431746 & $\odot . \odot \odot \odot \odot \odot \odot$ \\
\hline 17 & 7 & $\odot$ & -1.079363 & -1.495916 & $\odot . ๑ \odot \odot \odot \odot \odot$ \\
\hline
\end{tabular}




\section{Isoquinoline $\mathbf{S}_{\mathbf{0}}$}

$\mathrm{E}=-402.0291583$ a.u.

\begin{tabular}{|c|c|c|c|c|c|}
\hline \multirow{2}{*}{$\begin{array}{l}\text { Center } \\
\text { Number }\end{array}$} & \multirow{2}{*}{$\begin{array}{l}\text { Atomic } \\
\text { Number }\end{array}$} & \multirow{2}{*}{$\begin{array}{l}\text { Atomic } \\
\text { Type }\end{array}$} & \multicolumn{3}{|c|}{ Coordinates (Angstroms) } \\
\hline & & & $x$ & Y & Z \\
\hline 1 & 6 & $\theta$ & 2420786 & ๑ 676921 & $\odot .000000$ \\
\hline 2 & 6 & 0 & 1.241625 & 1.382538 & 0.000000 \\
\hline 3 & 6 & $\odot$ & $\odot . \odot \odot \odot \odot \odot \odot$ & 0.698479 & $\odot . \odot \odot \odot \odot \odot \odot$ \\
\hline 4 & 6 & $\odot$ & -0.018989 & -0.727420 & $\odot . \odot \odot \odot \odot \odot \odot$ \\
\hline 5 & 6 & $\odot$ & 1.214655 & -1.428624 & $\odot . \odot \odot \odot \odot \odot \odot$ \\
\hline 6 & 6 & $\odot$ & 2.404111 & -0.739526 & $\odot . \diamond \odot \odot \odot \odot \odot$ \\
\hline 7 & 1 & $\odot$ & -1.259556 & 2.462975 & $\odot . \diamond \odot \odot \odot \odot \odot$ \\
\hline 8 & 1 & $\odot$ & 3.370209 & 1.199911 & $\odot . \odot \odot \odot \odot \odot \odot$ \\
\hline 9 & 1 & $\odot$ & 1.245619 & 2.467619 & $\odot . \odot \odot \odot \odot \odot \odot$ \\
\hline 10 & 6 & $\odot$ & -1.250332 & 1.374127 & 0.000000 \\
\hline 11 & 6 & $\odot$ & -1.288235 & -1.358034 & $\odot .0 \odot \odot \odot \odot \odot$ \\
\hline 12 & 1 & $\odot$ & 1.205362 & -2.513392 & $\odot .000 \odot \odot \odot$ \\
\hline 13 & 1 & 0 & 3.343095 & -1.281762 & $\odot .0 \odot \odot \odot \odot \odot$ \\
\hline 14 & 6 & 0 & -2.425154 & -0.587843 & $\odot .000 \odot \odot \odot$ \\
\hline 15 & 1 & 0 & -1.358544 & -2.440351 & $\odot .0 \odot \odot \odot \odot \odot$ \\
\hline 16 & 1 & 0 & -3.407118 & -1.050029 & $\odot .0 \odot \odot \odot ० \odot$ \\
\hline 17 & 7 & $\odot$ & -2.418551 & $\odot .773046$ & $\odot . \odot \odot \odot \odot \odot \odot$ \\
\hline
\end{tabular}

\section{Isoquinoline $\mathbf{T}_{\mathbf{1}}$}

$\mathrm{E}=-401.9303076$ a.u.

\begin{tabular}{|c|c|c|c|c|c|}
\hline \multirow{2}{*}{$\begin{array}{l}\text { Center } \\
\text { Number }\end{array}$} & \multirow{2}{*}{$\begin{array}{l}\text { Atomic } \\
\text { Number }\end{array}$} & \multirow{2}{*}{$\begin{array}{c}\text { Atomic } \\
\text { Type }\end{array}$} & \multicolumn{3}{|c|}{ Coordinates (Angstroms) } \\
\hline & & & $\mathrm{X}$ & $\mathrm{Y}$ & Z \\
\hline 1 & 6 & $\odot$ & 2.476241 & 0.620926 & $\odot . \odot \odot \odot \odot \odot \odot$ \\
\hline 2 & 6 & $\odot$ & 1.243653 & 1.368435 & $\odot . \odot \odot \odot \odot \odot \odot$ \\
\hline 3 & 6 & $\odot$ & 0.000000 & 0.713045 & $\odot .000000$ \\
\hline 4 & 6 & $\odot$ & -0.022362 & -0.731664 & $\odot .00000 \odot$ \\
\hline 5 & 6 & $\odot$ & 1.198084 & -1.436907 & $\odot .00000 \odot$ \\
\hline 6 & 6 & 0 & 2.457094 & -0.741444 & $\odot .000000$ \\
\hline 7 & 1 & 0 & -1.259160 & 2.474365 & $\odot .000000$ \\
\hline 8 & 1 & 0 & 3.416754 & 1.159535 & $\odot .000000$ \\
\hline 9 & 1 & 0 & 1.276192 & 2.451970 & $\odot .00000 \odot$ \\
\hline 10 & 6 & $\odot$ & -1.235924 & 1.390037 & $\odot . \odot \odot \odot \odot \odot \odot$ \\
\hline 11 & 6 & $\odot$ & -1.283051 & -1.346933 & $\odot . \odot \odot \odot \odot \odot \odot$ \\
\hline 12 & 1 & $\odot$ & 1.182522 & -2.521035 & $\odot . \odot \odot \odot \odot \odot \odot$ \\
\hline 13 & 1 & $\odot$ & 3.378450 & -1.310999 & $\odot . \odot \odot \odot \odot \odot \odot$ \\
\hline 14 & 6 & $\odot$ & -2.476864 & -0.532174 & 0.000000 \\
\hline 15 & 1 & $\odot$ & -1.373273 & -2.427200 & $\odot .000000$ \\
\hline 16 & 1 & $\Theta$ & -3.446962 & -1.024806 & $\odot .00 \odot \odot \odot \odot$ \\
\hline 17 & 7 & $\odot$ & -2.473678 & 0.768321 & $\odot .0000 \odot \odot$ \\
\hline
\end{tabular}




\section{Chromenylium ion $\mathbf{S}_{\mathbf{0}}$}

$\mathrm{E}=-422.2396314$ a.u.

\begin{tabular}{|c|c|c|c|c|c|}
\hline Center & Atomic & Atomic & Coo & nates (An & coms ) \\
\hline Number & Number & Type & $X$ & Y & Z \\
\hline 1 & 6 & 0 & -2.395244 & -0.721585 & $\odot .000 \odot \odot \odot$ \\
\hline 2 & 6 & 0 & -1.199472 & -1.434188 & $\odot .000 \odot \odot \odot$ \\
\hline 3 & 6 & $\odot$ & ๑. . 030619 & -0.754595 & $\odot . \odot \odot \odot \odot \odot \odot$ \\
\hline 4 & 6 & $\odot$ & $\odot .0000 \odot \odot$ & $\odot .667344$ & $\odot .000000$ \\
\hline 5 & 6 & $\odot$ & -2.339312 & $\odot .654889$ & 0.000000 \\
\hline 6 & 1 & 0 & 1.343958 & -2.476013 & $\odot .00 \odot \odot ० \odot$ \\
\hline 7 & 1 & 0 & -3.358810 & -1.212502 & $\odot .0 \odot \odot \odot ० \odot$ \\
\hline 8 & 1 & 0 & -1.211934 & -2.519019 & $\odot .0000 \odot \odot$ \\
\hline 9 & 6 & $\odot$ & 1.298794 & -1.393509 & $\odot . \odot \odot \odot \odot \odot \odot$ \\
\hline 10 & 6 & 0 & 1.156997 & 1.441140 & $\odot .000 \odot \odot \odot$ \\
\hline 11 & 1 & 0 & -3.196367 & 1.316142 & $\odot .000 \odot \odot \odot$ \\
\hline 12 & 6 & 0 & 2.371387 & 0.778966 & $\odot .000 \odot \odot \odot$ \\
\hline 13 & 6 & $\odot$ & 2.443823 & -0.634291 & 0.000000 \\
\hline 14 & 1 & $\odot$ & 1.087090 & 2.521326 & 0.000000 \\
\hline 15 & 1 & 0 & 3.288418 & 1.356041 & $\odot .000 \odot \odot \odot$ \\
\hline 16 & 1 & 0 & 3.414044 & -1.114997 & $\odot .00 \odot \odot ० \odot$ \\
\hline 17 & 8 & 0 & -1.196493 & 1.313000 & $\odot . ๑ \odot \odot \odot \odot \odot$ \\
\hline
\end{tabular}

\section{Chromenylium ion $\mathbf{T}_{\mathbf{1}}$}

$\mathrm{E}=-422.1528952$ a.u.

\begin{tabular}{|c|c|c|c|c|c|}
\hline \multirow{2}{*}{$\begin{array}{l}\text { Center } \\
\text { Number }\end{array}$} & Atomic & \multirow{2}{*}{$\begin{array}{c}\text { Atomic } \\
\text { Type }\end{array}$} & \multicolumn{3}{|c|}{ Coordinates (Angstroms) } \\
\hline & Number & & $x$ & $Y$ & Z \\
\hline 1 & 6 & $\odot$ & -2.448042 & -0.619303 & 0.000000 \\
\hline 2 & 6 & $\odot$ & -1.278281 & -1.423210 & $\odot . \odot \odot \odot \odot \odot \odot$ \\
\hline 3 & 6 & $\odot$ & -0.027281 & -0.771354 & $\odot .000000$ \\
\hline 4 & 6 & $\odot$ & $\odot .0 \odot \odot \odot \odot \odot$ & 0.640609 & $\odot .000 \odot \odot \odot$ \\
\hline 5 & 6 & $\odot$ & -2.358043 & $\odot .735131$ & $\odot .000000$ \\
\hline 6 & 1 & $\Theta$ & 1.277404 & -2.500132 & $\odot .000000$ \\
\hline 7 & 1 & 0 & -3.432498 & -1.069692 & $\odot .000000$ \\
\hline 8 & 1 & 0 & -1.344506 & -2.502478 & $\odot .000000$ \\
\hline 9 & 6 & 0 & 1.240900 & -1.416643 & $\odot .000000$ \\
\hline 10 & 6 & $\odot$ & 1.211624 & 1.370958 & $\odot . \odot \odot \odot \odot \odot \odot$ \\
\hline 11 & 1 & $\odot$ & -3.164310 & 1.450835 & $\odot . \odot \odot \odot \odot \odot \odot$ \\
\hline 12 & 6 & $\odot$ & 2.466996 & 0.692801 & $\odot . \odot \odot \odot \odot \odot \odot$ \\
\hline 13 & 6 & $\odot$ & 2.478489 & -0.672038 & $\odot .000000$ \\
\hline 14 & 1 & $\odot$ & 1.156961 & 2.453965 & 0.000000 \\
\hline 15 & 1 & $\odot$ & 3.382954 & 1.268177 & 0.000000 \\
\hline 16 & 1 & $\Theta$ & 3.412208 & -1.220877 & $\odot .000000$ \\
\hline 17 & 8 & $\odot$ & -1.125798 & 1.362313 & $\odot .0 \odot \odot \odot \odot \odot$ \\
\hline
\end{tabular}




\section{Isochromenylium ion $\mathbf{S}_{\mathbf{0}}$}

$\mathrm{E}=-422.235895$ a.u.

\begin{tabular}{|c|c|c|c|c|c|}
\hline Center & Atomic & Atomic & Coo & nates (An & coms ) \\
\hline Number & Number & Type & $X$ & Y & Z \\
\hline 1 & 6 & 0 & 2.406306 & $\odot .805140$ & $\odot .000000$ \\
\hline 2 & 6 & 0 & 1.201510 & 1.459312 & $\odot .000 \odot \odot \odot$ \\
\hline 3 & 6 & $\odot$ & $\odot . ๑ \odot \odot \odot \odot \odot$ & $\odot .695460$ & $\odot . \odot \odot \odot \odot \odot \odot$ \\
\hline 4 & 6 & $\odot$ & 0.046862 & -0.742837 & $\odot .000000$ \\
\hline 5 & 6 & $\odot$ & 1.301380 & -1.376499 & 0.000000 \\
\hline 6 & 6 & 0 & 2.451933 & -0.611831 & $\odot .00 \odot \odot ० \odot$ \\
\hline 7 & 1 & 0 & -1.415137 & 2.371134 & $\odot .0 \odot \odot \odot ० \odot$ \\
\hline 8 & 1 & 0 & 3.331942 & 1.367078 & $\odot .0000 \odot \odot$ \\
\hline 9 & 1 & $\odot$ & 1.150801 & 2.541795 & $\odot . \odot \odot \odot \odot \odot \odot$ \\
\hline 10 & 6 & 0 & -1.247337 & 1.300591 & $\odot .000 \odot \odot \odot$ \\
\hline 11 & 6 & 0 & -1.194959 & -1.439313 & $\odot .000 \odot \odot \odot$ \\
\hline 12 & 1 & 0 & 1.358116 & -2.458232 & $\odot .000 \odot \odot \odot$ \\
\hline 13 & 1 & $\odot$ & 3.417364 & -1.104664 & 0.000000 \\
\hline 14 & 6 & 0 & -2.357369 & -0.746816 & $\odot .000 \odot \odot \odot$ \\
\hline 15 & 1 & 0 & -1.227686 & -2.521620 & $\odot .000 \odot \odot \odot$ \\
\hline 16 & 1 & 0 & -3.358429 & -1.150699 & $\odot .00 \odot \odot ० \odot$ \\
\hline 17 & 8 & 0 & -2.363365 & 0.611995 & $\odot . ๑ \odot \odot \odot \odot \odot$ \\
\hline
\end{tabular}

\section{Isochromenylium ion $\mathbf{T}_{\mathbf{1}}$}

$\mathrm{E}=-422.1527117$ a.u.

\begin{tabular}{|c|c|c|c|c|c|}
\hline \multirow{2}{*}{$\begin{array}{l}\text { Center } \\
\text { Number }\end{array}$} & \multirow{2}{*}{$\begin{array}{l}\text { Atomic } \\
\text { Number }\end{array}$} & \multirow{2}{*}{$\begin{array}{c}\text { Atomic } \\
\text { Type }\end{array}$} & \multicolumn{3}{|c|}{ Coordinates (Angstroms) } \\
\hline & & & $\mathrm{X}$ & $\mathrm{Y}$ & Z \\
\hline 1 & 6 & $\odot$ & 2.499586 & $\odot .579041$ & $\odot .000 \odot \odot \odot$ \\
\hline 2 & 6 & $\odot$ & 1.294555 & 1.352774 & $\odot . \odot \odot \odot \odot \odot \odot$ \\
\hline 3 & 6 & $\odot$ & 0.029437 & $\odot .719690$ & $\odot .000000$ \\
\hline 4 & 6 & $\odot$ & $\odot .0000 \odot \odot$ & -0.717748 & $\odot .00000 \odot$ \\
\hline 5 & 6 & $\odot$ & 1. 210948 & -1.447870 & $\odot .00000 \odot$ \\
\hline 6 & 6 & 0 & 2.468151 & -0.795759 & $\odot .000000$ \\
\hline 7 & 1 & $\odot$ & -1.296683 & 2.491547 & $\odot . \odot \odot \odot \odot \odot \odot$ \\
\hline 8 & 1 & 0 & 3.447985 & 1.103623 & $\odot .000000$ \\
\hline 9 & 1 & 0 & 1.358889 & 2.434337 & $\odot .00000 \odot$ \\
\hline 10 & 6 & $\odot$ & -1.169018 & 1.421233 & $\odot . \odot \odot \odot \odot \odot \odot$ \\
\hline 11 & 6 & $\odot$ & -1.271513 & -1.342022 & $\odot . \odot \odot \odot \odot \odot \odot$ \\
\hline 12 & 1 & $\odot$ & 1.166112 & -2.531844 & $\odot . \odot \odot \odot \odot \odot \odot$ \\
\hline 13 & 1 & $\odot$ & 3.379990 & -1.377338 & $\odot . \odot \odot \odot \odot \odot \odot$ \\
\hline 14 & 6 & $\odot$ & -2.411220 & -0.565904 & 0.000000 \\
\hline 15 & 1 & $\odot$ & -1.378378 & -2.419277 & $\odot .000000$ \\
\hline 16 & 1 & $\Theta$ & -3.416890 & -0.968652 & $\odot .000000$ \\
\hline 17 & 8 & $\Theta$ & -2.395823 & $\odot .755874$ & $\odot .000 \odot \odot \odot$ \\
\hline
\end{tabular}


1-Silanaphthalene $\mathbf{S}_{\mathbf{0}}$

$\mathrm{E}=-637.3495888$ a.u.

\begin{tabular}{|c|c|c|c|c|c|}
\hline \multirow{2}{*}{$\begin{array}{l}\text { Center } \\
\text { Number }\end{array}$} & \multirow{2}{*}{$\begin{array}{l}\text { Atomic } \\
\text { Number }\end{array}$} & \multirow{2}{*}{$\begin{array}{c}\text { Atomic } \\
\text { Type }\end{array}$} & \multicolumn{3}{|c|}{ Coordinates (Angstroms) } \\
\hline & & & $x$ & Y & Z \\
\hline 1 & 6 & $\odot$ & 2.259878 & 1.577091 & $\odot .0000 \odot \odot$ \\
\hline 2 & 6 & $\odot$ & 0.896271 & 1.764239 & $\odot .000000$ \\
\hline 3 & 6 & $\odot$ & $\odot .00000 \odot$ & 0.664598 & $\odot .00000 \odot$ \\
\hline 4 & 6 & $\odot$ & 0.529770 & -0.673529 & $\odot .0000 \odot \odot$ \\
\hline 5 & 6 & $\odot$ & 1.946559 & -0.821563 & $\odot . \odot \odot \odot \odot \odot \odot$ \\
\hline 6 & 6 & $\odot$ & 2.786135 & 0.266372 & $\odot . \odot \odot \odot \odot \odot \odot$ \\
\hline 7 & 1 & $\odot$ & -2.485647 & 2.115747 & $\odot . \odot \odot \odot \odot \odot \odot$ \\
\hline 8 & 1 & $\odot$ & 2.929405 & 2.429667 & $\odot .000 \odot \odot \odot$ \\
\hline 9 & 1 & $\odot$ & 0.496769 & 2.773881 & $\odot .000 \odot \odot \odot$ \\
\hline 10 & 6 & $\odot$ & -0.288893 & -1.844436 & $\odot .000000$ \\
\hline 11 & 1 & $\odot$ & 2.359519 & -1.825086 & $\odot .000000$ \\
\hline 12 & 1 & $\odot$ & 3.860654 & $\odot .119678$ & $\odot . \odot \odot \odot \odot \odot \odot$ \\
\hline 13 & 6 & $\odot$ & -1.670104 & -1.887158 & $\odot . \odot \odot \odot \odot \odot \odot$ \\
\hline 14 & 6 & $\odot$ & -2.543297 & -0.771165 & $\odot . \odot \odot \odot \odot \odot \odot$ \\
\hline 15 & 1 & $\odot$ & $\odot .238279$ & $-2.79300 \odot$ & $\odot . \odot \odot \odot \odot \odot \odot$ \\
\hline 16 & 1 & $\odot$ & -2.124260 & -2.875414 & $\odot . \odot \odot \odot \odot \odot \odot$ \\
\hline 17 & 1 & $\odot$ & -3.611550 & -0.953047 & $\odot .0 \odot \odot \odot \odot \odot$ \\
\hline 18 & 14 & $\odot$ & -1.797220 & $\odot .811491$ & $\odot .000 \odot \odot \odot$ \\
\hline
\end{tabular}

1-Silanaphthalene $\mathbf{T}_{\mathbf{1}}$

$\mathrm{E}=-637.2918095$ a.u.

\begin{tabular}{|c|c|c|c|c|c|}
\hline \multirow{2}{*}{$\begin{array}{l}\text { Center } \\
\text { Number }\end{array}$} & Atomic & \multirow{2}{*}{$\begin{array}{l}\text { Atomic } \\
\text { Type }\end{array}$} & \multicolumn{3}{|c|}{ Coordinates (Angstroms) } \\
\hline & Number & & $\mathrm{X}$ & $\mathrm{Y}$ & Z \\
\hline 1 & 6 & 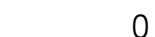 & -2.649608 & -0.794738 & -0.056256 \\
\hline 2 & 6 & 0 & -1.380875 & -1.385636 & -0.077492 \\
\hline 3 & 6 & $\odot$ & -0.213805 & -0.623990 & -0.034078 \\
\hline 4 & 6 & $\odot$ & -0.322176 & $\odot .799269$ & 0.023840 \\
\hline 5 & 6 & $\odot$ & -1.611116 & 1. 375222 & 0.058064 \\
\hline 6 & 6 & $\Theta$ & -2.758541 & $\odot .591839$ & ๑.016505 \\
\hline 7 & 1 & $\Theta$ & 1.685793 & -2.200403 & 1.275221 \\
\hline 8 & 1 & $\odot$ & -3.538537 & -1.413920 & $-\odot .096766$ \\
\hline 9 & 1 & $\odot$ & -1.310958 & -2.468358 & -0.129847 \\
\hline 10 & 6 & $\odot$ & 0.821875 & 1.675213 & 0.044756 \\
\hline 11 & 1 & $\odot$ & -1.699828 & 2.455032 & $\odot .123803$ \\
\hline 12 & 1 & $\odot$ & -3.735005 & 1.062620 & $\odot .040552$ \\
\hline 13 & 6 & $\odot$ & 2.186021 & 1.303629 & -0.034283 \\
\hline 14 & 6 & 0 & 2.672394 & 0.022580 & -0.122763 \\
\hline 15 & 1 & $\odot$ & 0.605732 & 2.737548 & ๑. 097108 \\
\hline 16 & 1 & $\odot$ & 2.895941 & 2.129364 & -0.045352 \\
\hline 17 & 1 & $\odot$ & 3.746110 & -0.113210 & -0.208424 \\
\hline 18 & 14 & $\odot$ & 1.491838 & -1.426358 & ๑.0०2425 \\
\hline
\end{tabular}




\section{2-Silanaphthalene $\mathbf{S}_{\mathbf{0}}$}

$\mathrm{E}=-637.349855$ a.u.

\begin{tabular}{|c|c|c|c|c|c|}
\hline \multirow{2}{*}{$\begin{array}{l}\text { Center } \\
\text { Number }\end{array}$} & \multirow{2}{*}{$\begin{array}{l}\text { Atomic } \\
\text { Number }\end{array}$} & \multirow{2}{*}{$\begin{array}{c}\text { Atomic } \\
\text { Type }\end{array}$} & \multicolumn{3}{|c|}{ Coordinates (Angstroms) } \\
\hline & & & $x$ & $Y$ & Z \\
\hline 1 & 6 & 0 & 2.255686 & 1.715320 & 0.000000 \\
\hline 2 & 6 & $\odot$ & ๑. 891378 & 1.871443 & $\odot .000 \odot \odot \odot$ \\
\hline 3 & 6 & 0 & 0.000000 & 0.757549 & $\odot .000000$ \\
\hline 4 & 6 & $\odot$ & $\odot .584314$ & -0.562746 & $\odot .0000 \odot \odot$ \\
\hline 5 & 6 & $\odot$ & 2.000689 & -0.677304 & $\odot . \odot \odot \odot \odot \odot \odot$ \\
\hline 6 & 6 & $\odot$ & 2.824227 & $\odot .422721$ & $\odot . \odot \odot \odot \odot \odot \odot$ \\
\hline 7 & 1 & $\odot$ & -1.734935 & 2.022737 & $\odot . \odot \odot \odot \odot \odot \odot$ \\
\hline 8 & 1 & $\odot$ & 2.899452 & 2.588162 & $\odot . \odot \odot \odot \odot \odot \odot$ \\
\hline 9 & 1 & 0 & 0.460399 & 2.867056 & $\odot .000000$ \\
\hline 10 & 6 & $\odot$ & -1.406506 & ๑. 988650 & 0.000000 \\
\hline 11 & 6 & 0 & -0.179911 & -1.773371 & 0.000000 \\
\hline 12 & 1 & $\odot$ & 2.431080 & -1.673674 & $\odot .000000$ \\
\hline 13 & 1 & $\odot$ & 3.901115 & $\odot .301087$ & 0.000000 \\
\hline 14 & 6 & $\odot$ & -1.550860 & -1.897538 & 0.000000 \\
\hline 15 & 1 & $\odot$ & 0.412378 & -2.687020 & 0.000000 \\
\hline 16 & 1 & $\odot$ & -1.979419 & -2.893667 & $\odot . \odot \odot \odot \odot \odot \odot$ \\
\hline 17 & 1 & $\odot$ & -3.967253 & -0.306122 & $\odot . \odot \odot \odot \odot \odot \odot$ \\
\hline 18 & 14 & $\odot$ & -2.495494 & -0.377636 & $\odot . \odot \odot \odot \odot \odot \odot$ \\
\hline
\end{tabular}

\section{2-Silanaphthalene $\mathbf{T}_{\mathbf{1}}$}

$\mathrm{E}=-637.2826632$ a.u.

\begin{tabular}{|c|c|c|c|c|c|}
\hline \multirow{2}{*}{$\begin{array}{l}\text { Center } \\
\text { Number }\end{array}$} & Atomic & \multirow{2}{*}{$\begin{array}{l}\text { Atomic } \\
\text { Type }\end{array}$} & \multicolumn{3}{|c|}{ Coordinates (Angstroms) } \\
\hline & Number & & $\mathrm{X}$ & $\mathrm{Y}$ & Z \\
\hline 1 & 6 & $\odot$ & -2.759139 & -0.781152 & $\odot .030254$ \\
\hline 2 & 6 & $\odot$ & -1.536973 & -1.426050 & $-\odot .019942$ \\
\hline 3 & 6 & 0 & -0.299841 & -0.712114 & -0.039546 \\
\hline 4 & 6 & 0 & -0.363558 & 0.732827 & -0.010989 \\
\hline 5 & 6 & $\odot$ & -1.613499 & 1.347243 & 0.039627 \\
\hline 6 & 6 & $\odot$ & -2.805823 & 0.616226 & 0.063256 \\
\hline 7 & 1 & $\Theta$ & 0.835922 & -2.500866 & -0.225955 \\
\hline 8 & 1 & $\odot$ & -3.676779 & -1.358361 & $\odot .046221$ \\
\hline 9 & 1 & $\odot$ & -1.497272 & -2.509883 & -0.043121 \\
\hline 10 & 6 & $\odot$ & $\odot .913555$ & -1.420073 & -0.138328 \\
\hline 11 & 6 & $\odot$ & $\odot .821803$ & 1.597549 & $-\odot .060016$ \\
\hline 12 & 1 & $\odot$ & -1.658200 & 2.431552 & $\odot .055586$ \\
\hline 13 & 1 & $\odot$ & -3.757275 & 1.133316 & $\odot .103350$ \\
\hline 14 & 6 & $\odot$ & 2.118740 & 1.223824 & $-\odot .071763$ \\
\hline 15 & 1 & $\odot$ & $\odot .586776$ & 2.661689 & -0.074682 \\
\hline 16 & 1 & $\odot$ & 2.869516 & 2.008757 & -0.095116 \\
\hline 17 & 1 & $\odot$ & 3.276228 & -0.882099 & 1.312004 \\
\hline 18 & 14 & $\Theta$ & 2.583535 & -0.575271 & 0.011885 \\
\hline
\end{tabular}


Phosphinoline $\mathbf{S}_{\mathbf{0}}$

$\mathrm{E}=-688.6328577$ a.u.

\begin{tabular}{|c|c|c|c|c|c|}
\hline \multirow{2}{*}{$\begin{array}{l}\text { Center } \\
\text { Number }\end{array}$} & \multirow{2}{*}{$\begin{array}{l}\text { Atomic } \\
\text { Number }\end{array}$} & \multirow{2}{*}{$\begin{array}{c}\text { Atomic } \\
\text { Type }\end{array}$} & \multicolumn{3}{|c|}{ Coordinates (Angstroms) } \\
\hline & & & $x$ & Y & Z \\
\hline 1 & 6 & $\odot$ & -1.794343 & -1.735138 & $\odot .000 \odot \odot \odot$ \\
\hline 2 & 6 & $\odot$ & -0.423832 & -1.851721 & $\odot . \odot \odot \odot \odot \odot \odot$ \\
\hline 3 & 6 & $\odot$ & $\odot .471905$ & -0.747596 & $\odot . \odot \odot \odot \odot \odot \odot$ \\
\hline 4 & 6 & $\odot$ & $\odot . ๑ \odot \odot \odot \odot \odot$ & $\odot .603411$ & $\odot . \odot \odot \odot \odot \odot \odot$ \\
\hline 5 & 6 & $\odot$ & -2.467906 & -0.497684 & $\odot .000 \odot \odot \odot$ \\
\hline 6 & 1 & $\odot$ & 2.231818 & -2.003298 & $\odot .000000$ \\
\hline 7 & 1 & $\odot$ & -2.387602 & -2.644991 & $\odot .000000$ \\
\hline 8 & 1 & $\odot$ & 0.013580 & -2.845204 & $\odot .0000 \odot \odot$ \\
\hline 9 & 6 & $\odot$ & 1.875624 & $-\odot .978205$ & $\odot .0000 \odot \odot$ \\
\hline 10 & 6 & $\odot$ & $\odot .953142$ & 1.655224 & 0.000000 \\
\hline 11 & 1 & $\odot$ & -3.554041 & -0.511897 & $\odot .000 \odot \odot \odot$ \\
\hline 12 & 6 & $\odot$ & 2.305018 & 1.397807 & $\odot .000 \odot \odot \odot$ \\
\hline 13 & 6 & $\odot$ & 2.770260 & $\odot .064532$ & $\odot . \odot \odot \odot \odot \odot \odot$ \\
\hline 14 & 1 & $\odot$ & $\odot .597790$ & 2.680903 & $\odot . \odot \odot \odot \odot \odot \odot$ \\
\hline 15 & 1 & $\odot$ & 3.015018 & 2.217083 & $\odot . \odot \odot \odot \odot \odot \odot$ \\
\hline 16 & 1 & $\odot$ & 3.836180 & -0.133690 & $\odot . \odot \odot \odot \odot \odot \odot$ \\
\hline 17 & 15 & $\odot$ & -1.726130 & 1.051821 & $\odot .000 \odot \odot \odot$ \\
\hline
\end{tabular}

Phosphinoline $\mathbf{T}_{\mathbf{1}}$

$\mathrm{E}=-688.5551304$ a.u.

\begin{tabular}{|c|c|c|c|c|c|}
\hline \multirow{2}{*}{$\begin{array}{l}\text { Center } \\
\text { Number }\end{array}$} & Atomic & \multirow{2}{*}{$\begin{array}{c}\text { Atomic } \\
\text { Type }\end{array}$} & \multicolumn{3}{|c|}{ Coordinates (Angstroms) } \\
\hline & Number & & $\mathrm{X}$ & $\mathrm{Y}$ & Z \\
\hline 1 & 6 & 0 & -1.765753 & -1.821992 & 0.000000 \\
\hline 2 & 6 & $\odot$ & -0.335139 & -1.871886 & $\odot . \odot \odot \odot \odot \odot \odot$ \\
\hline 3 & 6 & $\odot$ & $\odot .520006$ & -0.722484 & 0.000000 \\
\hline 4 & 6 & 0 & 0.000000 & 0.611543 & 0.000000 \\
\hline 5 & 6 & $\Theta$ & -2.496234 & -0.680508 & $\odot .000000$ \\
\hline 6 & 1 & $\Theta$ & 2.316830 & -1.900704 & $\odot .000000$ \\
\hline 7 & 1 & 0 & -2.286373 & -2.776675 & $\odot .000000$ \\
\hline 8 & 1 & 0 & 0.140069 & -2.846466 & $\odot .000000$ \\
\hline 9 & 6 & 0 & 1.914698 & -0.892715 & $\odot .000000$ \\
\hline 10 & 6 & 0 & 0.888732 & 1.680023 & 0.000000 \\
\hline 11 & 1 & 0 & -3.579924 & -0.736317 & $\odot .000000$ \\
\hline 12 & 6 & $\odot$ & 2.288826 & 1.486775 & $\odot . \odot \odot \odot \odot \odot \odot$ \\
\hline 13 & 6 & $\odot$ & 2.794512 & 0.202066 & $\odot . \odot \odot \odot \odot \odot \odot$ \\
\hline 14 & 1 & 0 & 0.498215 & 2.693247 & $\odot .000 \odot \odot \odot$ \\
\hline 15 & 1 & 0 & 2.951471 & 2.344255 & $\odot .0000 \odot \odot$ \\
\hline 16 & 1 & 0 & 3.864955 & 0.031110 & $\odot .000000$ \\
\hline 17 & 15 & $\odot$ & -1.784209 & 1.016441 & $\odot .000 \odot \odot \odot$ \\
\hline
\end{tabular}




\section{Isophosphinoline $\mathbf{S}_{\mathbf{0}}$}

$\mathrm{E}=-688.6327594$ a.u.

\begin{tabular}{|c|c|c|c|c|c|}
\hline \multirow{2}{*}{$\begin{array}{l}\text { Center } \\
\text { Number }\end{array}$} & \multirow{2}{*}{$\begin{array}{l}\text { Atomic } \\
\text { Number }\end{array}$} & \multirow{2}{*}{$\begin{array}{l}\text { Atomic } \\
\text { Type }\end{array}$} & \multicolumn{3}{|c|}{ Coordinates (Angstroms) } \\
\hline & & & $x$ & $\mathrm{Y}$ & Z \\
\hline 1 & 6 & 0 & 2.206981 & 1.756742 & $\odot . \odot \odot \odot \odot \odot \odot$ \\
\hline 2 & 6 & $\odot$ & $\odot .838526$ & 1.867847 & $\odot . \diamond \odot \odot \odot \odot \odot$ \\
\hline 3 & 6 & $\odot$ & $\odot . \diamond \odot \odot \odot \odot \odot$ & 0.716151 & $\odot . \diamond \odot \odot \odot \odot \odot$ \\
\hline 4 & 6 & $\odot$ & $\odot .620704$ & -0.575835 & $\odot . \odot \odot \odot \odot \odot \odot$ \\
\hline 5 & 6 & $\odot$ & 2.038284 & -0.652478 & $\odot . \odot \odot \odot \odot \odot \odot$ \\
\hline 6 & 6 & $\odot$ & 2.815965 & $\odot .480531$ & 0.000000 \\
\hline 7 & 1 & $\odot$ & -1.794719 & 1.876992 & 0.000000 \\
\hline 8 & 1 & $\odot$ & 2.825046 & 2.647494 & 0.000000 \\
\hline 9 & 1 & 0 & 0.369707 & 2.846068 & $\odot .00000 \odot$ \\
\hline 10 & 6 & 0 & -1.410132 & 0.860000 & $\odot .0 \odot \odot \odot \odot \odot$ \\
\hline 11 & 6 & 0 & -0.155400 & -1.769104 & $\odot .0 \odot \odot \odot \odot \odot$ \\
\hline 12 & 1 & $\odot$ & 2.502790 & -1.633043 & 0.000000 \\
\hline 13 & 1 & $\odot$ & 3.896941 & $\odot .399585$ & 0.000000 \\
\hline 14 & 6 & $\odot$ & -1.524480 & -1.808814 & $\odot . \odot \odot \odot \odot \odot \odot$ \\
\hline 15 & 1 & $\odot$ & $\odot .395762$ & -2.706942 & $\odot . \odot \odot \odot \odot \odot \odot$ \\
\hline 16 & 1 & $\odot$ & -2.012313 & -2.779153 & $\odot . \odot \odot \odot \odot \odot \odot$ \\
\hline 17 & 15 & $\odot$ & -2.584393 & -0.393416 & $\odot . \odot \odot \odot \odot \odot \odot$ \\
\hline
\end{tabular}

\section{Isophosphinoline $\mathbf{T}_{\mathbf{1}}$}

$\mathrm{E}=-688.5466139$ a.u.

\begin{tabular}{|c|c|c|c|c|c|}
\hline \multirow{2}{*}{$\begin{array}{l}\text { Center } \\
\text { Number }\end{array}$} & \multirow{2}{*}{$\begin{array}{l}\text { Atomic } \\
\text { Number }\end{array}$} & \multirow{2}{*}{$\begin{array}{c}\text { Atomic } \\
\text { Type }\end{array}$} & \multicolumn{3}{|c|}{ Coordinates (Angstroms) } \\
\hline & & & $x$ & $\mathrm{Y}$ & Z \\
\hline 1 & 6 & $\odot$ & 2.235467 & 1.802619 & $\odot . \odot \odot \odot \odot \odot \odot$ \\
\hline 2 & 6 & $\odot$ & 0.837907 & 1.902600 & 0.000000 \\
\hline 3 & 6 & $\odot$ & $\odot .0 \odot \odot \odot \odot \odot$ & 0.750334 & $\odot . \odot \odot \odot \odot \odot \odot$ \\
\hline 4 & 6 & $\odot$ & $\odot .645528$ & -0.542434 & $\odot .0 \odot \odot \odot \odot \odot$ \\
\hline 5 & 6 & $\odot$ & 2.024622 & -0.609042 & $\odot .000 \odot \odot \odot$ \\
\hline 6 & 6 & $\odot$ & 2.838715 & $\odot .560211$ & $\odot . \odot \odot \odot \odot \odot \odot$ \\
\hline 7 & 1 & $\odot$ & -1.808923 & 1.883472 & $\odot .000000$ \\
\hline 8 & 1 & $\odot$ & 2.836811 & 2.704740 & 0.000000 \\
\hline 9 & 1 & $\odot$ & 0.368165 & 2.880129 & 0.000000 \\
\hline 10 & 6 & $\odot$ & -1.392868 & ๑.880291 & $\odot .000 \odot \odot \odot$ \\
\hline 11 & 6 & $\odot$ & -0.139728 & -1.772455 & ๑. $0000 \odot \odot$ \\
\hline 12 & 1 & $\odot$ & 2.503381 & -1.583067 & $\odot .000 \odot \odot \odot$ \\
\hline 13 & 1 & $\odot$ & 3.917623 & $\odot .464853$ & $\odot .0 \odot \odot \odot \odot \odot$ \\
\hline 14 & 6 & $\odot$ & -1.508644 & -1.849758 & $\odot .0 \odot \odot \odot \odot \odot$ \\
\hline 15 & 1 & $\odot$ & $\odot .433073$ & -2.696646 & $\odot . \odot \odot \odot \odot \odot \odot$ \\
\hline 16 & 1 & $\odot$ & -1.957623 & -2.839488 & $\odot . \odot \odot \odot \odot \odot \odot$ \\
\hline 17 & 15 & $\odot$ & -2.635900 & -0.503213 & $\odot . \odot \odot \odot \odot \odot \odot$ \\
\hline
\end{tabular}


Thiochromenylium ion $\mathbf{S}_{\mathbf{0}}$

$\mathrm{E}=-745.2197693$ a.u.

\begin{tabular}{|c|c|c|c|c|c|}
\hline \multirow{2}{*}{$\begin{array}{l}\text { Center } \\
\text { Number }\end{array}$} & \multirow{2}{*}{$\begin{array}{l}\text { Atomic } \\
\text { Number }\end{array}$} & \multirow{2}{*}{$\begin{array}{l}\text { Atomic } \\
\text { Type }\end{array}$} & \multicolumn{3}{|c|}{ Coordinates (Angstroms) } \\
\hline & & & $x$ & $Y$ & Z \\
\hline 1 & 6 & 0 & -1.700105 & -1.823091 & $\odot .000000$ \\
\hline 2 & 6 & $\odot$ & -0.311692 & -1.866852 & $\odot . \odot \odot \odot \odot \odot \odot$ \\
\hline 3 & 6 & $\odot$ & $\odot .528920$ & -0.734144 & $\odot . \odot \odot \odot \odot \odot \odot$ \\
\hline 4 & 6 & $\odot$ & $\odot . \odot \odot \odot \odot \odot \odot$ & $\odot .595809$ & $\odot . \odot \odot \odot \odot \odot \odot$ \\
\hline 5 & 6 & $\odot$ & -2.405027 & -0.632414 & $\odot .000 \odot \odot \odot$ \\
\hline 6 & 1 & $\odot$ & 2.354360 & -1.891303 & 0.000000 \\
\hline 7 & 1 & $\odot$ & -2.263159 & -2.748648 & 0.000000 \\
\hline 8 & 1 & $\odot$ & $\odot .167016$ & -2.840595 & 0.000000 \\
\hline 9 & 6 & $\odot$ & 1.942339 & -0.888988 & $\odot .000000$ \\
\hline 10 & 6 & $\odot$ & ๑.855313 & 1.708639 & 0.000000 \\
\hline 11 & 1 & $\odot$ & -3.489580 & -0.613892 & 0.000000 \\
\hline 12 & 6 & 0 & 2.222322 & 1.509691 & $\odot .000000$ \\
\hline 13 & 6 & $\odot$ & 2.768469 & ๑. 208363 & 0.000000 \\
\hline 14 & 1 & $\odot$ & 0.447116 & 2.712605 & $\odot . \odot \odot \odot \odot \odot \odot$ \\
\hline 15 & 1 & $\odot$ & 2.883689 & 2.367941 & $\odot . \odot \odot \odot \odot \odot \odot$ \\
\hline 16 & 1 & 0 & 3.843718 & $\odot .079694$ & $\odot .0 \odot \odot \odot \odot \odot$ \\
\hline 17 & 16 & 0 & -1.709149 & $\odot .904507$ & $\odot .000000$ \\
\hline
\end{tabular}

Thiochromenylium ion $\mathbf{T}_{\mathbf{1}}$

$\mathrm{E}=-745.1401746$ a.u.

\begin{tabular}{|c|c|c|c|c|c|}
\hline \multirow{2}{*}{$\begin{array}{l}\text { Center } \\
\text { Number }\end{array}$} & \multirow{2}{*}{$\begin{array}{l}\text { Atomic } \\
\text { Number }\end{array}$} & \multirow{2}{*}{$\begin{array}{c}\text { Atomic } \\
\text { Type }\end{array}$} & \multicolumn{3}{|c|}{ Coordinates (Angstroms) } \\
\hline & & & $\mathrm{X}$ & $\mathrm{Y}$ & Z \\
\hline 1 & 6 & $\odot$ & -1.720579 & -1.831755 & $\odot . \odot \odot \odot \odot \odot \odot$ \\
\hline 2 & 6 & $\odot$ & $-\odot .299557$ & -1.902460 & $\odot . \odot \odot \odot \odot \odot \odot$ \\
\hline 3 & 6 & $\odot$ & 0.525560 & -0.750840 & $\odot .000000$ \\
\hline 4 & 6 & $\odot$ & $\odot .0000 \odot \odot$ & 0.569610 & $\odot .000000$ \\
\hline 5 & 6 & $\odot$ & -2.445346 & -0.679264 & $\odot .000 \odot \odot \odot$ \\
\hline 6 & 1 & $\Theta$ & 2.377658 & -1.854334 & $\odot .000000$ \\
\hline 7 & 1 & $\odot$ & -2.275985 & -2.764094 & $\odot . \odot \odot \odot \odot \odot \odot$ \\
\hline 8 & 1 & $\odot$ & 0.170270 & -2.877174 & $\odot .000000$ \\
\hline 9 & 6 & $\odot$ & 1.937840 & -0.863185 & $\odot .000000$ \\
\hline 10 & 6 & $\odot$ & $\odot .851749$ & 1.688025 & $\odot . \odot \odot \odot \odot \odot \odot$ \\
\hline 11 & 1 & $\odot$ & -3.526404 & $-\odot .648587$ & $\odot . \odot \odot \odot \odot \odot \odot$ \\
\hline 12 & 6 & $\odot$ & 2.264272 & 1.538747 & $\odot . \odot \odot \odot \odot \odot \odot$ \\
\hline 13 & 6 & $\odot$ & 2.795281 & 0.274546 & $\odot .000000$ \\
\hline 14 & 1 & $\odot$ & 0.423651 & 2.685393 & 0.000000 \\
\hline 15 & 1 & 0 & 2.894489 & 2.418308 & 0.000000 \\
\hline 16 & 1 & $\Theta$ & 3.868030 & 0.124188 & $\odot .000000$ \\
\hline 17 & 16 & $\odot$ & -1.711689 & $\odot .915985$ & $\odot .000000$ \\
\hline
\end{tabular}


Isothiochromenylium ion $\mathbf{S}_{\mathbf{0}}$

$\mathrm{E}=-745.21877$ a.u.

\begin{tabular}{|c|c|c|c|c|c|}
\hline Center & Atomic & Atomic & Coo & nates (An & coms ) \\
\hline Number & Number & Type & $X$ & Y & Z \\
\hline 1 & 6 & 0 & 2.146118 & 1.850082 & $\odot .000 \odot \odot \odot$ \\
\hline 2 & 6 & 0 & 0.776918 & 1.917141 & $\odot .000 \odot \odot \odot$ \\
\hline 3 & 6 & $\odot$ & $\odot . ๑ \odot \odot \odot \odot \odot$ & $\odot .720878$ & $\odot . \odot \odot \odot \odot \odot \odot$ \\
\hline 4 & 6 & $\odot$ & 0.666661 & -0.559066 & $\odot .000000$ \\
\hline 5 & 6 & $\odot$ & 2.076107 & -0.582366 & 0.000000 \\
\hline 6 & 6 & 0 & 2.797008 & 0.593506 & $\odot .00 \odot \odot ० \odot$ \\
\hline 7 & 1 & 0 & -1.881060 & 1.781477 & $\odot .0 \odot \odot \odot ० \odot$ \\
\hline 8 & 1 & 0 & 2.735524 & 2.758683 & $\odot .0000 \odot \odot$ \\
\hline 9 & 1 & $\odot$ & 0.269430 & 2.874603 & $\odot . \odot \odot \odot \odot \odot \odot$ \\
\hline 10 & 6 & 0 & -1.392048 & 0.812625 & $\odot .000 \odot \odot \odot$ \\
\hline 11 & 6 & 0 & -0.074448 & -1.774991 & $\odot .000 \odot \odot \odot$ \\
\hline 12 & 1 & 0 & 2.588716 & -1.536915 & $\odot .000 \odot \odot \odot$ \\
\hline 13 & 1 & $\odot$ & 3.880104 & $\odot .557414$ & 0.000000 \\
\hline 14 & 6 & 0 & -1.432921 & -1.853063 & $\odot .000 \odot \odot \odot$ \\
\hline 15 & 1 & 0 & 0.481664 & -2.706785 & $\odot .000 \odot \odot \odot$ \\
\hline 16 & 1 & 0 & -1.964780 & -2.796396 & $\odot .00 \odot \odot ० \odot$ \\
\hline 17 & 16 & 0 & -2.468123 & -0.480035 & $\odot . ๑ \odot \odot \odot \odot \odot$ \\
\hline
\end{tabular}

\section{Isothiochromenylium ion $\mathbf{T}_{\mathbf{1}}$}

$\mathrm{E}=-745.1394644$ a.u.

\begin{tabular}{|c|c|c|c|c|c|}
\hline \multirow{2}{*}{$\begin{array}{l}\text { Center } \\
\text { Number }\end{array}$} & \multirow{2}{*}{$\begin{array}{l}\text { Atomic } \\
\text { Number }\end{array}$} & \multirow{2}{*}{$\begin{array}{c}\text { Atomic } \\
\text { Type }\end{array}$} & \multicolumn{3}{|c|}{ Coordinates (Angstroms) } \\
\hline & & & $\mathrm{X}$ & $\mathrm{Y}$ & Z \\
\hline 1 & 6 & $\odot$ & 2.252355 & 1.789604 & $\odot .000 \odot \odot \odot$ \\
\hline 2 & 6 & $\odot$ & 0.833122 & 1.888928 & $\odot . \odot \odot \odot \odot \odot \odot$ \\
\hline 3 & 6 & $\odot$ & 0.000000 & 0.735692 & $\odot .000000$ \\
\hline 4 & 6 & $\odot$ & 0.653068 & -0.544001 & $\odot .00000 \odot$ \\
\hline 5 & 6 & $\odot$ & 2.062518 & -0.603213 & $\odot .00000 \odot$ \\
\hline 6 & 6 & 0 & 2.870796 & 0.562471 & $\odot .000000$ \\
\hline 7 & 1 & 0 & -1.872097 & 1.839603 & $\odot .000000$ \\
\hline 8 & 1 & 0 & 2.837974 & 2.701379 & $\odot .000000$ \\
\hline 9 & 1 & 0 & 0.373305 & 2.870332 & $\odot .00000 \odot$ \\
\hline 10 & 6 & $\odot$ & -1.387923 & $\odot .872361$ & $\odot . \odot \odot \odot \odot \odot \odot$ \\
\hline 11 & 6 & $\odot$ & $-\odot .09790 \odot$ & -1.753613 & $\odot . \odot \odot \odot \odot \odot \odot$ \\
\hline 12 & 1 & $\odot$ & 2.538969 & -1.578124 & $\odot . \odot \odot \odot \odot \odot \odot$ \\
\hline 13 & 1 & $\odot$ & 3.948820 & $\odot .473661$ & $\odot . \odot \odot \odot \odot \odot \odot$ \\
\hline 14 & 6 & $\odot$ & -1.473334 & -1.816292 & 0.000000 \\
\hline 15 & 1 & $\odot$ & 0.441493 & -2.695003 & $\odot .000000$ \\
\hline 16 & 1 & $\Theta$ & -1.983480 & -2.773270 & $\odot .000000$ \\
\hline 17 & 16 & $\Theta$ & -2.535075 & $-\odot .476887$ & $\odot .000 \odot \odot \odot$ \\
\hline
\end{tabular}


Anthracene $\mathrm{S}_{\mathbf{0}}$

$\mathrm{E}=-539.6602468$ a.u.

\begin{tabular}{|c|c|c|c|c|c|}
\hline Center & Atomic & Atomic & Coo & nates (An & roms ) \\
\hline Number & Number & Type & $X$ & $Y$ & Z \\
\hline 1 & 6 & $\odot$ & $\odot .000000$ & 3.656102 & -0.712388 \\
\hline 2 & 6 & $\odot$ & $\odot .00000 \odot$ & 2.477219 & -1.405274 \\
\hline 3 & 6 & $\odot$ & $\odot . \odot \odot \odot \odot \odot \odot$ & 1.222066 & -0.721430 \\
\hline 4 & 6 & $\odot$ & $\odot .000 \odot \odot \odot$ & 1.222066 & 0.721430 \\
\hline 5 & 6 & $\odot$ & $\odot .00000 \odot$ & 2.477219 & 1.405274 \\
\hline 6 & 6 & $\odot$ & $\odot .00000 \odot$ & 3.656102 & $\odot .712388$ \\
\hline 7 & 6 & $\odot$ & $\odot .00000 \odot$ & $\odot .000 \odot \odot \odot$ & -1.401924 \\
\hline 8 & 6 & $\odot$ & $\odot . \odot \odot \odot \odot \odot \odot$ & $\odot . \odot \odot \odot \odot \odot \odot$ & 1. 401924 \\
\hline 9 & 6 & $\odot$ & $\odot .000 \odot \odot \odot$ & -1.222066 & 0.721430 \\
\hline 10 & 6 & 0 & $\odot .00000 \odot$ & -1.222066 & -0.721430 \\
\hline 11 & 6 & 0 & $\odot .00000 \odot$ & -2.477219 & -1.405274 \\
\hline 12 & 1 & 0 & $\odot .00000 \odot$ & -2.476755 & -2.490366 \\
\hline 13 & 6 & 0 & $\odot .0 \odot \odot \odot \odot \odot$ & -3.656102 & -0.712388 \\
\hline 14 & 6 & 0 & $\odot .0000 \odot \odot$ & -3.656102 & ๑.712388 \\
\hline 15 & 6 & 0 & $\odot .000 \odot \odot \odot$ & -2.477219 & 1.405274 \\
\hline 16 & 1 & 0 & $\odot .00000 \odot$ & $\odot . \odot ० \odot \odot \odot \odot$ & -2.487846 \\
\hline 17 & 1 & 0 & $\odot .00000 \odot$ & 4.600534 & -1.244964 \\
\hline 18 & 1 & $\odot$ & $\odot .00000 \odot$ & 2.476755 & -2.490366 \\
\hline 19 & 1 & $\odot$ & $\odot .00 \odot \odot \odot \odot$ & 2.476755 & 2.490366 \\
\hline 20 & 1 & $\odot$ & $\odot .000 \odot \odot \odot$ & 4.600534 & 1.244964 \\
\hline 21 & 1 & $\odot$ & $\odot .0 \odot \odot \odot \odot \odot$ & $\odot . \odot \odot \odot \odot \odot \odot$ & 2.487846 \\
\hline 22 & 1 & $\odot$ & $\odot .0 \odot \odot \odot \odot \odot$ & -4.600534 & -1.244964 \\
\hline 23 & 1 & $\odot$ & $\odot .000000$ & -4.600534 & 1.244964 \\
\hline 24 & 1 & $\odot$ & $\odot .00 \odot \odot \odot \odot$ & -2.476755 & 2.490366 \\
\hline
\end{tabular}




\begin{tabular}{|c|c|c|c|c|c|}
\hline \multicolumn{6}{|c|}{$\begin{array}{l}\text { Anthracene } \mathbf{T}_{\mathbf{1}} \\
\mathrm{E}=-539.5937577 \text { a.u. }\end{array}$} \\
\hline \multirow{2}{*}{$\begin{array}{l}\text { Center } \\
\text { Number }\end{array}$} & \multirow{2}{*}{$\begin{array}{l}\text { Atomic } \\
\text { Number }\end{array}$} & \multirow{2}{*}{$\begin{array}{c}\text { Atomic } \\
\text { Type }\end{array}$} & \multicolumn{3}{|c|}{ Coordinates (Angstroms) } \\
\hline & & & $x$ & $\mathrm{Y}$ & Z \\
\hline 1 & 6 & 0 & $\odot .000 \odot \odot \odot$ & 3.700560 & -0.690630 \\
\hline 2 & 6 & $\odot$ & $\odot .0000 \odot \odot$ & 2.476963 & -1.394247 \\
\hline 3 & 6 & $\odot$ & $\odot . \odot \odot \odot \odot \odot \odot$ & 1.253011 & -0.719567 \\
\hline 4 & 6 & $\odot$ & $\odot . \odot \odot \odot \odot \odot \odot$ & 1.253011 & $\odot .719567$ \\
\hline 5 & 6 & $\odot$ & $\odot . \odot \odot \odot \odot \odot \odot$ & 2.476963 & 1.394247 \\
\hline 6 & 6 & 0 & 0.000000 & 3.700560 & $\odot .690630$ \\
\hline 7 & 6 & 0 & 0.000000 & $\odot .000000$ & -1.405484 \\
\hline 8 & 6 & $\odot$ & 0.000000 & 0.000000 & 1.405484 \\
\hline 9 & 6 & $\odot$ & $\odot .00000 \odot$ & -1.253011 & $\odot .719567$ \\
\hline 10 & 6 & $\odot$ & $\odot .0 \odot \odot \odot \odot \odot$ & -1.253011 & -0.719567 \\
\hline 11 & 6 & $\odot$ & $\odot .0 \odot \odot \odot \odot \odot$ & -2.476963 & -1.394247 \\
\hline 12 & 1 & $\odot$ & $\odot .00000 \odot$ & -2.481282 & -2.479271 \\
\hline 13 & 6 & $\odot$ & 0.000000 & -3.700560 & -0.690630 \\
\hline 14 & 6 & $\odot$ & $\odot . \odot \odot \odot \odot \odot \odot$ & -3.700560 & $\odot .690630$ \\
\hline 15 & 6 & $\odot$ & $\odot . \odot \odot \odot \odot \odot \odot$ & -2.476963 & 1.394247 \\
\hline 16 & 1 & $\odot$ & $\odot . \odot \odot \odot \odot \odot \odot$ & $\odot . \odot \odot \odot \odot \odot \odot$ & -2.490667 \\
\hline 17 & 1 & $\odot$ & $\odot .0 \odot \odot \odot \odot \odot$ & 4.635051 & -1.239671 \\
\hline 18 & 1 & $\odot$ & $\odot .0 \odot \odot \odot \odot \odot$ & 2.481282 & -2.479271 \\
\hline 19 & 1 & $\odot$ & $\odot .000 \odot \odot \odot$ & 2.481282 & 2.479271 \\
\hline 20 & 1 & $\odot$ & $\odot .00000 \odot$ & 4.635051 & 1.239671 \\
\hline 21 & 1 & $\odot$ & $\odot .0 \odot \odot \odot \odot \odot$ & $\odot .0 \odot \odot \odot \odot \odot$ & 2.490667 \\
\hline 22 & 1 & $\odot$ & $\odot .0 \odot \odot \odot \odot \odot$ & -4.635051 & -1.239671 \\
\hline 23 & 1 & $\Theta$ & $\odot .000 \odot \odot \odot$ & -4.635051 & 1.239671 \\
\hline 24 & 1 & $\odot$ & $\odot .0 \odot \odot \odot \odot \odot$ & -2.481282 & 2.479271 \\
\hline
\end{tabular}


Acridine $\mathrm{S}_{\mathbf{0}}$

$\mathrm{E}=-555.7047893$ a.u.

\begin{tabular}{|c|c|c|c|c|c|}
\hline Center & Atomic & Atomic & Coo & nates (An & croms ) \\
\hline Number & Number & Type & $x$ & $Y$ & Z \\
\hline 1 & 6 & $\odot$ & $\odot .00000 \odot$ & -3.582838 & 0.767687 \\
\hline 2 & 6 & $\odot$ & $\odot . \odot \odot \odot \odot \odot \odot$ & -2.383389 & 1.424361 \\
\hline 3 & 6 & $\odot$ & $\odot .0 \odot \odot \odot \odot \odot$ & -1.153809 & $\odot .695972$ \\
\hline 4 & 6 & 0 & $0.00000 \odot$ & -1.210179 & -0.746749 \\
\hline 5 & 6 & 0 & 0.000000 & -2.483668 & -1.392118 \\
\hline 6 & 6 & $\odot$ & $\odot . \odot \odot \odot \odot \odot \odot$ & -3.636206 & -0.656655 \\
\hline 7 & 6 & $\odot$ & $\odot . \odot \odot \odot \odot \odot \odot$ & $\odot . \odot \odot \odot \odot \odot \odot$ & -1.441813 \\
\hline 8 & 6 & $\odot$ & $\odot .0000 \odot \odot$ & 1.210179 & -0.746749 \\
\hline 9 & 6 & $\odot$ & $\odot .00000 \odot$ & 1.153809 & $\odot .695972$ \\
\hline 10 & 6 & $\odot$ & $\odot .000000$ & 2.383389 & 1.424361 \\
\hline 11 & 1 & $\odot$ & $\odot .00000 \odot$ & 2.323218 & 2.506026 \\
\hline 12 & 6 & $\odot$ & $\odot . \odot \odot \odot \odot \odot \odot$ & 3.582838 & $\odot .767687$ \\
\hline 13 & 6 & $\odot$ & $\odot . \odot \odot \odot \odot \odot \odot$ & 3.636206 & -0.656655 \\
\hline 14 & 6 & $\odot$ & $\odot .00000 \odot$ & 2.483668 & -1.392118 \\
\hline 15 & 1 & $\odot$ & $\odot .0000 \odot \odot$ & -4.508977 & 1.331662 \\
\hline 16 & 1 & $\odot$ & $\odot .00000 \odot$ & -2.323218 & 2.506026 \\
\hline 17 & 1 & $\odot$ & $\odot .00 \odot \odot \odot \odot$ & -2.518335 & -2.476779 \\
\hline 18 & 1 & $\odot$ & $\odot .000 \odot \odot \odot$ & -4.599791 & -1.153249 \\
\hline 19 & 1 & $\odot$ & $0.00000 \odot$ & $\odot .0000 \odot \odot$ & -2.528274 \\
\hline 20 & 1 & $\odot$ & $\odot .00000 \odot$ & 4.508977 & 1.331662 \\
\hline 21 & 1 & $\odot$ & $\odot .000000$ & 4.599791 & -1.153249 \\
\hline 22 & 1 & $\odot$ & $\odot .00000 \odot$ & 2.518335 & -2.476779 \\
\hline 23 & 7 & $\odot$ & $\odot .0 \odot \odot \odot \odot \odot$ & $\odot . \odot \odot \odot \odot \odot \odot$ & 1.379124 \\
\hline
\end{tabular}


Acridine $\mathbf{T}_{\mathbf{1}}$

$\mathrm{E}=-555.6340314$ a.u.

\begin{tabular}{|c|c|c|c|c|c|}
\hline \multirow{2}{*}{$\begin{array}{l}\text { Center } \\
\text { Number }\end{array}$} & \multirow{2}{*}{$\begin{array}{l}\text { Atomic } \\
\text { Number }\end{array}$} & \multirow{2}{*}{$\begin{array}{c}\text { Atomic } \\
\text { Type }\end{array}$} & \multicolumn{3}{|c|}{ Coordinates (Angstroms) } \\
\hline & & & $X$ & $Y$ & Z \\
\hline 1 & 6 & $\odot$ & $\odot .0000 \odot \odot$ & -3.625069 & 0.757351 \\
\hline 2 & 6 & 0 & 0.000000 & -2.374098 & 1.410643 \\
\hline 3 & 6 & $\odot$ & $\odot . \odot \odot \odot \odot \odot \odot$ & -1.176734 & $\odot .685429$ \\
\hline 4 & 6 & $\odot$ & 0.000000 & -1.233009 & -0.754606 \\
\hline 5 & 6 & 0 & 0.000000 & -2.483019 & -1.377172 \\
\hline 6 & 6 & 0 & 0.000000 & -3.678608 & -0.622168 \\
\hline 7 & 6 & 0 & 0.000000 & $\odot .000000$ & -1.466896 \\
\hline 8 & 6 & 0 & $0.00000 \odot$ & 1.233009 & -0.754606 \\
\hline 9 & 6 & $\odot$ & 0.000000 & 1.176734 & $\odot .685429$ \\
\hline 10 & 6 & 0 & 0.000000 & 2.374098 & 1.410643 \\
\hline 11 & 1 & $\odot$ & 0.000000 & 2.307839 & 2.492098 \\
\hline 12 & 6 & $\Theta$ & 0.000000 & 3.625069 & $\odot .757351$ \\
\hline 13 & 6 & $\odot$ & $0.00000 \odot$ & 3.678608 & -0.622168 \\
\hline 14 & 6 & $\odot$ & $\odot .0000 \odot \odot$ & 2.483019 & -1.377172 \\
\hline 15 & 1 & $\Theta$ & $\odot .0000 \odot \odot$ & -4.536744 & 1.343019 \\
\hline 16 & 1 & $\odot$ & $\odot .0 \odot \odot \odot \odot \odot$ & -2.307839 & 2.492098 \\
\hline 17 & 1 & 0 & $\odot .0 \odot \odot \odot \odot \odot$ & -2.533595 & -2.461205 \\
\hline 18 & 1 & 0 & $\odot .00000 \odot$ & -4.633525 & -1.134823 \\
\hline 19 & 1 & 0 & $\odot .0 \odot \odot \odot \odot \odot$ & $\odot .00 \odot \odot \odot \odot$ & -2.551493 \\
\hline 20 & 1 & 0 & $\odot .0000 \odot \odot$ & 4.536744 & 1.343019 \\
\hline 21 & 1 & $\odot$ & $\odot .00000 \odot$ & 4.633525 & -1.134823 \\
\hline 22 & 1 & 0 & $\odot .00000 \odot$ & 2.533595 & -2.461205 \\
\hline 23 & 7 & $\odot$ & $\odot .000000$ & $\odot . \odot \odot \odot \odot \odot \odot$ & 1.382996 \\
\hline
\end{tabular}




\section{Xanthylium ion $\mathbf{S}_{\mathbf{0}}$}

$\mathrm{E}=-575.932669$ a.u.

\begin{tabular}{|c|c|c|c|c|c|}
\hline \multirow{2}{*}{$\begin{array}{l}\text { Center } \\
\text { Number }\end{array}$} & \multirow{2}{*}{$\begin{array}{l}\text { Atomic } \\
\text { Number }\end{array}$} & \multirow{2}{*}{$\begin{array}{c}\text { Atomic } \\
\text { Type }\end{array}$} & \multicolumn{3}{|c|}{ Coordinates (Angstroms) } \\
\hline & & & $x$ & $\mathrm{Y}$ & Z \\
\hline 1 & 6 & 0 & $\odot . \odot \odot \odot \odot \odot \odot$ & 3559598 & Q. 761806 \\
\hline 2 & 6 & 0 & 0.000000 & 2.345761 & 1.424123 \\
\hline 3 & 6 & $\odot$ & $\odot .0 \odot \odot \odot \odot \odot$ & 1.179743 & 0.660122 \\
\hline 4 & 6 & $\odot$ & $\odot . \odot \odot \odot \odot \odot \odot$ & 1.217715 & -0.764592 \\
\hline 5 & 6 & $\odot$ & $\odot . \odot \odot \odot \odot \odot \odot$ & 2.489530 & -1.404963 \\
\hline 6 & 6 & $\odot$ & $\odot . \odot \odot \odot \odot \odot \odot$ & 3.635556 & $-\odot .651950$ \\
\hline 7 & 6 & $\odot$ & $\odot . \odot \odot \odot \odot \odot \odot$ & $\odot . \odot \odot \odot \odot \odot \odot$ & -1.452792 \\
\hline 8 & 6 & $\odot$ & $\odot .0 \odot \odot \odot \odot \odot$ & -1.217715 & -0.764592 \\
\hline 9 & 6 & $\odot$ & $\odot . \odot \odot \odot \odot \odot \odot$ & -1.179743 & $\odot .660122$ \\
\hline 10 & 6 & $\odot$ & $\odot . \odot \odot \odot \odot \odot \odot$ & -2.345761 & 1.424123 \\
\hline 11 & 1 & $\odot$ & $\odot . \odot \odot \odot \odot \odot \odot$ & -2.279720 & 2.504449 \\
\hline 12 & 6 & $\odot$ & $\odot . \odot \odot \odot \odot \odot \odot$ & -3.559598 & 0.761806 \\
\hline 13 & 6 & $\odot$ & $\odot .0000 \odot \odot$ & -3.635556 & -0.651950 \\
\hline 14 & 6 & $\odot$ & $\odot .00000 \odot$ & -2.489530 & -1.404963 \\
\hline 15 & 1 & $\odot$ & 0.000000 & 4.475975 & 1.340273 \\
\hline 16 & 1 & $\odot$ & $\odot . \odot \odot \odot \odot \odot \odot$ & 2.279720 & 2.504449 \\
\hline 17 & 1 & $\odot$ & $\odot . \odot \odot \odot \odot \odot \odot$ & 2.530482 & -2.487842 \\
\hline 18 & 1 & $\odot$ & $\odot .0000 \odot \odot$ & 4.605537 & -1.132672 \\
\hline 19 & 1 & $\odot$ & $\odot . \odot \odot \odot \odot \odot \odot$ & $\odot . ๑ \odot \odot \odot \odot \odot$ & -2.538773 \\
\hline 20 & 1 & $\odot$ & $\odot . \odot \odot \odot \odot \odot \odot$ & -4.475975 & 1.340273 \\
\hline 21 & 1 & $\odot$ & $\odot . \odot \odot \odot \odot \odot \odot$ & -4.605537 & -1.132672 \\
\hline 22 & 1 & $\odot$ & $\odot . \odot \odot \odot \odot \odot \odot$ & -2.530482 & -2.487842 \\
\hline 23 & 8 & $\odot$ & $\odot .0 \odot \odot \odot \odot \odot$ & $\odot .00000 \odot$ & 1.314068 \\
\hline
\end{tabular}


Xanthylium ion $\mathbf{T}_{\mathbf{1}}$

$\mathrm{E}=-575.8611094$ a.u.

\begin{tabular}{|c|c|c|c|c|c|}
\hline \multirow{2}{*}{$\begin{array}{l}\text { Center } \\
\text { Number }\end{array}$} & \multirow{2}{*}{$\begin{array}{l}\text { Atomic } \\
\text { Number }\end{array}$} & \multirow{2}{*}{$\begin{array}{c}\text { Atomic } \\
\text { Type }\end{array}$} & \multicolumn{3}{|c|}{ Coordinates (Angstroms) } \\
\hline & & & $x$ & $\mathrm{Y}$ & Z \\
\hline 1 & 6 & 0 & ค คคคคคค & -3.593739 & Q. 797069 \\
\hline 2 & 6 & 0 & 0.000000 & -2.336162 & 1.413973 \\
\hline 3 & 6 & $\odot$ & $\odot .0 \odot \odot \odot \odot \odot$ & -1.184921 & $\odot .620465$ \\
\hline 4 & 6 & $\odot$ & $\odot . \odot \odot \odot \odot \odot \odot$ & -1.224538 & $-\odot .799052$ \\
\hline 5 & 6 & $\odot$ & $\odot . \odot \odot \odot \odot \odot \odot$ & -2.498888 & -1.382539 \\
\hline 6 & 6 & $\odot$ & $\odot . \odot \odot \odot \odot \odot \odot$ & -3.670187 & $-\odot .587950$ \\
\hline 7 & 6 & $\odot$ & $\odot . \odot \odot \odot \odot \odot \odot$ & $\odot . \odot \odot \odot \odot \odot \odot$ & -1.521920 \\
\hline 8 & 6 & $\odot$ & $\odot .0 \odot \odot \odot \odot \odot$ & 1.224538 & -0.799052 \\
\hline 9 & 6 & $\odot$ & $\odot . \odot \odot \odot \odot \odot \odot$ & 1.184921 & $\odot .620465$ \\
\hline 10 & 6 & $\odot$ & $\odot . \odot \odot \odot \odot \odot \odot$ & 2.336162 & 1.413973 \\
\hline 11 & 1 & $\odot$ & $\odot . \odot \odot \odot \odot \odot \odot$ & 2.230010 & 2.492159 \\
\hline 12 & 6 & $\odot$ & $\odot . \odot \odot \odot \odot \odot \odot$ & 3.593739 & $\odot .797069$ \\
\hline 13 & 6 & $\odot$ & $\odot .000 \odot \odot \odot$ & 3.670187 & $-\odot .587950$ \\
\hline 14 & 6 & $\odot$ & $\odot .00000 \odot$ & 2.498888 & -1.382539 \\
\hline 15 & 1 & $\odot$ & 0.000000 & -4.491096 & 1. 401512 \\
\hline 16 & 1 & $\odot$ & $\odot . \odot \odot \odot \odot \odot \odot$ & -2.230010 & 2.492159 \\
\hline 17 & 1 & $\odot$ & $\odot . \odot \odot \odot \odot \odot \odot$ & -2.586311 & -2.462770 \\
\hline 18 & 1 & $\odot$ & $\odot .0000 \odot \odot$ & -4.636208 & -1.078190 \\
\hline 19 & 1 & $\odot$ & $\odot . \odot \odot \odot \odot \odot \odot$ & $\odot . \odot \odot \odot \odot \odot \odot$ & -2.604041 \\
\hline 20 & 1 & $\odot$ & $\odot . \odot \odot \odot \odot \odot \odot$ & 4.491096 & 1. 401512 \\
\hline 21 & 1 & $\odot$ & $\odot . \odot \odot \odot \odot \odot \odot$ & 4.636208 & -1.078190 \\
\hline 22 & 1 & $\odot$ & $\odot . \odot \odot \odot \odot \odot \odot$ & 2.586311 & -2.462770 \\
\hline 23 & 8 & $\odot$ & $\odot .0 \odot \odot \odot \odot \odot$ & $\odot .00000 \odot$ & 1.285817 \\
\hline
\end{tabular}


9-Silaanthracene $\mathbf{S}_{\mathbf{0}}$

$\mathrm{E}=-791.0199591$ a.u.

\begin{tabular}{|c|c|c|c|c|c|}
\hline \multirow{2}{*}{$\begin{array}{l}\text { Center } \\
\text { Number }\end{array}$} & \multirow{2}{*}{$\begin{array}{l}\text { Atomic } \\
\text { Number }\end{array}$} & \multirow{2}{*}{$\begin{array}{c}\text { Atomic } \\
\text { Type }\end{array}$} & \multicolumn{3}{|c|}{ Coordinates (Angstroms) } \\
\hline & & & $x$ & $\mathrm{Y}$ & Z \\
\hline 1 & 6 & $\odot$ & $\odot .00000 \odot$ & -3.890633 & 0.361793 \\
\hline 2 & 6 & $\odot$ & $\odot . \odot \odot \odot \odot \odot \odot$ & -2.803601 & 1.196610 \\
\hline 3 & 6 & $\odot$ & $\odot .0 \odot \odot \odot \odot \odot$ & -1.472894 & $\odot .685005$ \\
\hline 4 & 6 & $\odot$ & $\odot . \odot \odot \odot \odot \odot \odot$ & -1.267291 & -0.749139 \\
\hline 5 & 6 & $\odot$ & $\odot . \odot \odot \odot \odot \odot \odot$ & -2.438217 & -1.577595 \\
\hline 6 & 6 & $\odot$ & $\odot . \odot \odot \odot \odot \odot \odot$ & -3.698524 & -1.046025 \\
\hline 7 & 6 & $\odot$ & $\odot . \odot \odot \odot \odot \odot \odot$ & $\odot . \odot \odot \odot \odot \odot \odot$ & -1.363369 \\
\hline 8 & 6 & $\odot$ & $\odot .0000 \odot \odot$ & 1.267291 & -0.749139 \\
\hline 9 & 6 & $\odot$ & $\odot . \odot \odot \odot \odot \odot \odot$ & 1.472894 & $\odot .685005$ \\
\hline 10 & 6 & $\odot$ & $\odot . \odot \odot \odot \odot \odot \odot$ & 2.803601 & 1.196610 \\
\hline 11 & 1 & $\odot$ & $\odot . \odot \odot \odot \odot \odot \odot$ & 2.954964 & 2. 271771 \\
\hline 12 & 6 & $\odot$ & $\odot . \odot \odot \odot \odot \odot \odot$ & 3.890633 & $\odot .361793$ \\
\hline 13 & 6 & $\odot$ & $\odot .0000 \odot \odot$ & 3.698524 & -1.046025 \\
\hline 14 & 6 & $\odot$ & $\odot .00000 \odot$ & 2.438217 & -1.577595 \\
\hline 15 & 1 & $\odot$ & $\odot .00000 \odot$ & $\odot .000 \odot \odot \odot$ & 3.164009 \\
\hline 16 & 1 & $\odot$ & $\odot .00000 \odot$ & -4.895089 & $\odot .769372$ \\
\hline 17 & 1 & $\odot$ & $\odot . \odot \odot \odot \odot \odot \odot$ & -2.954964 & 2.271771 \\
\hline 18 & 1 & $\odot$ & $\odot . \odot \odot \odot \odot \odot \odot$ & -2.303329 & -2.654355 \\
\hline 19 & 1 & $\odot$ & $\odot .00000 \odot$ & -4.561658 & -1.702807 \\
\hline 20 & 1 & $\odot$ & $\odot . \odot \odot \odot \odot \odot \odot$ & $\odot . \odot \odot \odot \odot \odot \odot$ & -2.449245 \\
\hline 21 & 1 & $\odot$ & $\odot . \odot \odot \odot \odot \odot \odot$ & 4.895089 & $\odot .769372$ \\
\hline 22 & 1 & $\odot$ & $\odot . \odot \odot \odot \odot \odot \odot$ & 4.561658 & -1.702807 \\
\hline 23 & 1 & $\odot$ & $\odot .000 \odot \odot \odot$ & 2.303329 & -2.654355 \\
\hline 24 & 14 & $\odot$ & $\odot .00000 \odot$ & $\odot .0 \odot \odot \odot \odot \odot$ & 1.689264 \\
\hline
\end{tabular}


9-Silaanthracene $\mathbf{T}_{\mathbf{1}}$

$\mathrm{E}=-790.9833689$ a.u.

\begin{tabular}{|c|c|c|c|c|c|}
\hline Center & Atomic & Atomic & Coo & inates (An & (roms) \\
\hline Number & Number & Type & $x$ & $Y$ & Z \\
\hline 1 & 6 & $\odot$ & 0.324949 & -0.079277 & 3.907654 \\
\hline 2 & 6 & $\odot$ & 1.170449 & $-\odot .031858$ & 2.792490 \\
\hline 3 & 6 & $\odot$ & 0.670645 & ๑. 029358 & 1.492845 \\
\hline 4 & 6 & $\odot$ & -0.745819 & 0.045542 & 1.293089 \\
\hline 5 & 6 & $\odot$ & -1.580945 & -0.002869 & 2.434295 \\
\hline 6 & 6 & $\odot$ & -1.055507 & -0.062041 & 3.719272 \\
\hline 7 & 6 & 0 & -1.363065 & ๑.085643 & $\odot .0 \odot \odot \odot \odot \odot$ \\
\hline 8 & 6 & 0 & -0.745819 & $\odot .045542$ & -1.293089 \\
\hline 9 & 6 & $\odot$ & 0.670645 & $\odot .029358$ & -1.492845 \\
\hline 10 & 6 & 0 & 1.170449 & -0.031858 & -2.792490 \\
\hline 11 & 1 & $\odot$ & 2.244868 & -0.039088 & -2.952419 \\
\hline 12 & 6 & $\odot$ & ๑.324949 & $-\odot .079277$ & -3.907654 \\
\hline 13 & 6 & $\odot$ & -1.055507 & -0.062041 & -3.719272 \\
\hline 14 & 6 & 0 & -1.580945 & $-\odot .0 \odot 2869$ & -2.434295 \\
\hline 15 & 1 & 0 & 2.871482 & $-\odot .894656$ & $\odot .000 \odot \odot \odot$ \\
\hline 16 & 1 & $\odot$ & 0.743001 & -0.123609 & 4.906735 \\
\hline 17 & 1 & $\odot$ & 2.244868 & -0.039088 & 2.952419 \\
\hline 18 & 1 & $\odot$ & -2.657193 & $-\odot .0 \odot 4910$ & 2.294126 \\
\hline 19 & 1 & $\odot$ & -1.723079 & -0.096936 & 4.573076 \\
\hline 20 & 1 & $\Theta$ & -2.448812 & 0.107572 & $\odot .00 \odot \odot ० \odot$ \\
\hline 21 & 1 & $\odot$ & $\odot .743001$ & -0.123609 & -4.906735 \\
\hline 22 & 1 & $\odot$ & -1.723079 & -0.096936 & -4.573076 \\
\hline 23 & 1 & $\odot$ & -2.657193 & $-\odot .0 \odot 4910$ & -2.294126 \\
\hline 24 & 14 & $\odot$ & 1.795377 & $\odot .1440 \odot 2$ & $\odot . \odot \odot \odot \odot \odot \odot$ \\
\hline
\end{tabular}




\section{9-Phosphaanthracene $\mathbf{S}_{\mathbf{0}}$}

$\mathrm{E}=-842.3040281$ a.u.

\begin{tabular}{|c|c|c|c|c|c|}
\hline \multirow{2}{*}{$\begin{array}{l}\text { Center } \\
\text { Number }\end{array}$} & \multirow{2}{*}{$\begin{array}{l}\text { Atomic } \\
\text { Number }\end{array}$} & \multirow{2}{*}{$\begin{array}{c}\text { Atomic } \\
\text { Type }\end{array}$} & \multicolumn{3}{|c|}{ Coordinates (Angstroms) } \\
\hline & & & $X$ & $Y$ & Z \\
\hline 1 & 6 & 0 & $\odot .0000 \odot \odot$ & 3.798226 & $\odot .42604 \odot$ \\
\hline 2 & 6 & 0 & 0.000000 & 2.675932 & 1.211513 \\
\hline 3 & 6 & $\odot$ & $\odot . \odot \odot \odot \odot \odot \odot$ & 1.366531 & 0.642807 \\
\hline 4 & 6 & $\odot$ & 0.000000 & 1.246358 & -0.792683 \\
\hline 5 & 6 & 0 & 0.000000 & 2.444975 & -1.576555 \\
\hline 6 & 6 & 0 & 0.000000 & 3.679773 & -0.989942 \\
\hline 7 & 6 & 0 & 0.000000 & $\odot .000000$ & -1.431828 \\
\hline 8 & 6 & 0 & $0.00000 \odot$ & -1.246358 & -0.792683 \\
\hline 9 & 6 & $\odot$ & 0.000000 & -1.366531 & 0.642807 \\
\hline 10 & 6 & $\odot$ & 0.000000 & -2.675932 & 1.211513 \\
\hline 11 & 1 & 0 & 0.000000 & -2.771190 & 2.292674 \\
\hline 12 & 6 & 0 & 0.000000 & -3.798226 & 0.426040 \\
\hline 13 & 6 & 0 & $0.00000 \odot$ & -3.679773 & -0.989942 \\
\hline 14 & 6 & 0 & $\odot .0000 \odot \odot$ & -2.444975 & -1.576555 \\
\hline 15 & 1 & 0 & $\odot .0000 \odot \odot$ & 4.781646 & 0.882267 \\
\hline 16 & 1 & $\odot$ & $\odot .0 \odot \odot \odot \odot \odot$ & 2.771190 & 2. 292674 \\
\hline 17 & 1 & 0 & $\odot .0 \odot \odot \odot \odot \odot$ & 2. 351819 & -2.657672 \\
\hline 18 & 1 & 0 & $\odot .00000 \odot$ & 4.574125 & -1.602733 \\
\hline 19 & 1 & 0 & $\odot .0 \odot \odot \odot \odot \odot$ & $\odot .00 \odot \odot \odot \odot$ & -2.518181 \\
\hline 20 & 1 & 0 & $\odot .0000 \odot \odot$ & -4.781646 & 0.882267 \\
\hline 21 & 1 & $\Theta$ & $\odot .00000 \odot$ & -4.574125 & -1.602733 \\
\hline 22 & 1 & 0 & $\odot .00000 \odot$ & -2.351819 & -2.657672 \\
\hline 23 & 15 & $\odot$ & $\odot .000000$ & $\odot . \odot \odot \odot \odot \odot \odot$ & 1.748395 \\
\hline
\end{tabular}




\section{9-Phosphaanthracene $\mathbf{T}_{\mathbf{1}}$}

$\mathrm{E}=-842.2540693$ a.u.

\begin{tabular}{|c|c|c|c|c|c|}
\hline \multirow{2}{*}{$\begin{array}{l}\text { Center } \\
\text { Number }\end{array}$} & \multirow{2}{*}{$\begin{array}{l}\text { Atomic } \\
\text { Number }\end{array}$} & \multirow{2}{*}{$\begin{array}{c}\text { Atomic } \\
\text { Type }\end{array}$} & \multicolumn{3}{|c|}{ Coordinates (Angstroms) } \\
\hline & & & $X$ & $Y$ & Z \\
\hline 1 & 6 & 0 & $\odot .0000 \odot \odot$ & 3.844104 & $\odot .396454$ \\
\hline 2 & 6 & 0 & 0.000000 & 2.686301 & 1.194273 \\
\hline 3 & 6 & $\odot$ & $\odot . \odot \odot \odot \odot \odot \odot$ & 1.411061 & 0.634448 \\
\hline 4 & 6 & $\odot$ & 0.000000 & 1.275619 & -0.788798 \\
\hline 5 & 6 & 0 & 0.000000 & 2.448023 & -1.568133 \\
\hline 6 & 6 & 0 & 0.000000 & 3.718434 & -0.984492 \\
\hline 7 & 6 & 0 & 0.000000 & $\odot .000000$ & -1.433521 \\
\hline 8 & 6 & 0 & $0.00000 \odot$ & -1.275619 & -0.788798 \\
\hline 9 & 6 & $\odot$ & 0.000000 & -1.411061 & 0.634448 \\
\hline 10 & 6 & $\odot$ & 0.000000 & -2.686301 & 1.194273 \\
\hline 11 & 1 & 0 & 0.000000 & -2.789712 & 2.275166 \\
\hline 12 & 6 & 0 & 0.000000 & -3.844104 & 0.396454 \\
\hline 13 & 6 & 0 & $0.00000 \odot$ & -3.718434 & -0.984492 \\
\hline 14 & 6 & 0 & $\odot .0000 \odot \odot$ & -2.448023 & -1.568133 \\
\hline 15 & 1 & 0 & $\odot .0000 \odot \odot$ & 4.822300 & 0.862781 \\
\hline 16 & 1 & $\odot$ & $\odot .0 \odot \odot \odot \odot \odot$ & 2.789712 & 2.275166 \\
\hline 17 & 1 & 0 & $\odot .0 \odot \odot \odot \odot \odot$ & 2.355566 & -2.649422 \\
\hline 18 & 1 & 0 & $\odot .00000 \odot$ & 4.599883 & -1.615652 \\
\hline 19 & 1 & 0 & $\odot .0 \odot \odot \odot \odot \odot$ & $\odot .00 \odot \odot \odot \odot$ & -2.518952 \\
\hline 20 & 1 & $\Theta$ & $\odot . ๑ \odot \odot \odot \odot \odot$ & -4.822300 & ๑.862781 \\
\hline 21 & 1 & $\Theta$ & $\odot .00000 \odot$ & -4.599883 & -1.615652 \\
\hline 22 & 1 & 0 & $\odot .00000 \odot$ & -2.355566 & -2.649422 \\
\hline 23 & 15 & $\odot$ & $\odot .000000$ & $\odot . \odot \odot \odot \odot \odot \odot$ & 1.784619 \\
\hline
\end{tabular}




\section{Thioxanthylium ion $\mathbf{S}_{\mathbf{0}}$}

$\mathrm{E}=-898.9075673$ a.u.

\begin{tabular}{|c|c|c|c|c|c|}
\hline \multirow{2}{*}{$\begin{array}{l}\text { Center } \\
\text { Number }\end{array}$} & \multirow{2}{*}{$\begin{array}{l}\text { Atomic } \\
\text { Number }\end{array}$} & \multirow{2}{*}{$\begin{array}{c}\text { Atomic } \\
\text { Type }\end{array}$} & \multicolumn{3}{|c|}{ Coordinates (Angstroms) } \\
\hline & & & $x$ & $Y^{\prime}$ & Z \\
\hline 1 & 6 & 0 & $\bigcirc \quad ค ค ค ค ค ค$ & 3772531 & 0.422308 \\
\hline 2 & 6 & 0 & 0.000000 & 2.643270 & 1.217456 \\
\hline 3 & 6 & $\odot$ & $\odot .0 \odot \odot \odot \odot \odot$ & 1.373180 & 0.618314 \\
\hline 4 & 6 & $\odot$ & $\odot . \odot \odot \odot \odot \odot \odot$ & 1.250083 & -0.807364 \\
\hline 5 & 6 & $\odot$ & $\odot . \odot \odot \odot \odot \odot \odot$ & 2.444913 & -1.587871 \\
\hline 6 & 6 & $\odot$ & $\odot . \odot \odot \odot \odot \odot \odot$ & 3.676810 & $-\odot .987297$ \\
\hline 7 & 6 & $\odot$ & $\odot . \odot \odot \odot \odot \odot \odot$ & $\odot . \odot \odot \odot \odot \odot \odot$ & -1.440161 \\
\hline 8 & 6 & $\odot$ & $\odot .0 \odot \odot \odot \odot \odot$ & -1.250083 & -0.807364 \\
\hline 9 & 6 & $\odot$ & $\odot . \odot \odot \odot \odot \odot \odot$ & -1.373180 & $\odot .618314$ \\
\hline 10 & 6 & $\odot$ & $\odot . \odot \odot \odot \odot \odot \odot$ & -2.643270 & 1.217456 \\
\hline 11 & 1 & $\odot$ & $\odot . \odot \odot \odot \odot \odot \odot$ & -2.735132 & 2.297210 \\
\hline 12 & 6 & $\odot$ & $\odot . \odot \odot \odot \odot \odot \odot$ & -3.772531 & 0.422308 \\
\hline 13 & 6 & $\odot$ & $\odot .0000 \odot \odot$ & -3.676810 & -0.987297 \\
\hline 14 & 6 & $\odot$ & $\odot .00000 \odot$ & -2.444913 & -1.587871 \\
\hline 15 & 1 & $\odot$ & 0.000000 & 4.749528 & 0.891120 \\
\hline 16 & 1 & $\odot$ & $\odot . \odot \odot \odot \odot \odot \odot$ & 2.735132 & 2.297210 \\
\hline 17 & 1 & $\odot$ & $\odot . \odot \odot \odot \odot \odot \odot$ & 2.355779 & -2.668045 \\
\hline 18 & 1 & $\odot$ & $\odot .0 \odot \odot \odot \odot \odot$ & 4.578484 & -1.586592 \\
\hline 19 & 1 & $\odot$ & $\odot . \odot \odot \odot \odot \odot \odot$ & $\odot . ๑ \odot \odot \odot \odot \odot$ & -2.526248 \\
\hline 20 & 1 & $\odot$ & $\odot . \odot \odot \odot \odot \odot \odot$ & -4.749528 & 0.891120 \\
\hline 21 & 1 & $\odot$ & $\odot . \odot \odot \odot \odot \odot \odot$ & -4.578484 & -1.586592 \\
\hline 22 & 1 & $\odot$ & $\odot . \odot \odot \odot \odot \odot \odot$ & -2.355779 & -2.668045 \\
\hline 23 & 16 & $\odot$ & $\odot .0 \odot \odot \odot \odot \odot$ & $\odot .00000 \odot$ & 1.674579 \\
\hline
\end{tabular}




\section{Thioxanthylium ion $\mathbf{T}_{\mathbf{1}}$}

$\mathrm{E}=-898.8460121$ a.u.

\begin{tabular}{|c|c|c|c|c|c|}
\hline \multirow{2}{*}{$\begin{array}{l}\text { Center } \\
\text { Number }\end{array}$} & \multirow{2}{*}{$\begin{array}{l}\text { Atomic } \\
\text { Number }\end{array}$} & \multirow{2}{*}{$\begin{array}{c}\text { Atomic } \\
\text { Type }\end{array}$} & \multicolumn{3}{|c|}{ Coordinates (Angstroms) } \\
\hline & & & $x$ & $\mathrm{Y}$ & Z \\
\hline 1 & 6 & 0 & $\bigcirc \quad ค ค ค ค ค ค$ & 3810175 & ค. 453918 \\
\hline 2 & 6 & 0 & 0.000000 & 2.636568 & 1.215550 \\
\hline 3 & 6 & $\odot$ & $\odot .0 \odot \odot \odot \odot \odot$ & 1.384886 & $\odot .583952$ \\
\hline 4 & 6 & $\odot$ & $\odot . \odot \odot \odot \odot \odot \odot$ & 1.260918 & -0.835395 \\
\hline 5 & 6 & $\odot$ & $\odot . \odot \odot \odot \odot \odot \odot$ & 2.461487 & -1.565460 \\
\hline 6 & 6 & $\odot$ & $\odot . \odot \odot \odot \odot \odot \odot$ & 3.716288 & -0.930665 \\
\hline 7 & 6 & $\odot$ & $\odot . \odot \odot \odot \odot \odot \odot$ & $\odot . \odot \odot \odot \odot \odot \odot$ & -1.497451 \\
\hline 8 & 6 & $\odot$ & $\odot .0 \odot \odot \odot \odot \odot$ & -1.260918 & -0.835395 \\
\hline 9 & 6 & $\odot$ & $\odot . \odot \odot \odot \odot \odot \odot$ & -1.384886 & $\odot .583952$ \\
\hline 10 & 6 & $\odot$ & $\odot . \odot \odot \odot \odot \odot \odot$ & -2.636568 & 1.215550 \\
\hline 11 & 1 & $\odot$ & $\odot . \odot \odot \odot \odot \odot \odot$ & -2.695557 & 2. 298601 \\
\hline 12 & 6 & $\odot$ & $\odot . \odot \odot \odot \odot \odot \odot$ & -3.810175 & 0.453918 \\
\hline 13 & 6 & $\odot$ & $\odot .0000 \odot \odot$ & -3.716288 & -0.930665 \\
\hline 14 & 6 & $\odot$ & $\odot .00000 \odot$ & -2.461487 & -1.565460 \\
\hline 15 & 1 & $\odot$ & 0.000000 & 4.773350 & 0.947082 \\
\hline 16 & 1 & $\odot$ & $\odot . \odot \odot \odot \odot \odot \odot$ & 2.695557 & 2. 298601 \\
\hline 17 & 1 & $\odot$ & $\odot . \odot \odot \odot \odot \odot \odot$ & 2.413771 & -2.648332 \\
\hline 18 & 1 & $\odot$ & $\odot .0000 \odot \odot$ & 4.614234 & -1.536846 \\
\hline 19 & 1 & $\odot$ & $\odot . \odot \odot \odot \odot \odot \odot$ & $\odot . ๑ \odot \odot \odot \odot \odot$ & -2.580500 \\
\hline 20 & 1 & $\odot$ & $\odot . \odot \odot \odot \odot \odot \odot$ & -4.773350 & 0.947082 \\
\hline 21 & 1 & $\odot$ & $\odot . \odot \odot \odot \odot \odot \odot$ & -4.614234 & -1.536846 \\
\hline 22 & 1 & $\odot$ & $\odot . \odot \odot \odot \odot \odot \odot$ & -2.413771 & -2.648332 \\
\hline 23 & 16 & $\odot$ & $\odot .000 \odot \odot \odot$ & $\odot .0 \odot \odot \odot \odot \odot$ & 1.648838 \\
\hline
\end{tabular}

